\title{
ECLOSION au Sénégal: Pourquoi les populations abandonnent la pratique de l'Excision
}

Tostan

Follow this and additional works at: https://knowledgecommons.popcouncil.org/departments_sbsr-rh How does access to this work benefit you? Let us know!

\section{Recommended Citation}

Tostan. 1999. "ECLOSION au Sénégal: Pourquoi les populations abandonnent la pratique de l'Excision," Rapport du Projet de Recherche Operationnelle et d'Assistance Technique en Afrique II. Dakar: Population Council. 


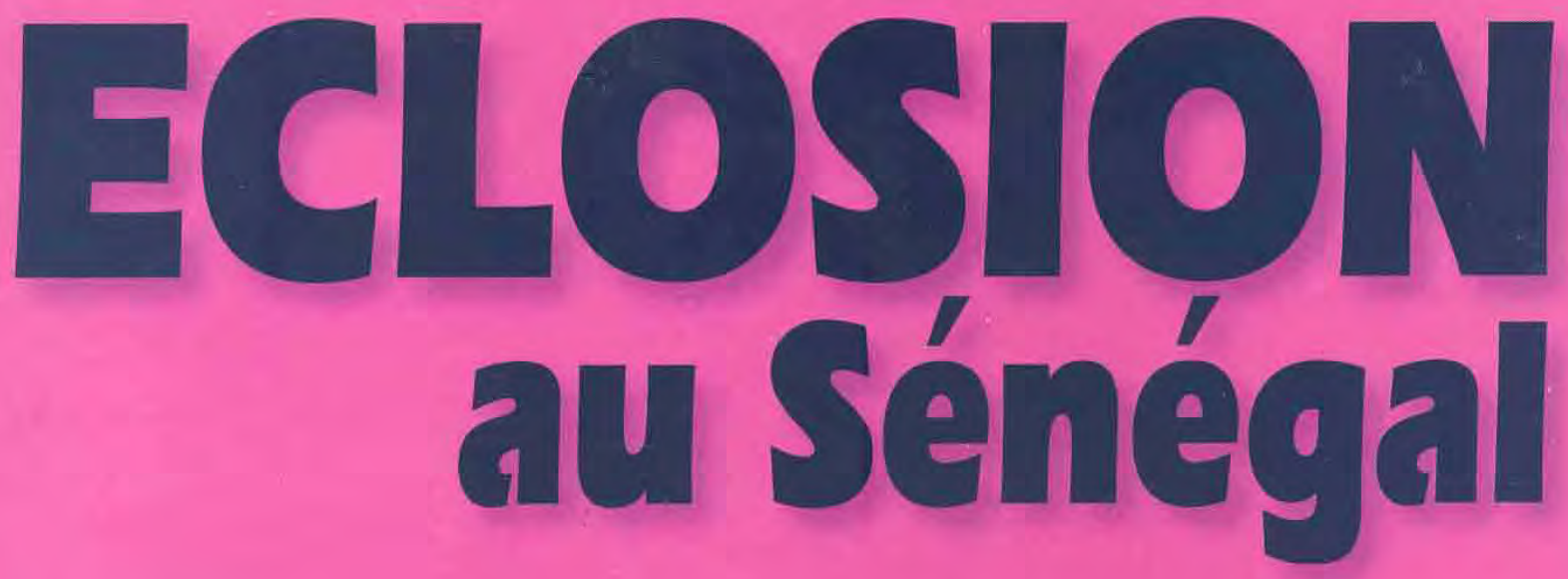

Pourquoi les populations abandonnent la pratique de rExcision

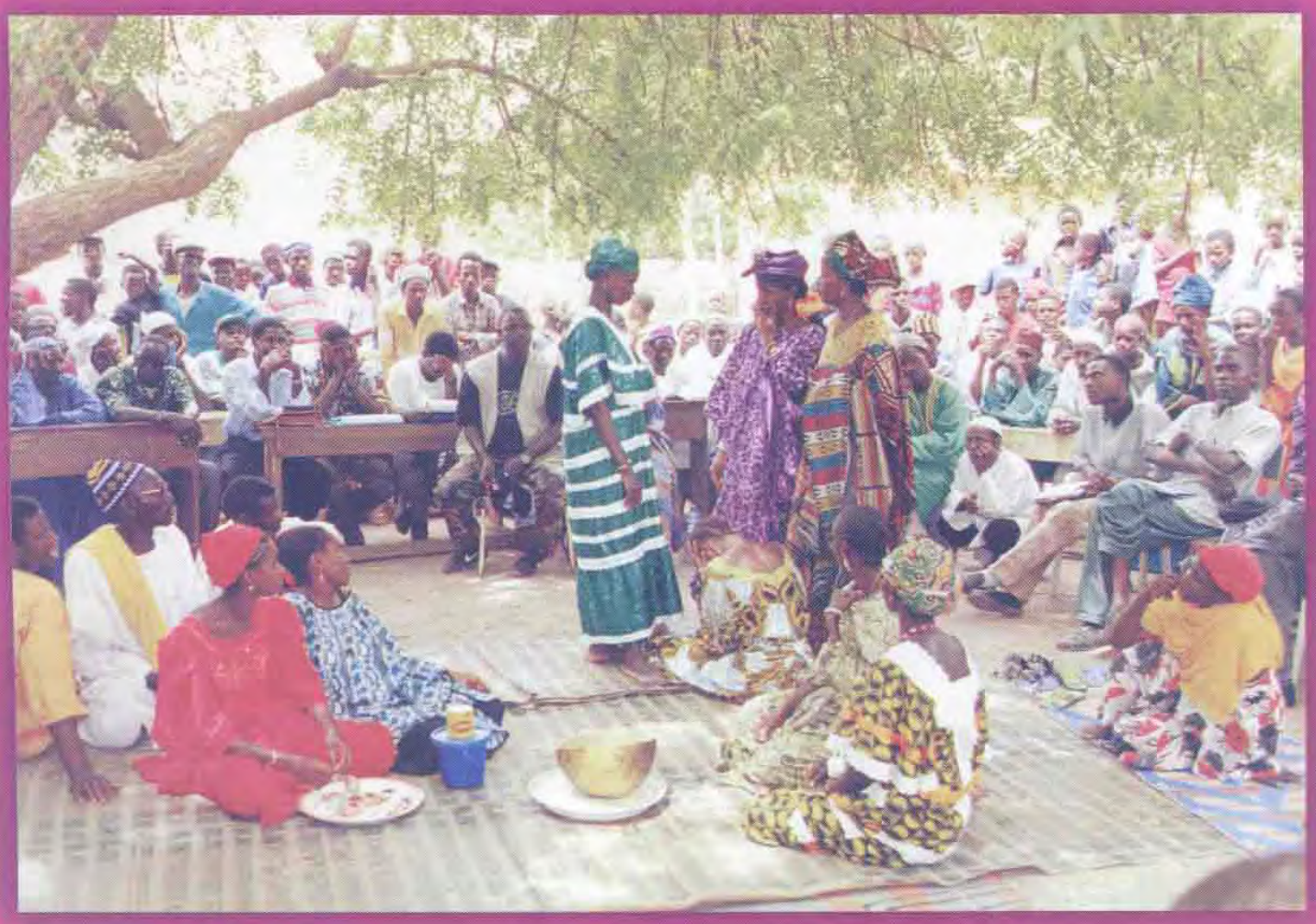




\section{TOSTAN}

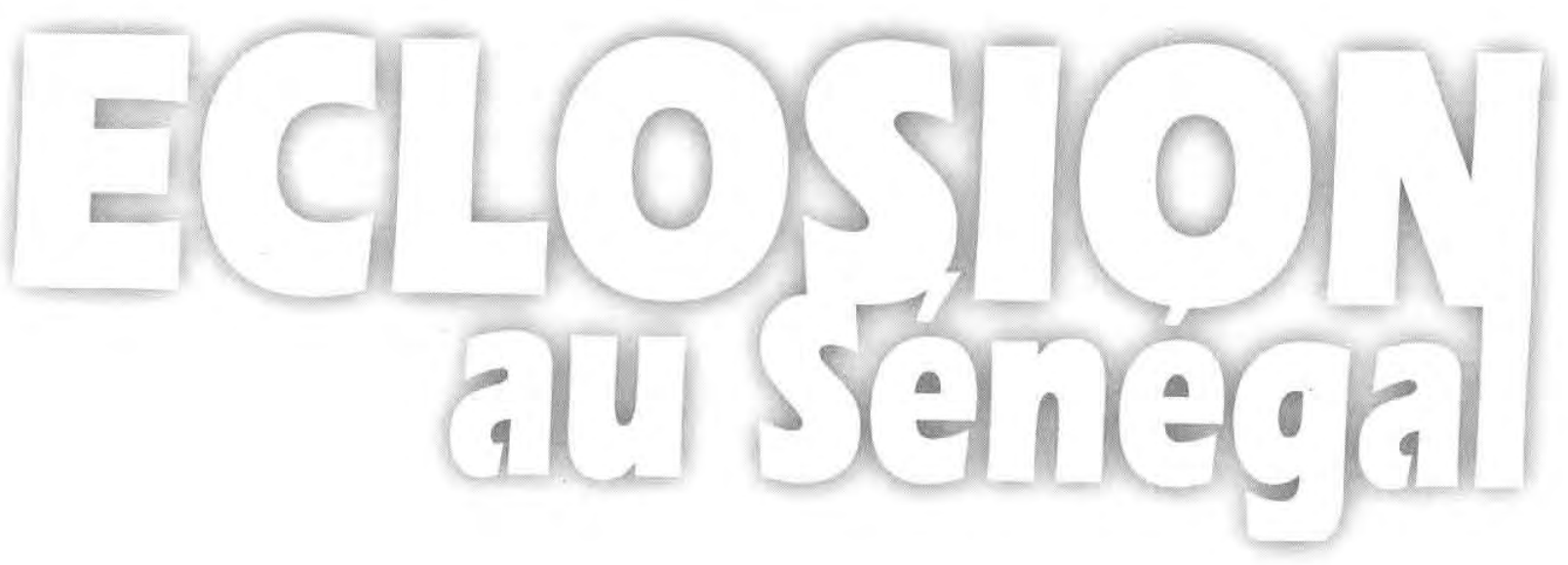

\section{LE PROCESSUS QUI A MIS FIN A L'EXCISION DANS 174 VILLAGES}

Cette publication est dédiée aux femmes courageuses de Malicounda Bambara qui ont osé les premières briser le silence et choisir la santé et la vie pour des générations futures de jeunes filles africaines. 


\section{REMERCIEMENTS}

Sans le constant soutien moral, intellectuel et financier de l'UNICEF Sénégal pendant les dix dernières années, Tostan n'aurait jamais pu expérimenter et mettre en place son Programme d'Education de Base.

Nous souhaiterions aussi remercier l'American Jewish World Service (AJWS) qui a financé l'élaboration et l'exécution des Modules 7 et 8 du programme de Tostan (1994-99). L'USAID a financé la formation de 8 Organisations Non Gouvernementales dans la région de Kaolack (1987) et le programme pilote sur «L'Education Non Formelle dans les Zones Rurales au Sénégal» à Saam Njaay (1982-85).

Le wolof dit : «Bu lëg lekkee aloom, war na gërëm coy.» (Si le lièvre goûte au fruit de l'arbre, il doit en remercier la pie.) Tostan a pu atteindre des résultats positifs grâce au soutien des personnes suivantes : David Shear, Directeur de l'USAID de 1981 à 1985, qui a soutenu les débuts du programme de Tostan dans le village de Saam Njaay et qui a compris l'importance de la culture pour le développement ; Denis Caillaux, Représentant de l'UNICEF au Sénégal de 1988 à 1990, dont la vision a propulsé le programme du rêve à la réalité ; Samir Sohby, Représentant de l'UNICEF au Sénégal de 1990 à 1998 qui a grandement contribué au programme ; Deborah Fredo de l'Institut pour l'Education Populaire (IEP) au Mali, qui a enrichi notre programme de formation de formateurs ; le professeur Ndioro Ndiaye, Ministre de la Femme, de l'Enfant et de la Famille (1987-95) qui a été la première à réclamer le programme de Tostan ; Aminata Tall, Ministre de l'Alphabétisation et de la Promotion des Langues Nationales (1990-93) ; Madame Aster Zaoudé représentant de l'UNIFEM et tout le Ministère de la Famille, de l'Action Sociale et de la Solidarité Nationale.

Gerry Mackie a apporté une théorie novatrice à nos expériences liées à la question des Mutilations Génitales Féminines. Maître Sidiki Kaba et Madame Shula Koenig ont renforcé nos travaux dans le domaine de l'éducation aux Droits Humains.

Le Président Abdou Diouf s'est battu pour mettre un terme à l'excision au Sénégal en encourageant les activités éducatives et les débats publics dans tous les villages. Tostan souhaiterait aussi remercier Mme Hillary Rodham Clinton qui suit de près le mouvement pour l'abandon de l'excision. Son soutien public aux efforts des hommes et des femmes impliqués dans cette lutte a été d'une importance capitale.

Nous exprimons aussi notre profonde gratitude à feu le Professeur Cheikh Anta Diop, père spirituel du programme d'éducation de base de Tostan. Ses contributions inestimables à la philosophie et au développement de notre programme ont porté leurs fruits dans des centaines de villages à travers le Sénégal.

Tostan souhaiterait enfin remercier le Population Council et l'USAID qui nous ont permis de partager notre expérience avec d'autres. 


\section{TABLE DES MATIERES}

I. INTRODUCTION

II. PREMIERE PARTIE : LE PROGRAMME DE TOSTAN

- MODULES 1 à 6 : PROGRAMME D'EDUCATION DE BASE DE TOSTAN

MODULES 7 à 8 : PROGRAMME D'EDUCATION CONTINUE DE TOSTAN

III. DEUXIEME PARTIE : ABANDON DE LA PRATIQUE DES MGF DANS 31 VILLAGES SENEGALAIS

- DESCRIPTION DE CE QUI S'EST PASSÉ

- CHRONOLOGIE DES FAITS DANS L'ABANDON DE LA PRATIQUE DE L'EXCISION DANS 31 VILLAGES

IV TROISIEME PARTIE : REFLEXION SUR CE QUI S'EST PASSE

- ÉlEMENTS DU PROGRAMME DE TOSTAN QUI ONT MENÉ A L'ABANDON DE LA PRATIQUE DE L'EXCISION DANS 31 VILLAGES

- $\quad$ AUTRES FACTEURS AYANT CONTRIBUÉ A L'ABANDON DE LA PRATIQUE DE L'EXCISION

- ENSEIGNEMENTS TIRÉS DE L'EXPÉRIENCE DE TOSTAN 
«Pour le groupe ethnique mandingue, Ngir-Ngiro est un «rab», un esprit qui attaque les femmes qui osent briser le silence et parler des souffrances ou des consếquences néfastes de leur expérience de l'excision. En fait, il est interdit aux femmes de discuter de tout ce qui a trait à ce qu'elles ont appris ou enduré durant cette opération. les conséquences d'une telle désobéissance pouvant être assez sérieuses : maladie mentale, paralysic ou mort. C'est pourquoi les femmes n'ont jamais osé parler de l'excision, encore moins à un non initié.

Je pense que le plus grand mérite du programme d'éducation de Tostan est que les discussions en classe et les déclarations publiques ont aidé à prouver aux femmes que Ngir-Ngiro n'existe plus et qu'il ne leur ferait aucun mal comme elles l'avaient toujours cru. Le fait de briser le silence a permis aux femmes de comprendre l'importance de mettre un terme à cette pratique, une pratique qui, comme elles l'ont appris à leur grande surprise, est source de souffrances, de problèmes psychologiques et de mort.p

\author{
Daouda Ndiaye \\ Maître «Juju»/ Guérisseur Traditionnel \\ Spécialiste en Connaissances Locales
}

«Non, je n'ai jamais entendu parler de «Ngir-Ngiro». Mais en fait nous avons d'autres esprits similaires dans nos traditions qui ont fait que nous, femmes Peuls, nous nous sommes tues tout au long de ces années. En fait, je pense que partout dans le monde, les femmes ont toutes un "Ngir-Ngiro" qui les empêche de parler des problemes troublants, ne le pensez-vous pas ?

\title{
Fatou Lala Baldé
}

Présidente du Groupement de

Promotion Féminine

Médina Chérif, KOLDA 
Le 31 juillet 1997, quarante femmes déterminées ont invité vingt journalistes sênégalais au village de Malicounda Bambara pour faire une déclaration historique. Elles avaient pris la décision de mettre un terme à la pratique de l'excision dans leur communatute bambara avee l'appui de leurs époux, du chel de village et des chefs religieux. Elles ont expliqué que la misé en cuvre du programme d'éducation de base de Tostan dans leur village a éveillé leurs consciences et les a aidées à prendrc leur décision. Elles ont cité des articles des instruments internationaux relatifs aux Droits Humains et ont parlé des conséquences néfastes de cette pratique sur la santé des jeunes filles et des fermmes. Elles ont joué une pièce de théâtre dans laquelle une jeune fille bambara décède d'une hémorragie consécutive à la douloureuse opération. Elles ont ensuite lancé un appel aux autres villageois à travers le Sénégal pour qu'ils suivent leur exemple.

Nul n'était plus surpris que Tostan d’apprendre leur décision, puisque l'abandon de la pratique de l'excision dans les communautés pratiquant cette tradition n’avait jamais été I'un des objectifs spécifiques du programme d'éducation. Cependant cette décision s'est rapidement répandue de Malicounda Bambara à Nguerigne Bambara, à Keur Simbara, à dix autres villages dans la région de Thiés puis à dix-huit villages dans la région de Kolda. Il s'est vite avéré que des éléments du programme d'éducation de base de Tostan avaient été déterminants pour l'abandon de cette pratique séculaire qui a perduré malgré les efforts considérables de divers acteurs pendant ces dernières années.

Les hommes et les femmes de Tostan qui ont vécu intensément ces évènements ont rédigé ce document afin de partager leur expérience avec les autres. Nous sommes convaincus que c'est l'ensemble du programme d'éducation intégrant des compétences cognitives, techniques et psychosociales, qui a induit l'engagement des femmes de la classe de Malicounda Bambara. Pour prendre cette décision, ici comme ailleurs, les femmes doivent prendre conscience de leurs droits humains et de ceux de toutes les autres femmes. Elles doivent parvenir à une confiance et à une estime de soi et avoir acquis des connaissances dans les domaines de la prise de décision et de défense de leurs intérêts, ainsi que des informations précises sur la santé. Par conséquent, la première partie du document présente le programme d'éducation de base de Tostan avant d'introduire son expérience sur l'excision.

La deuxième partie est une description de ce qui s'est passé durant le processus d'abandon de la pratique de l'excision dans 174 villages sénégalais.

La troisième partie est une analyse des facteurs ayant contribué à la décision des villageois d'abandonner la pratique de l'excision et une réflexion sur les enseignements à tirer de l'expérience de Tostan.

En effet, l'éclosion des Déclarations Publiques pour l'abandon de l'excision au Sénégal représente une avancée à une époque où le nombre de fermes subissant la 
pratique de l'excision dans 28 pays africains n'a que très peu diminué. Les différents programmes et stratégies n'ont pas souvent réussi à avoir un impact souhaité malgré les lois votées pour l'abolition de cette tradition. Nous espérons qu'une compréhension du processus décrit dans ce document contribuera à l'élaboration de stratégies et d'actions plus appropriées pour l'avenir. Il y a aussi un avantage supplémentaire : le programme d'éducation décrit a conduit à l'émergence d'un nouveau leadership féminin dans les zones rurales, une responsabilisation, une démocratisation accrue et une réelle amélioration des conditions socio-économiques.

Nous n'avons pas essayé de produire un rapport purement théorique, mais plutôt un document qui reflète la richesse et l'importance des transformations sociales dont Tostan a été le témoin et auxquelles il a participé durant ces dernières années. Ce rapport est dédié aux femmes courageuses qui ont osé briser le silence et dire publiquement «non» et qui, les premières, ont osé choisir la santé et la vie pour des générations futures de jeunes filles africaines. 


\section{PREMIERE PARTIE}

Le Programme

d'Education de base de

TOSTAN : Modules 1-6

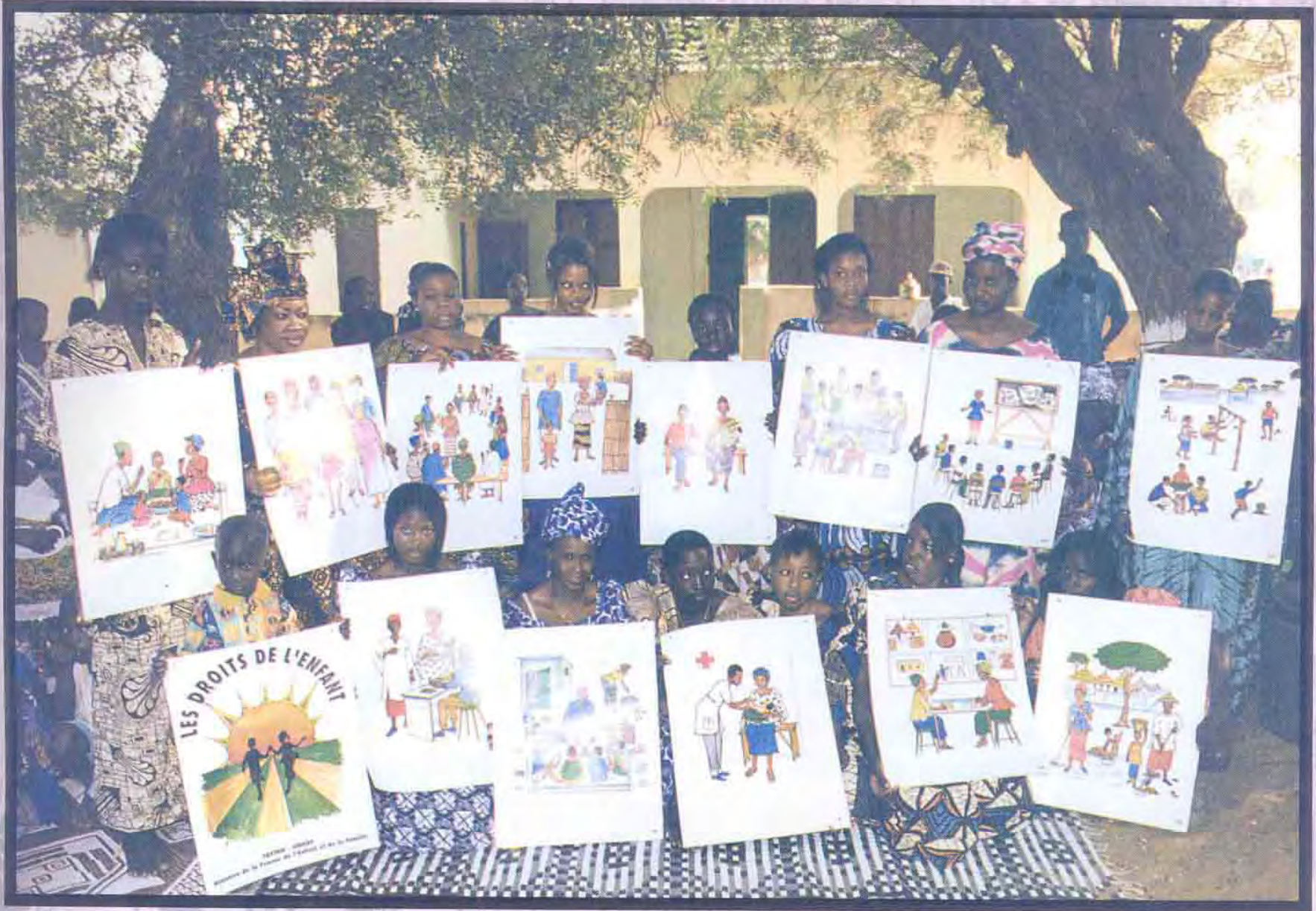

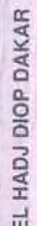

La classe à Ngaparou montre la boîte à images que Tostan a conçue pour les discussions sur les Droits de l'Enfant. 


\section{LE PROGRAMME D'EDUCATION DE BASE DE TOSTAN : MODULES 1 à 6}

\section{INTRODUCTION AU PROGRAMME}

Tostan, qui signifie Eclosion en wolof, est une Organisation Non Gouvernementale internationale basée au Sénégal, en Afrique de l'Ouest. Le programme d'éducation de Tostan comprend un programme de base composé de six modules et de quatre autres modules de formation continue. La philosophie qui sous-tend le programme part de l'idée selon laquelle le seul fait d'être alphabétisé ou bien de savoir lire et calculer ne suffit pas pour préparer le participant à contribuer aux prises de décisions sociales, politiques, économiques et culturelles liées au développement de leur communauté et par la suite à celui de leur pays.

Par conséquent, Tostan a développé une approche intégrée d'apprentissage qui offre un programme d'éducation complet en langues nationales, pas seulement en matière de lecture, d'écriture et de calcul, mais qui concourt aussi au développement d'aptitudes pour une amélioration de la qualité de vie et des conditions socio-économiques des participants. L'utilisation de techniques pédagogiques novatrices inspirées des traditions africaines et des connaissances locales a contribué à rendre les séances appropriées, vivantes et participatives. Tostan a maintenant exécuté ses programmes pour adultes et pour adolescents dans plus de 350 villages dans neuf régions du Sénégal et effectué des formations sur le programme pour plus de 25 Organisations Non Gouvernementales. Le programme a fait l'objet d'excellentes évaluations internes et externes effectuées par des experts de l'éducation et d'organisations internationales comme l'UNESCO, l'Agence Canadienne pour le Développement International (I'ACDI), l'UNICEF, le Club du Sahel et l'USAID.

\section{HISTORIQUE DU PROGRAMME}

Le Programme d'Education de Base de Tostan a pour origine le Centre de Ressources «Demb ak Tey» (Hier et Aujourd'hui) crée en 1976 à Dakar pour les enfants sénégalais. Le but de ce centre était de promouvoir une éducation non formelle pour les enfants sénégalais en leur donnant accès aux livres, au théâtre, aux marionnettes, aux jeux et à des activités artistiques s'inspirant des traditions et tout cela en wolof, la langue nationale parlée par $71 \%$ de la population. Bollé Mbaye, animateur culturel sénégalais et spécialiste des traditions orales, et Molly Melching, éducatrice américaine qui avait fréquenté l'Université Cheikh Anta Diop, ont créé ce centre sous l'égide du Ministère de la Culture du Gouvernement du Sénégal.

Le Centre Demb ak Tey a aussi touché des milliers d'enfants sénégalais par le biais d'une émission enfantine radiophonique de deux heures en wolof diffusée une fois par semaine de 1978 à 1982. La principale cible de cette émission était les enfants des zones rurales du Sénégal. Elle portait sur leurs activités et leurs centres d'intérêt. Compte tenu des conditions de vie de ces enfants, les initiateurs du projet décidèrent d'insérer dans les contes, le théâtre et les jeux, des messages portant sur la santé, 
l'environnement et le développement communautaire. Cette activité visant à véhiculer des connaissances et des informations à partir des éléments de la culture africaine s'est avérée extrêmement positive. Les enfants et même les adultes suivaient régulièrement cette émission. Ils s'en inspiraient pour alimenter des discussions sur la place publique du village.

Fort de ces résultats et soucieux de partir de l'idée d'utiliser la culture traditionnelle pour le développement et les activités éducatives, le Centre Demb ak Tey a déménagé en 1982 dans un petit village de 300 habitants du nom de Saam Njaay, à 10 kilomètres de Thiès. La collaboration entre les villageois et l'équipe pédagogique pour améliorer les conditions de vie à Saam Njaay a donné naissance à un développement participatif. Les classes d'alphabétisation devinrent l'élément moteur du changement dans la communauté parce qu'elles permirent à tous les groupes d'âge de se rencontrer, de discuter de leurs problèmes particuliers et d'en chercher des solutions. Les participants utilisèrent leurs connaissances en lecture et en écriture pour effectuer des études de faisabilité, rédiger des lettres et soumettre des projets en wolof qu'ils ont exécutés et gérés avec succès. De 1982 à 1985, bon nombre de ces projets reçurent l'appui des bailleurs de fonds et les villageois furent impliqués dans le processus de résolution de problèmes, de recherche participative, de planification, d'organisation, de gestion et d'évaluation de projets En partageant et en analysant leurs expériences, tous les participants au projet contribuèrent à créer un curriculum innovateur pour l'éducation de base et les activités de développement en Afrique.

Inspirés par cette expérience, les concepteurs du projet élaborèrent un programme d'éducation composé de quatre modules en langues wolof et Serer qui fut expérimenté en 1987-88 dans 42 villages dans la région de Kaolack avec un financement de l'USAID.

Par la suite, avec le soutien de l'UNICEF et du Ministère du Développement Social, l'équipe a étendu le programme à six modules de 1988 à 1991 et créé en 1991 l'ONG Tostan pour l'éclosion de l'éducation non formelle en Afrique. L'UNICEF et le Gouvernement du Sénégal reconnurent immédiatement le potentiel qu'avait ce nouveau programme en langues nationales pour assurer un meilleur avenir aux populations sénégalaises, particulièrement aux femmes et aux enfants, et de mettre à jour les bases pour un développement profond et durable.

Les modules furent réaménagés et expérimentés à nouveau afin de mieux répondre aux besoins des femmes rurales en wolof, pulaar, serer et mandingue pour constituer un programme d'éducation de base composé de six modules.

\section{BUTS, OBJECTIFS ET STRATEGIES DU PROGRAMME}

Le but du programme est de promouvoir une éducation de base des villageois particulièrement les femmes, qui en conséquence pourront améliorer leurs conditions de vie et celles de leurs enfants. Pour cela Tostan s'est assigné les objectifs suivants :

* contribuer à réduire l'analphabétisme au Sénégal

* promouvoir l'auto-développement grâce à l'utilisation de matériel éducatif approprié

* offrir un programme performant d'éducation de base 
Quatre stratégies majeures ont été identifiées :

\section{1) UN PROGRAMME D'EDUCATION COMPLET ET DE QUALITE COMPRENANT UNE APPROCHE INTEGREE DE L'APPRENTISSAGE}

Jusqu'en 1987, il n'existait pas encore au Sénégal de programme d'éducation de base en langues nationales. Bien que par le passé plusieurs projets d'alphabétisation fussent élaborés pour l'enseignement de la lecture, de l'écriture et du calcul, ils furent cependant souvent exécutés avec du matériel didactique insuffisant ainsi qu'une formation et une supervision inadéquates. Néanmoins, les bailleurs de fonds et le gouvernement dépensèrent d'importantes sommes d'argent dans des efforts d'alphabétisation dans les années 70 et 80 dans l'espoir d'atteindre des milliers de villageois. Malheureusement, peu de participants suivirent encore les cours après quelques mois et ceux qui persistaient oublièrent ce qu'ils avaient appris. De plus, les connaissances acquises n'étaient pas partagées avec le reste de la communauté.

Les projets qui avaient connu un tant soit peu de succès dans l'alphabétisation de base furent rapidement confrontés à de nouveaux problèmes. Alors que les femmes passaient des semaines à apprendre la différence entre le «a long» et le «à avec accent», un enfant sur quatre mourait dans les zones rurales au Sénégal. Comme le signalait en 1982 Abdun Noor, spécialiste en éducation : «Bien que l'alphabétisation ne soit pas interchangeable avec l'éducation de base, beaucoup de planificateurs la concevaient ainsi. Ils associaient le besoin d'acquérir une formation en alphabétisation à l'augmentation des connaissances sur le développement, alors qu'en fait, ils auraient dû associer le besoin d'acquérir une éducation de base plus complète aux activités de développement. Ainsi, l'alphabétisation devint un pré-requis absolu pour l'acquisition de connaissances qui menaient au développement, faute de quoi les campagnes d'alphabétisation ont souvent été vouées à l'échec. En effet, elles constituaient chez les participants des réels goulets d'étranglement, les privant des aptitudes nécessaires pour affronter un monde de plus en plus compétitif et de plus en plus dépendant de l'économie. En dépit des bonnes intentions qui la sous-tendent, cette vision étroite de l'éducation et du développement, s'est avérée en fin de compte décevante.»

Tostan s'est alors rendu compte de la nécessité d'un programme complet qui offrirait simultanément une formation en lecture, en écriture et en calcul, et des «connaissances qui permettent d'accéder au développement» : par exemple, les connaissances essentielles de la vie telles que le processus de résolution de problèmes, la promotion de la santé, l'hygiène, la santé des femmes, les soins aux enfants, la gestion financière et matérielle, le leadership, les droits de la personne, et la gestion des ressources naturelles. Tostan s'est évertuée à adapter les meilleures méthodes et techniques pédagogiques et à les intégrer dans un programme de qualité répondant aux besoins de nombreux participants dans le monde rural en Afrique. Donc, à la différence de l'alphabétisation fonctionnelle qui répond à un besoin spécifique, le programme d'éducation de Tostan est conçu pour une utilisation dans une perspective plus large en appui à toute activité utile au bien-être de la famille et de la communauté. 


\section{2) UN PROGRAMME ACCESSIBLE AUX FEMMES}

L'UNICEF et Tostan ont convenu qu'il serait nécessaire d'adaptẹr le programme aux besoins spécifiques et aux préférences des femmes du monde rural en matière de formation au Sénégal.

S'assurer que le programme était intéressant et approprié pour les femmes des zones rurales signifiait qu'il fallait effectuer des recherches plus approfondies avec l'aide des participants eux-mêmes pour comprendre et renforcer leurs «manières d'apprendre.» Ceci impliquait une nouvelle rédaction et une nouvelle expérimentation du programme du fait que la plupart des villageoises n'ont jamais fréquenté l'école primaire et sont rarement confrontées à l'écriture et au calcul dans leur environnement. Les principaux thèmes choisis comme information « de base » furent discutés avec les anciennes participantes et furent souvent changés pour mieux répondre à leurs besoins.

L'équipe de conception prit aussi en considération le fait que les femmes partout dans le monde apprennent mieux en utilisant une approche basée sur l'intimité, le partage d'expériences, les témoignages et l'interdépendance. Le vocabulaire en langues nationales, utilisé par les femmes pour décrire leurs expériences de l'apprentissage et leur perception des méthodologies, fut intégré dans les guides de formation et les livres didactiques.

Tostan a aussi analysé la période de 18 mois du programme durant laquelle les classes devaient avoir lieu trois fois par semaine. Bien que plus long que la plupart des projets d'alphabétisation, les villageoises ont soutenu que le fait de venir en classe un jour sur deux était primordial pour assurer un enseignement soutenu. Puisque la majorité de ces femmes n'avait jamais été à l'école, les jours de repos entre deux classes leur laissaient assez de temps libre à consacrer aux discussions, à l'assimilation et à la pratique des nouvelles connaissances acquises durant les séances de deux heures. Le programme a aussi permis une plus grande participation des femmes puisque l'emploi du temps flexible leur permettait de continuer à vaquer à leurs autres activités domestiques et villageoises.

\section{3) UN PROGRAMME UTILISABLE PAR D'AUTRES ORGANISATIONS ET D'AUTRES PAYS AFRICAINS}

Afin d'atteindre un plus grand nombre de participants, Tostan savait que le programme d'éducation devait être facilement accessible et compréhensible pour tous les utilisateurs. Pour cette raison, des guides détaillés des séances furent rédigés dans toutes les langues nationales à l'intention des formateurs et des facilitateurs villageois. Des séminaires de formation furent organisés pour tous les modules, assurant ainsi la compréhension et la maîtrise de tout le matériel didactique avant son utilisation. Le wolof, le pulaar, le mandingue et le serer furent utilisés pour le Sénégal, mais des versions en français et en anglais sont nécessaires pour les autres pays africains intéressés par des adaptations du programme dans leurs langues locales. 


\section{4) UNE APPROCHE PARTICIPATIVE POUR PROMOUVOIR L'AUTO-DEVELOPPEMENT}

En 1988, le terme «participatif» fut un concept clé dans le monde du développement et de l'éducation, mais peu de projets ont réellement mis cette théorie en pratique. Alors que l'alphabétisation fonctionnelle permettait aux populations d'acquérir de meilleures connaissances pour effectuer des tâches spécifiques, rares furent les expériences qui amenaient les participants à faire une analyse-critique nécessaire à tout changement social. Les formateurs passaient des heures à enseigner l'art de devenir participatif pendant que les futurs alphabétiseurs villageois restaient assis en rangs comme de petits élèves. La plupart de ces formateurs eux-mêmes n'avaient comme expérience pédagogique que quelques années dans le système de l'enseignement formel. Sans les modèles, guides, et matériels adaptés, ils ne pouvaient appliquer dans les classes dont ils avaient la charge, que les modèles d'enseignement usuels, passifs et centrés sur le professorat.

Tostan a voulu concevoir un programme d'éducation dẻ base qui cherche à responsabiliser les villageois et à assurer un accès égal à l'information et aux ressources au niveau communautaire, ce qui fut fait avec la conception d'un matériel didactique dynamique et interactif pour les formateurs et les participants et avec l'utilisation de techniques d'éducation traditionnelles. Ceci signifiait l'élaboration d'un programme d'éducation réellement participatif et des méthodes de formation pour les formateurs, les facilitateurs villageois et les participants. L'expérience avait démontré que les facilitateurs villageois avaient besoin d'un curriculum orienté vers la recherche-action avec une gamme variée de techniques participatives. À partir de ce curriculum, les facilitateurs furent à même de sélectionner et d'analyser les différentes démarches pédagogiques qui à leur avis avaient connu le plus de succès dans leurs classes. À travers une recherche participative plus approfondie avec les apprenants, ils furent capables de développer des théorịes afin de créer un nouveau matériel et de nouvelles approches pour répondre aux autres besoins des villageois et ainsi transformer l'environnement local.

\section{CONTENU, METHODOLOGIE ET ORGANISATION DU PROGRAMME}

\section{1) CONTENU DU PROGRAMME : MODULES 1 à 6}

Le contenu de chacun des six modules du programme de base a été choisi en collaboration avec les anciens participants, en particulier les femmes, en faisant constamment référence aux besoins fondamentaux des villageois à travers tout le pays. Des études effectuées sur le monde rural au Sénégal ont indiqué que les problèmes d'eau, de santé, d'hygiène, d'environnement et d'exode rural sont les problèmes prioritaires que rencontre la majorité de ces populations. Les villageois tenaient non seulement à débattre de ces problèmes, mais encore ils avaient exprimé le besoin d'acquérir des connaissances techniques et psychosociales leur permettant de prendre des décisions et de résoudre les problèmes liés à ces thèmes. 
Ainsi, une démarche de résolution des problèmes est introduite dans le Module 1 à laquelle les participants pourront se référer continuellement tout au long du programme pour aborder les thèmes. Les participants maîtrisent le processus au moyen de jeux et de différents exemples concrets. Ce processus comprend les étapes suivantes :

* identification et analyse du problème

* étude des solutions adaptées (basée sur la disponibilité des ressources financières, matérielles et humaines, ainsi que sur le facteur temps)

* planification de la solution (quelles activités doit-on accomplir ? pour chaque activité : quand doit-elle être achevée ? qui en est responsable ? quelles sont les ressources humaines, matérielles et financières nécessaires ? et quels sont les obstacles éventuels?).

* exécution de la solution

* évaluation des résultats - Avons-nous résolu le problème ?

Le livre de pré-lecture du Modulle $\mathbb{1}$ permet aux participants de s'initier à la lecture et à l'écriture et renforce ainsi les débats de chaque séance. Les participants apprennent à lire, à écrire et à analyser les chiffres de 0 à 9 . Ils sont indirectement initiés à l'addition et à la soustraction par l'utilisation de jeux les aidant à construire une base à la compréhension des opérations de calcul plus avancées du Modulle 2. Le participant utilise le même livre de calcul du Modulle $\mathbb{1}$ au Modulle 5.

Au Modulle 2, les participants acquièrent des notions sur la transmission des microbes, l'importance d'une bonne hygiène personnelle et communautaire et appliquent le processus de résolution de problèmes à l'hygiène dans leur propre village. Des petits groupes de recherche sont formés pour identifier et analyser les principaux problèmes de santé et d'hygiène dans leur environnement et trouver ensemble des solutions. Ils mettent en ouvre les solutions en utilisant leurs propres ressources, puis en évaluent les résultats.

Ensuite les participants reçoivent un livre de lecture avec des textes qui renforcent les thèmes du Module 1 . Ce livre est utilisé du Module 2 au Module 4. Ils commencent aussi à analyser des textes, des phrases, des mots, des syllabes et des lettres. Ils lisent un livret illustré sur la santé portant sur la transmission des microbes. En calcul, ils apprennent l'addition et la soustraction ainsi que les grands nombres.

Au Modulle 3 des informations sont présentées sur la santé, notamment sur les 2 principales causes de mortalité chez les enfants de moins de 5 ans : la déshydratation et les maladies infantiles liées au défaut de vaccination. Des mobilisations sociales sont organisées afin d'assurer un apprentissage actif et adapté à l'environnement.

Les participants poursuivent la lecture en débutant et en terminant chaque cours par l'étude d'un texte. Ils reçoivent aussi deux livrets : l'un sur la Réhydratation par Voie Orale et l'autre sur les Vaccinations. À la fin du Modulle 3, les participants sont capables de faire des additions et des soustractions avec retenues. 
Au Module 4 les participants apprennent les rudiments de gestion financière et matérielle pour différents types de projets communautaires. Ce module est introduit à un moment où les participants ont déjà assimilé en lecture, en écriture et en calcul, les notions nécessaires pour une bonne tenue des documents de comptabilité. Ils terminent leur livre de lecture et l'étude des lettres de l'alphabet au cours du Module 4. Des notions de multiplication sont introduites pendant ce module.

Au Modulle 5, les participants discutent des notions de leadership et de dynamique de groupe. A travers des études de cas très animées, et relatives à leurs propres expériences, ils étudient les côtés positifs et négatifs du leadership traditionnel et les voies et moyens d'apporter de réels changements.

Pendant ce cinquième module, les participants font l'apprentissage d'un «processus d'écriture» qui les aide à démystifier l'acte de rédaction d'un texte. En travaillant individuellement ou en groupe, les participants rédigent une variété de textes : correspondances, articles de journaux, projets, poèmes et nouvelles. «L' atelier des écrivains » qui a lieu toutes les deux semaines est une activité très prisée par les participants puisqu'il leur permet de «rendre publics» leur écrits. Ce processus renforce aussi leurs connaissances en grammaire, en orthographe et en ponctuation. En calcul, ils font une révision de leurs connaissances à travers la solution de problèmes concrets, mais apprennent aussi à faire des divisions.

Au Modulle 6, les villageois apprennent à prendre des décisions relatives à des projets générateurs de revenus et autres, pour leurs groupements communautaires. En utilisant des jeux, des boîtes à images et des pièces de théâtre, les participants arrivent à comprendre l'importance des études de faisabilité avant d'entreprendre des projets pouvant mener à un échec.

Toutes les notions de calcul et de lecture sont réutilisées par les participants lorsqu'ils décident d'entreprendre une étude de faisabilité.

\section{2) METHODOLOGIE DU PROGRAMME}

\section{Lecture et Ecriture}

Dans beaucoup de projets d'alphabétisation au Sénégal et en Afrique de l'Ouest, les séances d'alphabétisation se déroulent comme suit : un alphabétiseur anime une discussion sur un thème qui intéresse les villageois, puis les participants font un résumé de la discussion en une phrase. Ensuite l'alphabétiseur isole un mot clé dans la phrase, il met l'accent sur une syllabe, et finalement sur la lettre à apprendre durant cette séance. La plupart des alphabétiseurs, influencés par les méthodes traditionnelles d'enseignement de la lecture et ne disposant pas de guides stimulants, passent en classe de longs moments à travailler sur la répétition des lettres de l'alphabet et la combinaison de syllabes. Dans la majorité de ces projets, ce n'est que plusieurs mois après le début du programme que de vraies séances de lecture ont lieu. Cette méthode d'enseignement de la lecture présente un gros inconvénient : elle met l'accent sur les sons et les lettres (ou syllabes) qui sont des abstractions et n'ont aucun sens pour les participants.

Les formateurs de Tostan ont constaté que les femmes en particulier avaient beaucoup plus de problèmes lorsque l'accent était mis sur la répétition d'une lettre et la combinaison de syllabes. Lors des évaluations, les participants étaient si occupés à 
décoder les lettres qu'ils n'avaient aucune idée du sens du texte bien qu'il fut écrit dans leur langue maternelle. Les méthodes de reconnaissance de mots présentaient aussi un inconvénient car elles isolaient des éléments du texte et ne représentaient pas la langue comme les femmes avaient appris à la parler toute leur vie.

C'est pourquoi Tostan a décidé de développer et d'enrichir les méthodes de lecture expérimentées à Saam Njaay où l'on mettait très peu l'accent sur le décodage grapho-phonétique. La méthode utilisée s'inspirait d'une approche dite du « langage intégré » dans laquelle les participants comprennent d'abord le texte, car ils sont exposés à de vrais textes, pas seulement à des fragments de langues isolés tels que les mots et les syllabes. Ainsi les participants s'initient dès le début de leur apprentissage à la création de textes qu'ils pourront ensuite lire parce qu'étant déjà familiarisés avec leur contenu.

Ce n'est que plus tard qu'ils apprennent le décodage à l'aide de différentes techniques comme «la chanson de l'alphabet» qui s'inspire des chansons africaines. Comme les participants ont déjà vu des textes et des mots lorsqu'ils apprennent la chanson, la perception auditive et la différenciation des lettres se font rapidement. Ils utilisent une méthode éclectique du Module 2 au Module 4, qui combine l'approche du langage intégré avec l'étude de phrases, de mots, de syllabes et de lettres.

Cependant les séances de lecture misent toujours sur la compréhension. Pendant le Modulle 1 , à chaque séance, des textes sont lus aux participants, puis à leur tour ils créent et lisent des textes. Dans le programme de Tostan, «la post-alphabétisation» débute le premier jour de classe ! Les participants sont aussi exposés aux livres dès le début. Ainsi, la motivation joue un rôle important dans le processus puisque c'est ainsi qu'ils appréhendent immédiatement les résultats potentiels de leur apprentissage.

L'écriture est introduite dès le début, d'abord par des exercices de lecture puis par l'écriture de mots et de textes ayant un sens. Au terme du premier module, les participants savent lire et écrire leur nom, celui de leur village et même rédiger une correspondance avec l'aide de leur facilitateur !

Avec ces méthodes, la majorité des participants savent lire et écrire à la fin du quatrième module.

\section{Calcull}

Les séances utilisées pour enseigner le calcul furent adaptées d'une méthodologie introduite à l'Institut des Langues Nationales en Mauritanie. Cet Institut fut créé en 1979 avec comme but d'expérimenter l'introduction des langues nationales dans le système éducatif. L'approche de l'enseignement du calcul était novatrice parce qu'elle mettait beaucoup l'accent sur le langage mathématique et la logique. Ainsi, la notion de «base», fondement de toute numération écrite ou orale, fut introduite à partir des premières séances. L'étude de la «base 10» a permis aux participants de comprendre la première étape de l'apprentissage des mathématiques : en utilisant le concret (les objets) pour comprendre le semi-concret (le dessin de ces objets) et l'abstrait (les chiffres). Ceci en fait est un principe pédagogique très connu dans l'enseignement des mathématiques qui devrait normalement être appliqué à tous les stades de la numération écrite et pour les quatre opérations de base - l'addition, la soustraction, la multiplication, la division. Cependant, cet important principe est souvent ignoré dans beaucoup de programmes de mathématiques alors que le participant 
est confronté à de nouveaux concepts.

Tostan a effectué des recherches plus poussées en théorie et en pratique sur la base de l'expérience mauritanienne. À un niveau théorique, les formateurs de Tostan ont étudié la connaissance locale du calcul dans l'environnement sénégalais. Ils ont comparé la numération écrite et orale, étudié les problèmes de syntaxe en numération orale et leur transposition en numération écrite, et établi une corrélation entre les numérations qui utilisent la base 10. Les participants apprennent donc le calcul en utilisant les trois étapes importantes de l'apprentissage des mathématiques : le concret, le semi-abstrait et l'abstrait.

Sur le plan pratique, Tostan a adapté la méthode de mathématiques à l'environnement rural et a en particulier cherché à faciliter aux femmes l'apprentissage des mathématiques. Le guide détaillé des séances couvre les quatre opérations de base en mathématiques y compris la multiplication et la division. Chaque module comprend 10 séances de mathématiques, et va de la numération au sens de l'addition et de la soustraction dans le Module 1, aux notions les plus difficiles dans chaque module subséquent. Les séances de mathématiques sont toujours liées à des connaissances pratiques nécessaires au développement communautaire. Par exemple, après que les participants ont maîtrisé les chiffres de 10 à 100 (en utilisant la base 10) dans le Module 2, ils apprennent immédiatement à utiliser le calendrier et à lire l'heure. À ce niveau, les agents de développement de la communauté qui travaillent à l'implantation de projets dans le village encouragent les participants à pratiquer leurs nouvelles connaissances hors de la classe, en leur demandant de planifier des activités à l'aide d'un agenda et d'un calendrier. Tostan a aussi intégré des jeux mathématiques conçus et testés dans les villages pour favoriser la pratique fréquente des concepts de base.

\section{Présentation des Thènes de Développement Communautailre}

Les méthodes d'enseignement de la majorité des thèmes présentés dans le programme de Tostan s'inspiraient de l'expérience des formateurs et des participants du Centre Demb ak Tey et du village de Saam Njaay. L'approche pédagogique repose sur le fait que les villageois ont d'abord besoin :

a) de voir et d'analyser ce qu'eux et d'autres villageois font, et de comprendre pourquoi ils le font ;

b) de recevoir de nouvelles informations appropriées et souvent techniques de manière à ce qu'ils comprennent le message ;

c) de travailler en groupe afin de traiter l'information et de décider si elle est utile ou si elle peut améliorer leur situation. Les villageois ne reçoivent jamais de directives ; on leur transmet plutôt les connaissances appropriées qui vont leur permettre de prendre des décisions éclairées.

Ces connaissances sont transmises en utilisant comme support des techniques d'éducation inspirées de la culture africaine telles que les proverbes, les contes, les pièces de thêâtre, les jeux et les chants. Souvent le processus d'apprentissage comporte plusieurs étapes utilisant des techniques participatives.

Étape 1-Se familiariser avec la nouvelle information. Connaissances techniques présentées de manière à faciliter la compréhension chez les participants.

Lorsqu'un thème est présenté durant les premières séances, des boîtes à 
images, des dessins, des contes, des pièces de théâtre et des chansons sont utilisées pour encourager l'assimilation de nouvelles connaissances. Les participants débattent de leurs idées sur le sujet et le facilitateur les implique dans le processus d'apprentissage en faisant constamment référence à leurs propres expériences. Une présentation détaillée des nouvelles informations techniques est faite et peut aider à donner aux participants la majorité des informations dont ils ont besoin pour prendre des décisions appropriées. Les facilitateurs encouragent un dialogue de fond parmi les participants pour s'assurer que toutes les opinions sont exprimées. Les superstitions et les croyances traditionnelles liées au thème sont soulevées et débattues ouvertement.

\section{Étape 2-Renforcer les nouvelles connaissances}

Durant les séances suivantes, les participants révisent et assimilent mieux les nouvelles informations apprises par le biais des jeux et des pièces de théâtre.

\section{Étape 3- Utiliser la lecture et l'écriture pour renforcer les connaissances}

Les participants reçoivent des livres ou rédigent des articles, des contes, des poèmes ou des chansons qui décrivent ce qu'ils ont appris. Il leur est facile de lire ou d'écrire des textes parce qu'ils se sont familiarisés avec les informations.

\section{Étape 4- Apporter un changement au sein de la communauté}

Pendant ces séances, les participants élaborent des stratégies qui les aident à s'assurer que leurs nouvelles connaissances sont partagées dans la communauté et mises en pratique. Ils analysent les obstacles à franchir pour réaliser une transformation sociale positive et identifient les acteurs clés du processus. Ils font aussi des jeux de rôle pour pratiquer leurs techniques de plaidoyer avec les autres membres de la communauté ou les représentants du gouvernement.

\section{Étape 5- Partager avec d'autres les connaissances acquises. les participants deviennent des facilitateurs}

Les participants apprennent à présenter la nouvelle information par eux-mêmes en utilisant les boîtes à images, les pièces de théâtre et autres supports. On les incite ensuite à présenter les boîtes à images aux membres de leurs familles, aux organisations de leur voisinage, ou dans d'autres villages. On les encourage aussi à lire et à discuter avec beaucoup d'autres personnes des livres et des textes qu'ils ont rédigés. La cinquième étape renforce le sentiment de confiance de la part des participants qui réalisent qu'ils sont capables de communiquer des messages importants et vitaux en utilisant des techniques qui suscitent l'intérêt de leur auditoire. Ils démystifient le rôle de l'enseignant et saisissent le fait qu'ils peuvent aussi apporter d'importants changements dans leur environnement. Ceci leur procure la motivation nécessaire pour identifier d'autres problèmes au sein de la communauté et élaborer de nouveaux outils pour résoudre ces problèmes.

\section{Utillisation d'Activités de Mobillisation Sociale}

Tostan a compris l'importance d'utiliser les activités de mobilisation sociale pour renforcer les classes d'éducation. Un des facilitateurs villageois par exemple, est un chef religieux local et président de l'association des Imams (chef religieux de la religion musulmane) dans son fief. Sa conviction profonde de l'importance de l'éducation pour le développement l'a amené à organiser des rencontres et des activités éducatives dans d'autres villages que ceux inclus dans le programme de Tostan pour 
renforcer l'idée que l'alphabétisation en langues locales est une force positive dans les zones rurales au Sénégal. Les populations réagissent avec un grand enthousiasme à ses visites parce que c'est une personne très respectée.

Tostan a organisé des séances de théâtre, poésie et des débats en langues nationales dans beaucoup de villages. Des musiciens traditionnels, des chanteurs, des poètes et des acteurs ont visité des classes pour des récitals de poésie, pour faire des représentations théâtrales en langues nationales, et ensuite animer des discussions sur des sujets souvent controversés. Les villageois assistent à ces séances en très grand nombre. Comme l'a déclaré un père de famille : «Après avoir écouté plusieurs poèmes, j'ai su que j'allais changer !» .

Les débats publics et les discussions en classe sont essentiels pour induire le changement au niveau communautaire. Pour cette raison, les activités de mobilisation sociale constituent un suivi nécessaire aux apprentissages.

\section{Méthodologie d'évaluation}

\section{Études de départ}

Avant de débuter un programme d'éducation au sein d'une communauté, Tostan réalise une étude de départ en collaboration avec un grand nombre de membres de la communauté afin d'établir une base de comparaison à la fin du programme.

\section{Système de gestion de l'information}

D'importantes données sur le développement du programme sont mises en place dans un système qui permet aux évaluateurs de stocker et de fournir rapidement l'information aux décideurs du programme. Cette information est collectée tout au long des modules du programme. Le système consiste en des fiches mensuelles standard remplies par les facilitateurs, les formateurs et les coordonnateurs. Ils remplissent aussi des fiches d'évaluation pour les différents modules ainsi que le suivi des progrès du participant.

\section{Évaluation naturaliste}

Comme alternative aux modèles traditionnels d'évaluation du programme, Tostan utilise aussi une approche «naturaliste» qui prend en considération les valeurs des participants, puisque ces valeurs seront utilisées comme critères de jugement. Aussi, la structure utilisée pour collecter et analyser les informations peut changer durant le processus d'évaluation. Ce type d'évaluation correspond mieux à la philosophie de Tostan puisqu'il donne une meilleure indication de la manière dont les participants vivent le programme. Dans les entrevues de groupe par exemple, les participants évaluent les modules de formation, le contenu, l'approche pédagogique et le matériel utilisé. Ces évaluations leur permettent de comprendre que le programme est conçu pour eux, et que par conséquent leur opinion est primordiale pour les concepteurs du programme. Janet Kelly disait à juste raison que : « Le fait pour les participants de voir et ressentir clairement leurs propres progrès est un facteur de motivation important, en particulier dans un domaine aussi stimulant que l'éducation de base des adultes. Les tests standardisés ne peuvent pas mesurer le développement de l'amour propre, la connaissance de la vie, le degré de responsabilisation, le rôle au sein de la communauté, et le degré de confiance en soi, ils ne mesurent pas réellement 
non plus les capacités d'apprentissage que les adultes acquièrent dans beaucoup de programmes.» Ainsi, les entrevues de groupe, structurées ou non, permettent aux participants de réfléchir sur leurs propres changements de comportement ainsi que sur les changements apportés dans leurs foyers ou leur environnement grâce à leurs nouvelles connaissances et activités. Les anecdotes racontées par les participants sont particulièrement importantes parce que souvent révélatrices de grands changements d'attitude ou de comportement.

Tostan demande aussi aux facilitateurs et aux formateurs d'observer et de noter leurs impressions sur les progrès des participants autant que faire se peut. Les formateurs d'une région décidèrent d'eux-mêmes d'interviewer les habitants des localités voisines des villages où Tostan avait implanté des classes afin de recueillir les impressions d'impact du programme sur les villages environnants.

Chaque participant est aussi évalué individuellement afin de vérifier ses progrès durant le module. Mis à part les besoins d'évaluation des connaissances, cet outil peut servir de moyen de collecte de récits liés à l'apprentissage. Enfin, les évaluateurs eux-mêmes deviennnent des instruments d'évaluation puisqu'ils sont en interaction constante avec le milieu et les participants. Ils font appel à leur imagination et à leur créativité ainsi qu'à celle des apprenants.

Comme le programme de Tostan utilise une approche pédagogique basée sur des objectifs spécifiques pour chaque module, il est assez aisé de faire passer de petits «tests» aux participants à la fin de chaque module. Ceux-ci ne sont pas «notés» car la notation, avec une interprétation normative des résultats, peut avoir des effets négatifs sur le moral et la motivation des adultes. Ils vérifient plutôt avec leurs formateurs et facilitateurs si les objectifs du module sont pour eux , «atteints», «en progrès» ou «non atteints». Les résultats de ces tests sont ensuite restitués aux formateurs, aux facilitateurs et aux participants qui découvrent alors leurs problèmes, leurs difficultés, comment les surmonter et quels sont les buts à atteindre pour eux et pour le groupe au prochain module. Ainsi, l'évaluation «sommative» devient « formative ». De plus, les facilitateurs et les formateurs sont incités à faire des évaluations formatives sur une base régulière tout au long du programme.

\section{3) ORGANISATION DU PROGRAMME}

Le Programme d'Education de Base de Tostan comprend six modules de formation. Chaque module couvre 24 séances et dure deux mois. Chaque séance est conçue pour durer approximativement deux heures. En fonction de leur horaire de travail, les participants choisissent leurs jours et leurs heures de classe, mais normalement la majorité des classes ont lieu 3 fois par semaine, un jour sur deux. Durant la seconde séance, les participants établissent leur propre règlement pour le fonctionnement de la classe et définissent ensemble le rôle du facilitateur ainsi que leur propre rôle. Les objectifs du programme sont présentés durant la première séance de classe et les objectifs de chaque module sont aussi discutés avant qu'il ne débute. Pendant la saison des pluies, les participants se réunissent une ou deux fois par semaine, mais pendant la saison sèche (7 mois dans l'année), plusieurs classes créent des groupes de travail et se rencontrent en dehors des six heures de séances pour réviser et appliquer leurs nouvelles connaissances. 
Après les séances de formation qui ont lieu avant chaque module, le formateur effectue des visites régulières dans les classes des villages sous sa supervision. Un formateur peut en principe superviser dix à treize villages situés proches les uns des autres. Les formateurs aident les facilitateurs villageois à préparer les séances pour la semaine à venir et assistent aux cours pour s'assurer qu'il n'y a pas de problème majeur. Ils rencontrent les agents locaux du développement pour coordonner les sujets traités en classe et les activités de projet. Ils rencontrent aussi les autorités administratives locales.

\section{Les facilltateurs villageois}

Les facilitateurs villageois sont toujours choisis par la communauté d'où sont issus les participants, sur la base de critères spécifiques établis par Tostan et d'anciens participants :

- Les facilitateurs doivent avoir fréquenté l'école primaire pendant quatre années au moins ou doivent déjà êtres alphabétisés en langues nationales;

- Les facilitateurs doivent être disposés à demeurer en permanence dans le village durant la semaine et pendant la période des 18 mois du programme ;

- Les facilitateurs doivent être patients, tolérants, respectueux des autres, compétent et dévoué ;

- Les facilitateurs reçoivent soit une indemnité de $\$ 50$ par module (qui peut durer 2 à 3 mois), soit sont rémunérés d'une manière ou d'une autre par les villageois.

\section{Ba Tormation}

Les facilitateurs reçoivent une formation intensive, comprise dans le programme, avant le début de chaque module. La formation sur le Module 1 dure un mois et couvre les domaines suivants :

\section{Familiarisation avec l'organisation Tostan et son programme d'éducation non formelle en millieu rural}

Fournir aux facilitateurs les informations nécessaires pour comprendre leur rôle au sein de Tostan et se familiariser avec tous les aspects du programme d'éducation non formelle, y compris une introduction à la composante évaluation du programme.

\section{Connaissances Locales}

Systématiser les connaissances du facilitateur et de celles de l'apprenant pour établir un dialogue authentique et élaborer un matériel didactique approprié.

\section{Perfectionnement de la langue écrite}

Permettre au facilitateur d'acquérir les connaissances nécessaires à la transmission des langues nationales et d'élargir leur connaissance de la syntaxe de la langue.

Favoriser l'écriture pour la poursuite de leur formation continue et pour l'élaboration d'un nouveau matériel didactique et de nouvelles pratiques en éducation non formelle.

\section{Approches participatives à l'éducation des adultes}

Inciter les facilitateurs à être sensibles à l'environnement éducatif dans lequel la classe d'alphabétisation évolue, à distinguer les différentes formes d'éducation au Sénégal et leurs buts respectifs, à identifier les objectifs particuliers du programme 
d'éducation non formelle en langue nationale et à développer leur aptitude à créer un environnement propice à l'éducation des adultes dans une perspective d'un autodéveloppement communautaire.

\section{Créer un environnement lettré : maîtriser la lecture et l'écriture}

Amener les facilitateurs à réfléchir sur ce que représentent la lecture et l'écriture et les encourager à beaucoup pratiquer, à analyser ce que font les bons lecteurs et comment le programme de Tostan enseigne la lecture en langues nationales. Faire le lien entre la lecture et l'écriture en produisant des textes et en «publiant» les écrits des facilitateurs.

\section{Comprendre ce que sont les chiffres et comment les utilliser}

Initier les facilitateurs à la «logique» des mathématiques, expliquer la théorie globale de l'apprentissage des mathématiques du programme de Tostan ainsi que les procédés pédagogiques utilisés lors des séances de calcul.

\section{Apprentissage de la facilitation du module}

Préparer les facilitateurs à se servir des guides de séance pour le module, les amener à pratiquer les techniques de facilitation nécessaires pour les séances et à mieux comprendre les composantes du programme d'éducation non formelle de Tostan.

Les formations pour les cinq modules suivants sont plus courtes, elles durent habituellement 10 à 12 jours, anticipent toujours sur le module à suivre, et révisent toutes les composantes du programme.

\section{LES RESULTATS DU PROGRAMME}

\section{1) ÉLABORATION ET PUBLICATION DES MATERIELS PEDAGOGIQUES}

- Production de dix modules (six modules dans le programme de base et quatre modules de formation continue) pour le Programme d'Education des Adultes et six modules pour le Programme d'Education des Adolescents. Ceci comprend 16 guides détaillés (100 à 150 pages chacun) pour les facilitateurs pour chaque module ainsi que 12 livres pour les participants dans les principales langues nationales ;

- Livres de poésie, de contes et pièces de théâtre pour les lecteurs ;

- Boîtes à images accompagnées de guides en langues nationales sur des sujets liés à la santé, aux droits de l'homme, à l'entreprenariat et au développement de la petite enfance ;

- Jeux pédagogiques pour participants adultes et adolescents.

\section{2) FORMATION POUR FORMATEURS, FACILITATEURS ET PARTICIPANTS}

Tostan a formé :

- 32 formateurs pour les programmes d'éducation de base pour adultes, adolescents et jeunes filles ; 
- 152 facilitateurs chargés de dispenser des enseignements aux participants villageois et travaillant avec le Comité de Gestion Villageois ;

- 286 responsables de 143 Comités de Gestion Villageois composés de membres élus qui gèrent des activités dans les centres d'éducation, en collaboration avec Tostan. Les Comités de Gestion Villageois permettent aux membres de participer à la réalisation et à la gestion des activités de Tostan dont ils bénéficient directement. Ces comités renforcent l'application des compétences en leadership et en gestion apprises lors des modules de base ;

- 18.834 villageois adultes et 2.532 adolescents et jeunes femmes à travers neuf régions du Sénégal ;

Tostan a aussi formé des formateurs, des facilitateurs et des participants villageois pour 25 Organisations Non Gouvernementales (ONG) nationales et internationales, associations villageoises et groupements féminins dans neuf régions du Sénégal et dans d'autres pays africains atteignant approximativement 10.000 autres participants villageois.

\section{3) AUTRES RESULTATS}

- Tostan a réalisé un programme de construction de 153 latrines el de plus de 4000 foyers améliorés, en collaboration avec les villages participants au programme d'éducation à travers le Sénégal.

- Tostan a initié des programmes de crédit et mis en ceuvre plusieurs types de micro-entreprises pour les villages ayant bénéficié du programme d'éducation de base, en formant les comités de gestion villageois chargés de leur exécution.

- En collaboration avec une radio privée sénégalaise, Sud-FM, Tostan produit un programme hebdomadaire sur les droits de l'enfant pour contribuer à l'éducation civique des adolescents et des jeunes filles.

L'immense expérience que Tostan a acquise durant ces années dans l'élaboration de matériel, la formation, la gestion des centres d'enseignement sur le terrain, la mobilisation sociale et l'évaluation de programmes lui a permis de répondre efficacement aux besoins exprimés par les populations du Sénégal. De plus, durant ces trois dernières années, Tostan a aussi acquis une certaine expérience en matière d'assistance aux participants pour l'exécution de projets et d'obtention de crédits pour les petites activités génératrices de revenus qui renforcent les connaissances acquises durant le programme.

\section{4) MMPACT DU PROGRAMME}

Les résultats du Programme d'Education de Base de Tostan dans les villages participants ont été positifs. Des évaluations montrent que dans les nombreux domaines couverts par le programme, d'importantes améliorations ont été notées :

\section{Module 1-Résolution de Problèmes}

- Les participants ont utilisé le processus de résolution de problèmes pour réparer les pompes, les puits, les machines à moudre le mil, construire des centres d'alphabétisation, planter des arbres pour le bois de village, résoudre des problèmes liés à l'eau, etc. ;

- Les participants ont créé des projets maraîchers, améliorant ainsi l'alimentation 
de leurs enfants et l'économie familiale ;

- Les participants ont construit des milliers de foyers améliorés dans tous les villages pour réduire la consommation de bois et protéger ainsi l'environnement ;

- Les participants sont en train de concevoir de nouvelles séances (pièces de théâtre, jeux, etc.) sur des thèmes liés à leurs besoins et à leurs problèmes.

\section{Module 2- Hygiène}

- Les participants connaissent la signification des «microbes», lavent les légumes avant la préparation du repas et se lavent les mains avant de manger ;

- Les participants utilisent systématiquement le savon et ont débuté des projets de fabrication de savon dans plusieurs villages pour être sûrs de toujours en disposer ;

- Les participants organisent régulièrement des séances d'assainissement collectif du village, environ une fois par semaine ; les personnes ne respectant pas la propreté sont passibles d'amende ;

- Les enfants des participants sont plus propres ;

- Les participants construisent et utilisent des latrines;

- Les participants filtrent leur eau et utilisent de l'eau de javel pour la stériliser.

\section{Module 3- Diarrhée et Vaccination}

- Moins de cas de diarrhée sont notés du fait d'une amélioration de l'hygiène dans les foyers et dans les villages (comités formés pour gérer continuellement ce volet dans la plupart des villages) ;

- Presque aucun cas de déshydratation due à la diarrhée n'a été noté dans les villages ;

- Les femmes connaissent et comprennent le calendrier des vaccinations ;

- Il existe un «réflexe vaccinal» dans les villages où Tostan avait des centres. Selon les agents sanitaires locaux, les femmes font vacciner régulièrement leurs enfants.

\section{Module 4- Connaissances en Gestion}

- Les femmes sont capables de gérer leurs propres projets ;

- Une bonne connaissance de la tenue des registres des projets communautaires :

- Les comités de gestion assurent la transparence dans les projets :

- Les comités de gestion sont bien organisés et se réunissent régulièrement ;

- Les participants gèrent des budgets familiaux.

\section{Module 5- Leadership}

- Les participants choisissent leurs dirigeants sur la base de leurs compétences et non sur la base du genre, de l'âge ou du statut social ;

- Les relations entre les autorités locales et les villageois ont changé.

Les femmes n'ont plus peur de rencontrer et de discuter avec les fonctionnaires de l'administration;

- Plusieurs femmes sont devenues des leaders dans ces villages ;

- Les participants demandent des comptes à leurs leaders (justification de l'emploi des fonds) ;

- Les participants n'hésitent plus à dénoncer les pratiques de corruption ; 
- Les femmes participent plus dans la politique locale ;

- Les participants servent de médiateurs pour la communauté ;

- Les femmes se font régulièrement entendre lors de réunions;

- Les femmes prennent une part plus active dans le processus de prise de décision;

- Les participants organisent des séances d'éducation dans le voisinage et dans d'autres villages

- Les femmes savent où aller pour trouver l'information et savent aussi comment utiliser les ressources.

\section{Module 6- Etude de Faisabillité}

- Les femmes effectuent des études de faisabilité et ont débuté leurs propres projets ;

- Les femmes ont reçu et géré des crédits pour l'acquisition de moulins à mil, pour faire de petits projets et autres activités génératrices de revenus ;

- Les participants organisent des visites dans les autres villages pour un échange d'expériences.

Les résultats du Programme d'Education de Base de Tostan au Sénégal ont contribué :

* à la diminution des taux de mortalité infantile en mettant l'accent sur l'hygiène, la vaccination, la Thérapie de Réhydratation par Voie Orale (TRO), l'allaitement au sein, les soins de l'enfant, la prévention et le traitement du paludisme et les conséquences néfastes de l'excision ;

* à la diminution des taux de mortalité maternelle en mettant l'accent sur les soins de santé chez la femme, l'hygiène, la planification familiale, les grossesses, les accouchements et les conséquences néfastes de la pratique de l'excision ;

\section{* au renforcement des capacités des femmes et à la promotion de la démocratie en mettant l'accent sur les droits de la personne et le leadership et en fournissant des connaissances en résolution de problèmes, négociation, planification familiale, transformation sociale et résolution de conflits ;}

* à la dimimution de lla pauvreté à travers l'emploi, l'entreprenariat et la mise en place de crédits par le renforcement des capacités locales, résultat de l'enseignement du calcul, de la gestion, et d'études de faisabilité. 


\section{LE PROGRAMME D'EDUCATION CONTINUE DE TOSTAN : MODULES 7 ET 8}

\section{INTRODUCTION AUX MODULES 7 ET 8}

Pendant l'étude des Modules 7 et 8 , les participants au programme de Tostan ont pris la decision importante de mettre fin a la pratique de l'excision dans leurs villages. Il est par conséquent, important d'entrer plus dans les détails et d'expliquer le processus de l'élaboration de ces modules ainsi que la méthodologie et le contenu des séances. Il est maintenant évident pour nous que l'éducation aux droits humains vat une composante essentielle à la transformation des comportements dans plusieurs domaines de la vie et pas seulement à l'abandon de la pratique de l'excision.

\section{INFORMATIONS DE BASE SUR LES MODULES 7 ET 8}

En 1994. Tostan a présenté un projet à l'Ameriean Jewish World Service (AJWS) afin de contribuer à une diminution du taux de morbidité et de mortalité chez les fenmes et les enfants au Sénégal. Le projet êtait conçu pour l'élaboration et la mise en ceuvre d'un programme d'éducation continue lié à la santé féminine et au développement le la petite enfance, Ce programme visait des milliers de villageois sénégalais lettrés et illettrés, en particulier les femmes, Le but du programme était d'améliorer le bienêtre physique et mental de milliers de femmes et d'enfants à travers le Sénégal.

Ses objectifś étaient:

- L’élaboration pour les villageois sénégalais de matériel didactique approprié el participatif lié à la santé de la femme, à la survie de l'enfant et au développement de la petite enfance:

- L'expérimentation du matériel didactique dans des villages des régions du centre et du nord du Sénégal ;

- L'extension du programme à d'autres villages à travers le Sénégal ;

- L'enrichissement du programme d'éducation non formelle de Tostan en produisant des modules post-éducatifs pour les villages ayant bénéficié du programme et dautres Organisations Non Gouvernementales utilisant le programme de Tostan. Le processus utilisé pour élaborer les modules comprend les étapes suivantes:

\section{Enquêtes dans les villages pour déterminer les thèmes qui intéressent} les futurs participants aux modules d'éducation.

Trois formatrices de Tostan ont pris part à cette activité et ont passé beaucoup de temps dans 13 villages dans les régions de Kolda, Diourbel el Thiès.

Comparaison de thèmes qui intéressent les futurs participants y compris les priorités du gouvernement aux niveaux local et national-choix des themes

Cette étape était importante puisque la plupart des thèmes qui intéressaient les femmes n†étaient pas nécessairement considérés comme prioritaires par le gouvernement sénégalais. En faisant une étude des statistiques de santé et en discutant des problèmes avec les travailleurs de la santé aux niveaux national et local, les membres de l'équipe 
ont réussi à avoir une meilleure idée de ce qui devrait être inclus dans les deux modules. La plupart des problèmes tels que l'information sur les périodes de menstrues, la ménopause, l'excision, l'avortement, les relations avec les travailleurs de la santé au niveau local, et la violence envers les femmes n'étaient pas đes priorités pour le gouvernement. La plupart des femmes avaient exprimé un grand intérêt pour ces sujets et ils furent par conséquent retenus pour êtres étudiés dans les Modules 7 et 8. Cependant, l'une des préoccupations majeures du gouvernement et des femmes était la mortalité maternelle ; ainsi l'équipe de Tostan a décidé de consacrer plusieurs séances du module à la grossesse et à l'accouchement.

\section{Retour aux villages pour une recherche participative plus poussée}

Une fois que les thèmes furent choisis, les membres de l'équipe retournèrent dans les villages pour effectuer des recherches plus poussées avec les femmes sur les différents sujets. Tostan avait accordé un intérêt particulier au vocabulaire dans les langues locales, utilisé pour décrire les problèmes de santé, les pratiques traditionnelles, les préoccupations et les tabous culturels liés au thème. L'équipe a demandé des suggestions pour les solutions aux problèmes qui pourraient être intégrées dars le module.

\section{EEtude du matériel existant et auties efforts d'éducation llés aux} thèmes choisis

L'équipe a ensuite identifié le matériel didactique déjà élaboré au Sénégal sur les thèmes choisis. Ceci s'est avéré être un processus difficile et long, puisqu'une bonne partie du matériel n'était disponible qu'à Dakar. Certaines agences citaient des publications, mais étaient incapables de localiser le matériel. En fait, très peu de matériels avaient pu être trouvé en particulier dans les langues nationales.

\section{Rédaction des informations trouvées sur chaque thème}

Cette étape fuţ essentielle pour déterminer les objectifs de la séance et pour établir les priorités. Elle a aussi servi à résumer les informations collectées au niveau des femmes sur le sujet. Ces fiches de résumés ont servi de référence constante lors de la rédaction de chaque séance.

\section{Rédaction des modules}

Chaque module comprend 24 séances et chaque séance fut minutieusement planifiée pour véhiculer des informations techniques simples à travers des contes, des pièces de théâtre, des jeux, des poèmes, des chansons et des interviews. Les modules comprenaient des stratégies de mobilisation sociale et des idées d'actions concrètes inspirées de la recherche participative. L'accent fut mis sur la réflexion critique et le temps fut laissé aux femmes pour le libre-échange d'idées dans une atmosphère sans pesanteurs, de confidence et de confiance.

\section{Autres opinions dans le domaine de la santé et du développenent des femmes}

Plusieurs personnes ont lu les modules en français avant qu'ils ne soient traduits en wolof et en pulaar. Tostan a travaillé en collaboration avec les responsables de la santé directement concernés (le Chef de la Division de la Santé Maternelle, de l'Hygiène et de la Nutrition, le Dr. Guèye) ainsi qu'avec des personnes-ressources à 
l'UNICEF et d'autres agences qui ont lu les Modules 7 et 8 et en ont donné un avis important quant à leur fiabilité. Ces différentes personnes ressources avaient donné d'excellents avis.

Calendrier d'organisation des thèmes pour le Module 7 :

1ère SEMAINE

\begin{tabular}{|ll|}
\hline Séance 1 & $\begin{array}{l}\text { Présentations } \\
\text { Appréhensions et attentes du Module 7 } \\
\text { Les objectifs du Module 7 }\end{array}$ \\
\hline Séance 2 & $\begin{array}{l}\text { Une définition de la santé } \\
\text { La situation des femmes dans le village } \\
\text { Facteurs favorables et défavorables liés à la santé dans le village }\end{array}$ \\
\hline Séance 3 & $\begin{array}{l}\text { La situation des femmes au Sénégal, en Afrique et dans le } \\
\text { monde } \\
\text { Utilisation des statistiques pour comprendre les priorités }\end{array}$ \\
\hline
\end{tabular}

2ème SEMAINE

\begin{tabular}{|ll|}
\hline Séance 4 & $\begin{array}{l}\text { Les droits des femmes (2 séances) } \\
\text { Les droits de la personne en santé et en soins de santé }\end{array}$ \\
\hline Séance 5 & L'importance de la prévention en matière de santé \\
\hline Séance 6 & Le développement du corps : puberté et menstrues \\
\hline
\end{tabular}

3ème SEMAINE

\begin{tabular}{|ll|}
\hline Séance 7 & La sexualité \\
\hline Séance 8 & Rédaction de poèmes sur la santé \\
\hline Séance 9 & La grossesse - 1 \\
\hline
\end{tabular}

4ème SEMAINE

\begin{tabular}{|ll|}
\hline Séance 10 & La grossesse - 2 \\
\hline Séance 11 & L'accouchement \\
\hline Séance 12 & L'avortement \\
\hline
\end{tabular}

5ème SEMAINIE

\begin{tabular}{|ll|}
\hline Séance 13 & La ménopause \\
\hline Séance 14 & L'excision (2 séances) \\
\hline Séance 15 & La violence envers les femmes \\
\hline
\end{tabular}

Gème SEMAINE

\begin{tabular}{|ll|}
\hline Séance 16 & Révision des séances précédentes \\
\hline$\underline{\text { Séance } 17}$ & Les maladies sexuellement transmissibles \\
\hline Séance 18 & Le VIH et le SIDA \\
\hline
\end{tabular}




\begin{tabular}{|ll|}
\hline$\underline{\text { Séance 19 }}$ & Les relations avec les travailleurs locaux de la santé \\
\hline$\underline{\text { Séance 20 }}$ & $\begin{array}{l}\text { Le processus de résolution de problèmes appliqué aux } \\
\text { problèmes de santé du village }\end{array}$ \\
\hline$\underline{\text { Séance 21 }}$ & $\begin{array}{l}\text { Mise sur pied d'une association villageoise pour la santé } \\
\text { (buts, objectifs, activités) }\end{array}$ \\
\hline
\end{tabular}

\section{Bème SEMAINE}

\begin{tabular}{|ll|}
\hline Séance 22 & $\begin{array}{l}\text { Mise sur pied d'une association villageoise pour la santé } \\
\text { (Organisation et fonctions) }\end{array}$ \\
\hline Séance 23 & Révision du Module 7 \\
\hline Séance 24 & Evaluation finale du Module 7 \\
\hline
\end{tabular}

\section{INFORMATIONS SPECIFIOUES LIEES A L'EXCISION DANS LE MODULE 7}

L'équipe féminine de Tostan, en effectuant la recherche participative pour le Module 7, Santé de la Femme, a débattu en longueur du thème de l'excision pour décider si celui-ci devrait être inclus dans le module. Ces hésitations étaient dues à des considérations d'ordre culturel : les femmes avaient été peu disposées à discuter de l'excision pendant la phase de recherche participative. Quelques femmes avaient exprimé une certaine hostilité à la simple évocation du problème. L'équipe avaient néanmoins décidé de parler, lors de la Séance 14 , du cas d'une fille après avoir été excisée, a fait une hémorragie et en est décédée. Cette séance fut expérimentée avec des femmes des groupes ethniques Peul et Bambara. Il est important de noter que la séance vient après d'autres séances durant lesquelles les participantes apprennent ce qu'est le développement du corps et discutent aussi de la sexualité comme composante du développement normal de la femme. Après que 13 villages aient décidé de mettre un terme à la pratique de l'excision, une seconde séance fut ajoutée pour les nouveaux participants, dans les Modulles 7 et 8 , y compris l'importance de la déclaration publique des villageois. 
Dans l'ensemble, quelque 8.000 femmes ont participé à la formation sur les Modules 7 et 8 dans 4 régions du Sénégal: Thiès, Diourbel, Kolda et St Louis. De multiples évaluations montrent que les femmes connaissent et comprennent les informations présentées. De plus, elles utilisent les informations reçues pour apporter des changements dans leurs villages.

Les commentaires faits lors des évaluations reflètent les changements d'attitude et de comportement suivants :

- Les femmes sont de plus en plus conscientes de l'importance de leur propre santé et de celle de leurs enfants;

- Les femmes peuvent citer et donner des exemples d'application de leurs droits (droit d'être protégé contre toute forme de discrimination, droit à la santé, droit de s'exprimer, droit au choix du conjoint, droit à la planification familiale, droit à la protection contre toute forme de violence, etc.) ; droit à la terre;

- Les parents sont maintenant plus conscients et sont plus respectueux des droits des enfants (droit à l'éducation, droit de ne pas être exploités, droit de vivre avec leurs deux parents, droit à la santé, droit aux loisirs, etc.) ;

- Les femmes connaissent les symptômes et les traitements de plusieurs maladies, elles savent quand aller se faire soigner et comment prévenir les maladies ;

- Les femmes partagent les nouvelles informations qu'elles ont acquises avec d'autres villageoises et organisent des débats dans leur quartier et dans d'autres villages ;

- Les femmes allaitent exclusivement au sein pendant les quatre premiers mois ;

- Les femmes ont commencé à utiliser les méthodes de planification familiale ;

- Les femmes expliquent les menstrues et la sexualité à leurs enfants pour la première fois ;

- Les femmes enceintes effectuent des visites prénatales et pour la première fois à préparer la naissance de leurs enfants (matériellement et financièrement);

- Les couples commencent à discuter ouvertement et honnêtement des problèmes ;

- Les hommes ne prennent plus toutes les décisions pour le couple ;

- Pour la première fois, les femmes discutent de la sexualité avec leurs conjoints et disent que les séances du Module 7 ont amélioré leur rapport de couple ;

- Les femmes post-ménopausées dont les époux avaient une attitude discriminatoire envers elles ont consulté les leaders du village et ont trouvé des solutions à cette situation ;

- Les femmes remettent en cause et mettent souvent un terme aux pratiques traditionnelles qui sont préjudiciables à leurs enfants, telles que l'excision, les mariages précoces, etc. ;

- Les femmes connaissent l'importance d'une bonne nutrition et ont changé d'habitudes alimentaires pour améliorer la santé de leurs enfants ;

- Les villageois ont établi un système d'amendes à payer par les personnes qui donnent trop de travail à leurs enfants ;

- Les villageois ont mené des campagnes de sensibilisation pour ramener dans leurs familles les jeunes filles parties chercher du travail à la ville ;

- Les participants assurent une couverture vaccinale suivie aux enfants dans les villages ; 
- Un nouveau type de communication s'est instauré entre les mères et leurs enfants, en particulier pour ce qui concerne les sujets naguère tabous comme la sexualité ;

- Les participants utilisent maintenant du sel iodé ;

- Les villageois ont construit des cases de santé, des tables de consultation et mènent d'autres activités liées à la santé telles que la collecte et l'analyse de données, etc. ;

- Les participants ont créé des « fonds de solidarité » pour aider les villageois dans le besoin ;

- Pour la première fois, les femmes écrivent des poèmes et des textes, décrivant ouvertement leurs souffrances et leurs expériences.

Il fut unanimement reconnu que l'éducation aux droits humains et les discussions sur les voies et moyens de faire respecter ces droits dans la vie de tous les jours était une expérience qui a beaucoup contribué à femmes dans cette entreprise.

Tostan reçut plusieurs délégations villageoises qui voulaient exprimer leur gratitude concernant les Modulles 7 et 8 d'éducation continue. Une délégation villageoise déclara : «Vous n'avez aucune idée de l'impact que ces modules ont eu sur la vie dans le village. Vous ne pouvez pas savoir combien c'est important pour nous. et les changements qu'ils ont apportés ! » (Délégation de Kulug). Ils nous ont fait savoir que l'échange d'informations dans les Modulles 7 et 8 avait lieu pendant que les femmes en rang attendaient leur tour pour puiser de l'eau au puits, effectuaient leurs corvées journalières ou étaient au marché. À la fin du module, plusieurs villages organisèrent des manifestations auxquelles les villageois voisins furent invités, ainsi que les autorités locales, et des attestations furent distribuées. L'utilisation de la poésie fut un outil prépondérant lors des Modules 7 et 8 . Les femmes rédigeaient souvent des poèmes collectifs pour exprimer leurs sentiments sur plusieurs sujets allant de la ménopause au SIDA en passant par la sexualité. Les poèmes étaient ensuite lus lors des cérémonies publiques, souvent accompagnés de musique traditionnelle ou de chants. Un des participants du village de Ngaparou écrivit le poème suivant : 


\section{QUI EST LE MODULE 7?}

\section{Ah ! Module 7!}

Tu es venu à Ngaparou et as chassé la maladie de nos familles !

Viens Module 7 !

Aide nos femmes sénégalaises à connaître leurs droits

En particulier leurs droits à la santé.

Aide-les à connaître leur corps.

Vous, femmes de Ngaparou,

Partagez votre savoir avec vos filles

En particulier en période de puberté.

Parlez-leur des menstrues, de la sexualité,

N'ayez plus honte !

Femmes du Sénégal, répondez à l'appel du Module 7

Et il vous informera sur les grossesses,

Il vous aidera à apprendre

Comment faire pour vivre une grossesse réussie.

Répondez à l'appel du Modulle 7!

II vous informera sur l'accouchement.

Et sur l'importance de la planification des naissances.

Vous comprendrez

Que l'excision est une violence envers vos filles

Ainsi vous y mettrez un terme et demanderez à vos frères et sours

D’abandonner de telles pratiques traditionnelles néfastes !

Vous, femmes mariées, écoutez le Module

Et apprenez ce qu'est une MST et surtout ce qu'est le SIDA.

Vous, femmes mûres du Sénégal,

Écoutez le Modulle 7 ....

Il vous enseignera les signes de la ménopause

Pour que vous ne soyez pas surprises mais plutôt préparées!

Nous devons tous écouter le Module 7 pour savoir comment analyser Nos ressources, leurs coûts, et où les trouver.

\section{Toi, Module 7}

Tu nous a aidés à créer des Associations dans les classes, dans les villages

Pour que nous, femmes, trouvions des solutions à nos problèmes...

Les problèmes de notre vie quotidienne, les problèmes dans nos foyers, Avec nos époux, avec nos enfants

Avec nos leaders et nos voisins.

Merci Module 7 !

Un autre poème écrit par les femmes d'une autre classe renforce l'importance de l'éducation pour ce qui concerne les droits de la femme. 
Nous, femmes de cette classe

Avons un nouvel ami -

Un ami formidable

Un ami honnête et juste

Et qui maintenant nous guide

Sur les chemins de la vie.

Vous voulez savoir «Qui est cet ami ?»

Le nom de notre ami

Est les Droits de la Femme.

Et penser que nous ne savions rien

De lui auparavant dans notre classe !

Rien sur ces droits

Dont nous souhaitons vous entretenir :

Tous les hommes naissent égaux en droits !

Le droit d'être protégé contre toute forme de discrimination

En particulier les FEMMES

Le droit de participer à la vie politique

Le droit au travail

Le droit à l'information

Le droit à l'expression

Le droit de choisir sa religion

Le droit d'être protégé de toute forme de violence !

Le droit de fonder sa propre famille et d'épouser la personne de son choix

Le droit à la vie privée

Le droit d'adhérer aux organisations de son choix

Le droit à l'éducation

Le droit à la terre

Le droit au crédit

Le droit à la SANTE !

Ces droits

Ont changé nos vies

Et nos comportements

Dans nos foyers, dans notre entourage

Et dans notre pays.

Auparavant nous étions peu sûres de nous et nous sentions opprimées

Nous marchions têtes baissées!

Mais aujourd'hui nos têtes sont bien droites -

Nous avons confiance en nous-mêmes et sommes prêtes

À participer à toutes les activités !

Tout le monde devrait comprendre

Que les Droits de la Femme sont les Amis de la Femme ! 
Donc répandez la nouvelle partout

En particulier chez toutes les femmes !

Pour que la connaissance se répande sur tout le territoire

Et que l'ignorance et l'injustice ne soient que du passé.

Plusieurs exemples d'actions concrètes entreprises après la formation du village, font état du succès des modules:

Durant le mois de janvier 1997, l'un des formateurs, Mamadou Niang, rapporta que dans un village près de Thiés, un homme avait battu sa femme. Les membres de la classe de santé de la femme se sont tout de suite réunis pour analyser le problème. Elles discutèrent de la séance sur la violence contre les femmes dans le Module 7, répétèrent le sketch encore une fois, formèrent une délégation comprenant le Chef de village et les chefs religieux, et rendirent visite à l'époux. Dans leur sketch, elles firent une présentation des droits de la personne et en particulier le droit d'être protégé contre toute forme de violence. L'époux présenta ses excuses aux femmes et remit ensuite 5.000 CFA à leur association. Il promit de ne plus jamais porter la main sur son épouse, et déclara que seules l'ignorance et certaines traditions et habitudes qui n'avaient jamais été remises en question l'avaient poussé à commettre ce geste. Il dit au formateur qu'il regrettait beaucoup son geste et qu'il avait tiré un grand enseignement du sketch des femmes ce jour-là. Il encouragea le formateur à continuer la vulgarisation du module dans les autres villages, mais aussi pour les hommes.

Une femme de Malicounda Bambara dit à Molly Melching dans une interview : «Tout le monde pense que l'abandon de la pratique de l'excision fut l'aspect le plus significatif de notre formation sur les Modules $\mathbf{7}$ et $\mathbf{8}$, mais nous avons appris beaucoup d'autres choses aussi importantes que nous avons pu mettre en pratique. Par exemple, j'étais mariée depuis quatre ans et ne pouvais pas avoir d'enfants. Lorsque j'ai eu connaissance de la planification familiale dans le Module 8 , je fus très étonnée. J'avais toujours cru que la planification familiale s'occupait de l'arrêt et de la limitation des naissances et je ne savais donc pas qu'elle pouvait vous aider à AVOIR un enfant. J'ai donc participé activement en classe, posant plusieurs questions. Plus tard, arrivée à la maison, je me suis mise à faire mes calculs. J'ai par la suite demandé à mon époux qui voyage fréquemment de faire en sorte d'être à la maison à une période donnée du mois à venir. Il s'est mis à me regarder comme si j'étais folle, mais je l'ai supplié de suivre mes instructions sans lui expliquer pourquoi. Il s'exécuta et c'est ainsi que je suis tombée enceinte pour la première fois. Nous étions tous les deux surpris. J'ai ensuite compté le nombre de jours depuis la conception et suis donc tombée sur une date approximative pour la naissance de mon enfant. Utilisant dans le Module 8 les séances de planification portant sur les naissances, je commençais à mettre de côté l'argent, les médicaments et le matériel utiles pour mon accouchement. Je demandais à mon époux de planifier son emploi du temps de manière à être à la maison à cette période. Il me dit : «Qui crois-tu être ? Dieu ? » Je lui répondis : « Non, j’ai juste étudié et ai obtenu beaucoup d'informations que je n'avais pas auparavant. » Le moment venu, mes amies commencèrent à planifier les activités pour les vacances, mais je leur dis que je ne serai pas en mesure d'y participer car je serai occupée autrement. Elles se demandèrent comment je pouvais le savoir et je leur souris mystérieusement. Mon enfant naquit ici à la date prévue. Tout le monde était surpris 
sauf moi. Les médicaments dont $\mathrm{j}$ 'avais besoin étaient disponibles, ainsi que tout le matériel utile à l'accouchement et aux soins postnatals. J'avais mis de l'argent de côté en cas d'urgence par conséquent j'étais rassurée. Mon époux était là. Et maintenant regardez mon bébé si beau et en bonne santé. »

A ce jour, les Modules 7 et 8 de Tostan sont les deux modules qui remportent le plus de succès parmi tous ceux qui ont été élaborés. Il y a beaucoup d'éléments qui en ont fait des modules efficaces :

- la recherche participative sur un an, qui a permis le choix des sujets par les participantes

- l'utilisation d'histoires vraies et d'expériences des femmes

- l'utilisation de la pratique de «ndey-dikke» (en wolof), par laquelle les participantes « adoptent » une amie ou un parent avec lequel elles partagent les informations obtenues lors des séances

- le renforcement des pratiques et valeurs culturelles positives

- l'accent mis sur l'action et les stratégies pacifiques pour le changement social

- la sélection de facilitatrices hautement qualifiées, motivées et bienveillantes

- le renforcement des connaissances et des informations acquises lors des Modulles 1 à 6

- l'implication de travailleurs locaux de la santé et de guérisseurs traditionnels dans l'exécution du programme.

Enfin, Tostan avait acquis beaucoup d'expérience en élaboration de modules destinés aux villageois. La combinaison de tous ces éléments à une solide composante sur les droits de la personne a eu pour conséquence un évenement historique : l'albandon de la pratique de l'excision dans 174 villages au Sénégall. 


\section{DEUXIEME PARTIE \\ Une description de ce qui a mis fin à l'excision dans 174 villages au Sénégal}

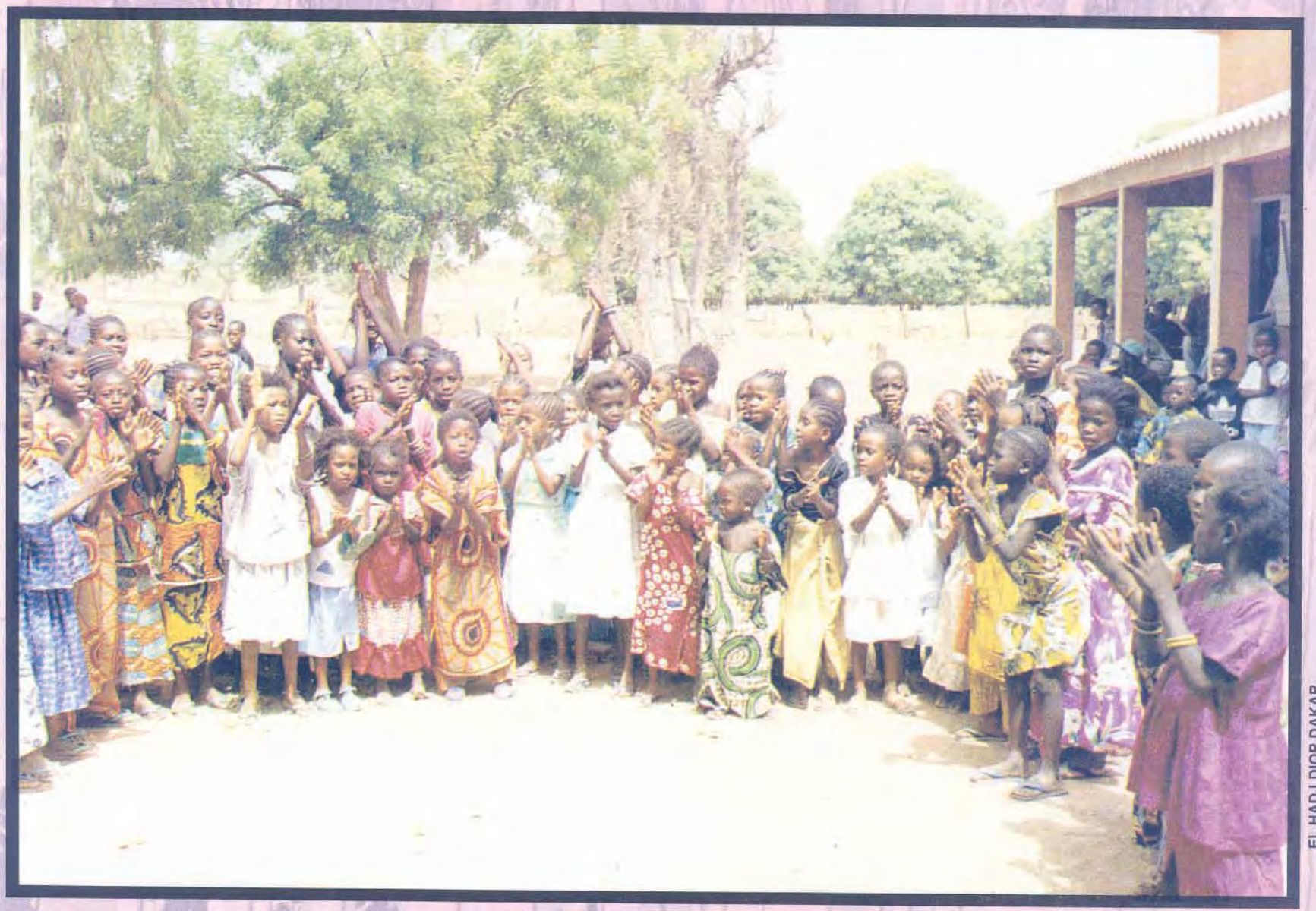

Les filles de Médina Chérif célébrant la fin de la pratique de l'excision le 1er juin 1998. 


\section{UNE DESCRIPTION DE CE QUI S'EST PASSE}

\section{MALICOUNDA BAMBARA : LE DEBUT DE LA FIN}

Malicounda Bambara est l'un des nombreux villages des régions de Thiés et de St Louis qui, de 1995 à 1997, ont participé au programme d'éducation de base de Tostan, Modules 1 à 8 . En août 1996, les femmes de Malicounda Bambara ont étudié la Séance 14 du Module 7 sur l'excision.

Selon Ndéye Maguette Diop, la facilitatrice : «Au début, les femmes n’étaient pas très sûres de vouloir jouer une pièce adaptée de l'histoire. Nous avions gardé le même nom que celui de la fillette de l'histoire, Poolel, qui est un nom pulaar et qui par conséquent n'impliquait pas directement les Bambaras dans cette tragédie, ce qui a peut-être aidé. Les femmes transformèrent l'histoire en pièce de théâtre, mais refusèrent d'en débattre après. Je continuais de leur poser les questions qui accompagnent la séance et aucune d'entre elles ne voulait y répondre. Les discussions lors des Séances 1 à 13 étaient habituellement vivantes et animées. Ce qui me conduisit à me poser des questions : Pourquoi donc refusaient-elles de répondre aux questions ? Est-ce parce que je suis wolof et que je n'ai pas été excisée ? Ainsi je refis la séance trois fois de suite. À la troisième reprise, elles commencèrent enfin à parler timidement, puis de plus en plus de femmes se déridèrent. Elles admirent que c'était une pratique ancienne qu'elles respectaient parce que c'était la tradition et que les hommes et les chefs religieux attendaient d'elles qu'elles la respectent. Néanmoins, leur formation sur les droits de la personne leur permit de comprendre qu'elles avaient droit à une bonne santé. Qu'elles avaient aussi le droit de s'exprimer et de donner leurs opinions. Elles n'avaient aucune connaissance de ces faits auparavant et n'en avaient jamais parlé entre elles. Enfin, nous avons fini par en discuter souvent ensemble. Les femmes décidèrent de discuter avec leurs sours «adoptives» et avec leurs époux des conséquences néfastes d'une telle pratique sur la santé. Elles ont aussi cru important de d'abord demander conseil à l'Imam et au Chef de village sur le problème. Elles furent surprises de constater que plusieurs de leurs congénères soutenaient l'effort pour l'abandon de la pratique de l'excision. Elles jouèrent donc la pièce dans d'autres localités voisines du village et décidèrent d'amener les femmes de ces localités à discuter du problème.

Les femmes dirent qu'elles avaient commencé à discuter en classe du problème et à en débattre encore plus hors de la classe. Elles dirent qu'il y avait des choses que la facilitatrice, Ndéye Maguette, ne pourrait jamais comprendre et qu'elles avaient besoin de régler entre elles.

Vers juin 1997, les femmes avaient convaincu tant de personnes dans le village des dangers de l'excision qu'il n'y eut pas de cérémonies publiques d'excision cette année-là durant la saison des pluies. « C'est alors » dit une participante, « que chacun prit conscience qu'un mouvement d'abandon de l'excision était en place dans le village. Si une femme faisait exciser sa fille, elle le faisait en cachette pour la première fois, sachant que sinon, elle ferait l'objet d'une réprobation publique. »

En juin 1997, Malick Guéye, coordonnateur de Tostan, nous appelle pour nous annoncer 
la nouvelle. «Savez-vous que les femmes de Malicounda Bambara ont mis un terme à la pratique de l'excision? Elles m'ont dit que c'est l'un de résultats les plus significatifs de leur programme d'éducation de base et j'ai pensé que vous souhaiteriez en être informés.»

Une équipe de Tostan rendit visite à la classe cette même semaine et rencontra Maïmouna Traoré, Présidente du Comité de Gestion de la classe des Femmes, le Chef de village et une autorité religieuse. Tostan hésita à aborder le problème de l'excision connaissant la sensibilicé du sujet. Mais les participants en avaient tellement parlé entre eux, que ce n'était plus un sujet délicat. Ils ouvrirent le débat en affirmant clairement : «Nous avons décidé de metrre un terme à "cette tradition" dans notre village.» Suite à cette rencontre, Tostan rédigea le rapport suivant:

\section{Malicounda Bambara}

Région de Thiés

Département de Mbour

Population : environ 3000

Situé à $10 \mathrm{~km}$ de Nguékhokh

Les femmes de Malicounda Bambara se sont décidées. Plus d'excision pour les jeunes filles du village ! Plus de cérémonies annuelles marquant le moment où les «filles » deviennent de « vraies femmes » selon les traditions séculaires de leur groupe ethnique. Plus d'aiguilles ni de lames pour exciser les filles. Plus de sang versé. Plus de souffrances pour les filles lors de la nuit nuptiale. Plus de complications à l'accouchement. Plus de décès inutiles dus aux infections ou aux hémorragies causées par ce rite qu'est l'excision !

Mais comment un groupe de femmes africaines, issues d'un groupe ethnique qui connât et pratique l'excision depuis des millénaires, ont-elles pu prendre leur courage à deux mains et clamer tout haut «plus jamais çà » à une tradition aussi puissante et ancrée ? Comment sont-elles arrivées à convaincre les autres membres de leur communauté, en particulier les hommes et les femmes âgées qui sont les garants les plus déterminées des traditions Bambara ? Les femmes ont donné les explications suivantes :

«Nous nous étions inscrites pour suivre le Programme d'Education de base en langues nationales initié par Tostan/UNICEF/Gouvernement du Sénégal, et nous, femmes de Malicounda Bambara, avions déjà commencé à changer.» raconte Maïmouna Traoré, Présidente du Comité de Gestion de la classe du village. «En classe, nous avions commencé à parler de choses dont nous n'avions jamais discuté auparavant, de choses qui avaient toujours été 'tabous' si l'on peut dire. Lors du Module $\mathbb{1}$, nous avions travaillé sur le processus de résolution de problèmes et partant de là, nous nous sommes attelées à étudier quelques problèmes que nous femmes, rencontrions dans notre village, et pour lesquels nous avons cherché différentes solutions. Lors du Modulle 2, nous avons appris ce que sont les microbes et la transmission de la maladie, ceci nous a ramené à certaines de nos traditions qui pouvaient s'avérer dangereuses pour nos enfants.» Tout en parlant, Maïmouna coupe une longue barre de savon produit par les femmes de la classe, «En fait, le programme de Tostan nous a donné une énorme confiance en nous, ce qui nous avait toujours fait défaut, et l'assurance que 
nous pouvions changer les choses quand nous le voulions. »

«C'est exact,» ajoute une autre participante, «Les séances d'éducation de base nous ont réveillées. Elles ont mis à notre disposition des informations que nous $n$ 'avions jamais eues, et ces nouvelles connaissances nous ont permis de nous exprimer au sein de notre communauté. Pour la première fois, lorsque nous parlons, tout le monde nous écoute parce que ce que nous disons est basé sur des faits vérifiables.»

Kerthio Diarra prend la parole : «Nous avons étudié les Droits de la Personne lors du Modvlle 7 de Tostan sur la Santé de la Femme, en particulier le droit à la santé. Nous avons appris que ce droit implique la liberté de toute femme de disposer librement de son corps et le droit de préserver l'intégrité de son corps, sans mutilation ni altérations. Ce fut pour nous une révélation, car ce droit remettait en question une de nos plus anciennes traditions: l'excision de toutes les fillettes. En fait, dans nos traditions, il est impensable de ne pas exciser une jeune fille - car cela ferait d'elle la risée de la communauté, quelqu'un que personne n'épouserait ! C'était si important que l'on nous avait fait comprendre qu'une femme non excisée était 'souillée' et impropre à préparer et à servir le repas à ceux qui étudient le Coran ! Et pourtant, nous avions toujours été troublées par les inconvénients liés à l'excision.»

Après avoir pris conscience des conséquences néfastes de l'excision sur la santé, les femmes de la classe eurent pour la première fois le courage d'aller voir l'Imam du village et lui demandèrent son opinion sur la question. Il leur dit que non seulement le Coran ne les obligeait pas à pratiquer ce rite, mais encore, lui-même ne l'approuvait pas. Il leur expliqua que sa propre fille aînée avait été excisée à son insu. Lorsqu' il l'apprit, il somma sa femme de ne plus recommencer. Par conséquent, ses autres filles n'avaient pas été excisées. Ceci fit grande impression sur les femmes de la classe qui avaient toujours cru que la pratique de l'excision faisait en réalité partie des obligations de l'Islam. Pour elles donc, il allait de soi que toutes les filles de I'Imam avaient été excisées. «Grâce à cette information, nous étions en possession d'arguments mouveaux et puissants qui devaient nous aider à convaincre nos époux et nos amies afin qu'un terme soit mis à la pratique de l'excision. L'information fut aussitôt incluse dans la pièce de théâtre que nous avions montée en vue de sensibiliser contre cette pratique,» dit une autre participante.

«Vous savez, nous sommes aujourd'hui conscientes que nous avons droit à une vie sexuelle normale et digne ! Nos filles aussi. Nous nous sommes ainsi posé nombre de questions, par exemple : l'excision est-elle un acte de violence envers nos filles ?» dit une autre participante.

Maïmouna explique que les femmes ont d'abord pris la décision de mettre un terme à la pratique de l'excision en classe. « Ensuite nous en avons parlé avec les chefs traditionnels et religieux du village, comme indiqué dans les modules de notre programme d'éducation. Nous avions appris que la religion musulmane n'obligeait pas les fermmes à subir cette pratique, que seuls les hommes devaient être circoncis. Nous en discutâmes avec nos époux qui nous comprirent. Encouragées par leur soutien, nous avons monté une pièce de théâtre sur les droits de la personne qui comprenait des messages sur les dangers de l'excision et nous l'avons présenté dans les différents quartiers - Binabougou, Julacounda et Kahaydacounda. Nous avions invité la sagefemme du village à ces séances et elle aussi fut très convaincante puisque ayant vécu 
plusieurs cas de souffrances chez les femmes et les filles victimes de cette pratique. En quelques mois seulement, les femmes de Malicounda Bambara ont décidé d'un commun accord de ne pas organiser de cérémonies d'excision cette année-là, mais en plus de mettre un terme définitif à une pratique qui n'a plus sa raison d'être au sein de notre communauté pour ses conséquences néfastes sur la santé de nos filles.»

Une femme d'un certain âge qui écoutait attentivement les propos des jeunes femmes pris soudain la parole: «Avant, c'était nous qui insistions pour que toutes les filles de la communauté soient excisées ! Même lorsque les parents étaient contre, nous prenions l'enfant et pratiquions l'opération à leur insu. Mais aujourd'hui je fréquente cette classe et j'ai pris connaissance des droits de la personne. Saviez-vous que chaque être humain a le droit de fonder sa propre famille et de vivre sa vie selon ses propres convictions? Ceci m'a fait prendre conscience du fait que je ne pouvais plus imposer ma volonté à mes enfants et à mes petits-enfants.»

Le Chef de village qui était présent tout au long de la séance de discussions donna son opinion pour la première fois : «Je ne fréquente pas cette classe, mais je soutiens la décision des femmes. Le monde est en perpétuelle évolution. Nous avons même entendu dire qu'au Mali, notre pays d'origine, la pratique de l'excision fait l'objet de débats et est remise en cause. Mais les changements dans les traditions ne se font pas du jour au lendemain. Il est difficile de mettre un terme à une pratique ancestrale millénaire.»

Kerthio lui répond immédiatement : «C'est peut-être vrai, mais nous les femmes après avoir bien réfléchi au problème toute l'année passée, sommes entièrement décidées ! Plus d'excision à Malicounda Bambara ! Aujourd'hui, ce sont celles qui s'entêteront à les pratiquer qui seront la risée du village. Elles auront à se cacher pour le faire, comme le font ceux qui ont des choses à se reprocher:»

Maïmouna nous montre les morceaux de savon prêts pour la vente au marché et qu'elle vient juste de terminer de couper. Elle ajoute :

«Cette décision que nous avons prise nous a apporté beaucoup d'autres avantages. Nous nous sommes rendu compte du rôle que nous pouvions jouer dans le monde. C'est peut-être la raison pour laquelle nous avons choisi la plupart des séances d'éducation des modules que nous avons étudiés, et nous allons de quartier en quartier pour animer des débats avec les autres membres de notre communauté : hommes, femmes et jeunes.

Nous avons aussi réalisé une étude de faisabilité comme nous l'avons appris au Module 6 et ensuite, avons démarré un petit projet de fabrication et de commercialisation de savon qui génère des revenus et tant soit peu, aide à améliorer les conditions d'hygiène, de santé et de vie des participants. Nous gérons le projet nous-mêmes et sommes en train de planifier d'autres activités plus ambitieuses pour l'année prochaine.»

\section{IMPACT DE LA DECISION DE MALICOUNDA}

Molly Melching fit parvenir l'interview des femmes de Malicounda au représentant de l'UNICEF à Dakar, M. Samir Sobhy, et ensemble ils discutèrent de cette décision. M. Sobhy pensa qu'il était important que les femmes partagent leurs idées avec le maximum de sénégalais, pour plusieurs raisons : 
- les femmes avaient pris cette décision de leur propre chef et non parce que Tostan avait essayé de la leur imposer ;

- Ia décision avait été prise après que les femmes eurent déjà fréquenté le programme d'éducation de base pendant deux années. Ces femmes étaient habituées à travailler en groupe, se faisaient confiance et croyaient au programme. Elles étaient capables de bien défendre leur décision à partir des informations tirées des modules sur I'hygiène, la santé, le processus de résolution de problèmes, le leadership et les conventions sur les droits de la personne;

- il n'y avait pas eu de cérémonie publique d'excision cette anné-là. ce qui prouvait qu'elles avaient réellement mis en pratique leur décision et ne s'étaient pas contentées d'exprimer un souhait.

Lorsque M. Sobhy dir qu'il voulait envoyer 20 journalistes sénégalais de lá presse parlée, écrite et télévisée, Moliy Melching n'était pas très convaincue kie me fais du souci pour les femmes, lu dit-elle.

M. Sobhy de lui rétorquer: «Molly, si ces femmes ont été assez fortes pour prendre d'elles-mêmes cette décision extraordinaire, elles le sont assez pour défendre leur position devant 20 journalistes».

Il avait bien raison car les femmes n'eurent aucune hésitation forsque Molly leur annonça que Tostan et l'UNICEF souhaitaient amener 20 journalistes au village. «Bien sur,» dirent-elles «Nous voulons partager cette bonne nouvelle avec tout it monde. Pourquoi n'en discuterions-nous pas ? Ce sera pour nous l'occasion d'expliquer pourquoi nous avons pris cette décision.»

Fendant qu'elles se préperaient à cefévénement, elles demandèrent à avoir pius. d'informations sur les articles des droits de la personne pour pouvoir meux défendre et argumenter leur position le moment venu, et firent une répétition de leur piece. Les chefs religieux et le Chef de village furent invités à assister à l'événement.

La visite des jounalistes se déroula au mieux. Des représentants de haut niveau des Ministeres de la Sané et de la Famille, de I'Action Sociale et de la Solidarita Nationale félicitèrent les femmes et leur réitérèrent le soutien sans faille de ces ministères au sein du gouvernement. Plusieurs articles apparurent dans la presse nationale Des interviews radiophoniques en français et en langues nationales furent diftusées durant les deux semaines qui suivirent l'événement, alors que la télévision montrait des extratte des entretiens des femmes, de leur pièce ei de lonterview des leaders du viliage. La couverture fut extrêmement posicive et présentait les membres de la chasse comme des femmes comrageuses et intelligentes qui avaient pris une décision basé stir leur connaissance des droits de la personne, des conséquences néfastes de cetre prattique sur la santé, et un désir de mette un teme à une pratique qui navait plus de rai son d'être au sein de leur communauté.

La réaction à leur décision fut à la fois positive et négative. Hs eurent des partisans et des détracteurs. D'autres encore pensaient qu'il leur faltair du temps frear assimiler cette décision. Des hommes er des fernmes du même groupe ethnque a une ville des cmyirons étaient furieux ; ils se sentaient trahis. De nouveaux anticles paturen: dans les journaux faisant état de réactions diverses de la part des senégalais, centum critiquant ouvertement la décision des femmes. D'autres pensaient que les femmes avaient été infiuencées par des occidentaux parce que la direcrice de Tostan est américaine. 
Un article paru dans le «Soleil» était accompagné d'un dessin montrant une femme qui brûle la «case de l'excision» et une jeune fille derrière elle qui lui dit : «Anitche», qui signifie merci en bambara.

Les femmes de Malicounda Bambara furent choquées par ce dessin : «Ils nous représentent comme des révolutionnaires! Nous ne sommes pas des révolutionnaires. Nous sommes en train d'effectuer un changement pacifique dans le but de promouvoir la santé de la femme. Nous ne sommes PAS en train d'aller à l'encontre de nos traditions. Nous nous attaquons à une pratique qui a des conséquences néfastes sur la santé de nos filles !» se lamenta Ndèye Touré.

En même temps, les hommes de Malicounda Bambara commencèrent à se plaindre. «Lorsque nous avons accepté la décision des femmes, il ne nous était jamais venu à l'esprit qu'elles parleraient de ce problème au su de tous, aussi publiquement, «nous dit l'un d'eux.» Si elles avaient pris leur décision et l'avaient appliquées calmement nous n'aurions pas eu de problèmes. Mais elles divulguent des secrets liés à notre culture qui ne devraient en aucun cas être discutés en public.»

Tostan rencontra donc les femmes après la parution de ces articles. Elles avaient toutes le visage tiré et paraissaient déprimées. L'effervescence et la joie de la rencontre avec les journalistes s'étaient envolées et elles étaient visiblement inquiètes à cause des réactions qu'elles avaient suscitées dans tout le pays, dans la ville voisine de Mbour et dans leur propre village.

«Ceci pourrait empirer,» leur dit Molly Melching, «car on ne peut jamais prévoir ni contrôler ce que les journalistes écrivent dans les journaux ou montrent à la télévision. Les choses pourraient être déformées encore plus. Ce n'est pas encore trop tard. Si vous ne voulez plus en parler avec les média, nous pouvons arrêter dès à présent. Nous pouvons arrêter d'amener les journalistes ici, ainsi personne n'écrira. plus d'articles sur Malicounda Bambara.»

Après plusieurs minutes d'un silence profond, Téné Cissoko, une jeune mère de famille de 34 ans avec 3 enfants, se leva et dit : «Non, nous n'allons nullement arrêter de parler de ce problème avec les autres. Nous avons pris notre décision et y croyons fermement. Par conséquent, nous devons avoir le courage de continuer d'expliquer pourquoi nous avons mis un terme à cette 'tradition' ici chez nous. Nous sommes des Amazones. Nous continuerons la lutte pour aider nos sœurs et nos filles.»

Une semaine plus tard, les femmés apprirent que les villageois de Keur Simbara étaient en train de se préparer pour la cérémonie d'excision de leurs filles.» «Pensez-vous que nous pouvons aller leur parler ?» demanda Ndèye Marème Touré. Par une après-midi pluvieuse d'août, les femmes s'en furent au village bambara de Keur Simbara où la population les accueillit avec beaucoup de réserve. Les femmes de Malicounda Bambara jouèrent leur pièce de théâtre sur l'excision, suivi d'un débat animé sur les problèmes de santé et les droits de la personne en particulier.

Cependant, la plupart des femmes de Keur Simbara défendirent leur position par rapport à la pratique, soutenant que c'était une tradition ancienne à laquelle il serait difficile de mettre un terme du jour au lendemain. Maïmouna Traoré conclut cette rencontre en leur disant : «Prenez votre temps et pensez-y comme nous l'avons fait nous-mêmes. À tous égards, nous sommes des femmes bambara comme vous et nous avons pris notre décision et sommes convaincues du bien fondé de ce que nous faisons.» Quelque trois semaines après la rencontre, Demba Diawara, Imam de Keur 
Simbara et ancien participant au programme de Tostan, informa Molly qu'un des problèmes de la réunion était la présence parmi eux de villageois wolof du voisinage, qui ne pratiquent pas l'excision. Il expliqua que de l'avis des hommes et des femmes, critiquer l'excision devant ces autres villageois aurait signifié une perte de leur honneur. La meilleure façon pour lui d'attaquer le problème serait d'impliquer le «clan» dans sa totalité, ensemble et sans aucune pression ni jugement de l'extérieur. «Ce n'est que lorsque tous les membres de la famille élargie auront approuvé que nous seront assurés que les filles non excisées ne subiront aucun préjudice et pourront trouver un époux,» expliqua Demba.

En septembre 1997, un journaliste du journal français Le Monde, RolandPierre Paringaux, passa une semaine à Tostan pour enquêter sur la décision des femmes de Malicounda Bambara. Il rédigea un article d'une page intitulé «Le serment de Malicounda Bambara», qui apparut le 14 octobre 1997. Dans cet article, un autre problème fut posé : le type d'excision qui était pratiqué à Malicounda Bambara. Ceci suscita un nouveau débat et causa d'autres problèmes aux femmes. En fait, les femmes avaient expliqué lors de plusieurs réunions publiques, que dans la tradition bambara, une partie des grandes lèvres étaient sectionnés et ensuite scellés en laissant le sang coaguler et sécher comme pour une plaie, créant un genre d'infibulation, sans toutefois les recoudre comme c'est le cas dans certains pays comme la Somalie, Djibouti et le Soudan. Ceci est une pratique que l'on retrouve non seulement chez les Bambara du Sénégal, du Mali et de la Gambie mais aussi chez les al pulaar dans la région de St Louis du Sénégal, en particulier chez les «tooroodo» ou nobles guerriers, la classe la plus élevée de la hiérarchie sociale al pulaaren.

M. Parigaux écrivit dans son article que les femmes de Malicounda Bambara pratiquaient l'infibulation ce qui enragea les hommes du village. Seules quelque 25 femmes de la classe étaient présentes à la réunion que nous avions organisée après la parution de l'article. Il y avait beaucoup de tension dans l'air. «Où sont les autres,» demanda Molly «Il y a un décès dans le village.» répondirent-elles. Cette réponse devint un leitmotiv pour les femmes, qui de moins en moins venaient aux réunions. En réalité, du fait de la pression qu'exerçaient sur elles les hommes, certaines femmes n'osaient plus trop participer aux activités pour le moment. Aucun homme ne se présenta non plus à la réunion. Molly appris plus tard que le jour même de sa visite, les hommes avaient convié une «Assemblée Générale du Village» pour discuter des articles qui avaient paru dans la presse. Téné Cissoko décrivit cette réunion dans une interview en octobre 1998, en ces termes:

« Ce jour-là, les hommes nous ont convié à une réunion. Il y avait beaucoup d'adultes présents, en particulier des hommes. Ils nous dirent, en gros, de cesser de nous exprimer sur la décision que nous avions prise. Ils nous expliquèrent qu'ils n'étaient pas d'accord avec nous sur ce point précis. Que la presse faisait des déclarations qui ne devaient pas être discutées publiquement et qu'ils en avaient assez.

Je pris la parole et dit que bien que nous leur reconnaissions le droit d'exprimer leurs idées, nous connaissions nos droits et savions que nous, les femmes, avions aussi le droit d'exprimer nos opinions. Les nouvelles sont bonnes et non pas mauvaises. Nous nous devons d'aider les autres en partageant notre décision. Nous avons foi en ce que nous avons fait.

Un des hommes dit: Nous vous dénoncerons. 
Je lui répondis : Je sais lire et écrire et je vous dénoncerai aussi !

Ceci sembla les calmer. Après, ils ne nous dirent plus rien, mais certaines femmes avaient peur de participer aux réunions lorsque des visiteurs arrivaient. Nous décidâmes que ce n'était pas important, que nous continuerions même si on ne devait être que 15. Nous avions le soutien de la Présidente du Comité de Gestion, ce qui pour nous importait plus, »

\section{NGUERIGNE BAMBARA SUIT L'EXEMPLE}

Lors de sa visite en septembre 1997, Roland Paringaux avait aussi rencontré les populations de Nguerigne Bambara, village situé à quelque $20 \mathrm{~km}$ de Malicounda Bambara. Lors d'une réunion avec plusieurs villageois, y compris l'Imam et le Chef de village, Roland avait reçu comme information que les différents groupes ethniques du village qui y pratiquaient l'excision le faisaient jusqu'à présent. Une femme wolof qui avait épousé un al pulaar avait fini par se faire exciser pour ne plus être méprisée par les membres de sa belle famille.

La Présidente du Groupement de Promotion Féminine de Nguerigne, Ourèye Sall, fille d'une exciseuse, raconta publiquement pour la première fois le jour où sa propre fille avait failli mourir après l'opération. «J'ai eu la peur de ma vie» explique-t-elle. «J'avais demandé à ma mère de rester m'aider ce jour-là, mais elle me répondit qu'elle devait partir car elle ne pouvait pas voyager le jour suivant - les esprits n'étant pas favorables à un tel voyage. Elle me laissa donc seule avec ma fille qui faisait une hémorragie. J'essayais d'utiliser certaines méthodes traditionnelles pour arrêter l'hémorragie, sans résultat. En fin de compte, j'ai amené ma fille au dispensaire à Mbour. Ils s'en sont tous pris à moi là-bas parce qu'ils savaient que la petite avait été excisée. J'avais honte et pour la première fois, à cet instant je me suis demandé si vraiment je continuerai à respecter la tradition et si comme le souhaitait ma mère, je deviendrai une exciseuse. Je me suis dit : «Ma mère est supposée être une experte en la matière, mais elle n'était même pas en mesure de me venir en aide dans ce cas-ci. Que pourra-t-il m'arriver dans un cas similaire. Je ne voudrais pas que quelqu'un d'autre souffre par ma faute». Des années plus tard ma fille s'est mariée et a eu d'énormes problèmes à l'accouchement». À ce moment précis, Ourèye Sall se tourne vers Amadou Lamine Diagne, l'Imam du village et demande avec circonspection : «Puisque c'est la première fois que nous parlons aussi ouvertement de cette tradition, et puisque l'Imam est là présent, je souhaiterais poser une question qui me préoccupe depuis des années. Est-il vrai qu'une femme non excisée est réellement souillée et impure comme on nous l'a toujours fait comprendre? Est-il vrai qu'une femme non excisée ne peut pas servir à boire ou à manger aux autres, en particulier aux hommes ?»

L'Imam se tourna vers Ourèye Sall et lui dit : «Lorsque vous quittez votre maison, vous vous rendez compte que vos enfants vous suivent, bien que vous leur ayez demandé de rester à la maison, pour leur faire rebrousser chemin vous leur dites : «Retournez à la maison! Sinon la vieille méchante hyène va vous manger !» Ce qui bien sûr est faux. La méchante hyène n'existe pas, n'est-ce pas ? Voilà la réponse à votre question !»

Cette démystification par l'Imam lui-même, d'un mythe commun sur les 
femmes non excisées, eut un énorme impact à Nguerigne Bambara. Néanmoins, les femmes devaient entamer l'étude du Modulle 7 sur la Santé de la Fermme à cette période, elles expliquèrent qu'elles avaient besoin d'informations supplémentaires sur l'excision et de discussions plus approfondies avec les membres de la classe, ainsi que de consulter leurs époux et le Chef de village avant de prendre une décision aussi importante.

Le 6 novembre, l'équipe de Tostan effectua une visite à Nguerigne Bambara avec un journaliste et un photographe du journal français «Point de Vue». Les journalistes posèrent aux femmes des questions sur l'excision et Ourèye Sall leur dit qu'après en avoir longuement discuté en classe et ensuite avec les hommes et les femmes du village, en soutien aux femmes de Malicounda Bambara, toute la communauté villageoise se sentait maintenant prête à abandonner la pratique de l'excision. Elle déclara qu'elle n'exciserait jamais plus de petite fille parce qu'elle avait appris que beaucoup de problèmes de santé étaient liés à l'excision. Les journalistes étaient à la fois surpris et émus car rien ne présageait que les femmes allaient faire cette déclaration aussi inattendue. Ils décidèrent de faire de cet événement le sujet principal de leur article.

\section{LE PRESIDENT DIOUF FELICITE PUBLIQUEMENT LE VILLAGE DE MALICOUNDA BAMBARA}

Le Président de la République du Sénégal, Abdou Diouf, rendit un vibrant hommage aux femmes de Malicounda Bambara dans son discours lors du 33ème Congrès de la Fédération Internationale des Droits de l'Homme qui s'est tenu à Dakar le 20 novembre 1997, dans lequel il dit :

«Qui dit Droits de l'Homme dit nécessairement Droits de la Femme. Je suis convaincu que dans ce domaine, nous pouvons également faire des progrès. Le Ministère de la Femme, de l'Enfant et de la Famille a élaboré un Plan d'Action que nous devons promulguer sans plus attendre. Un groupe de femmes parlementaires a aussi indiqué la nécessité de modifier nos lois pour renforcer l'égalité entre les sexes dans les domaines comme la fiscalité, la protection sociale, le code du travail et le Code de la famille.

Enfin nous devons lutter vigoureusement contre l'excision. Une loi est sans doute nécessaire pour marquer l'engagement des pouvoirs publics dans ce domaine. Mais surtout, il nous faut tous ensemble, Gouvernement et Organisations Non Gouvernementales convaincre les populations que cette pratique constitue un danger pour la santé de la femme. L'excision a souvent eu comme conséquence des hémorragies, des infections et même des décès. De nos jours, cette tradition ne peut plus se justifier.

A cet égard, l'exemple de Malicounda Bambara mérite d'être cité. Dans ce village du Sénégal, les femmes ont pris conscience des dangers de cette pratique et ont engagé un dialogue avec leurs maris, l'Imam et le Chef de village. Par une décision collective, la communauté a décidé que plus jamais il n'y aurait de l'excision au village.

Je lance aujourd'hui un appel solennel à tous les Sénégalais pour que le serment de Malicounda Bambara se propage dans tout le Sénégal. Je demande que soit organisé dans chaque village un grand débat sur l'excision, et que chacun prenne conscience que le temps est venu de changer les anciennes pratiques dans ce domaine.» 
Le Président avait aussi décidé qu'une loi contre l'excision devait nécessairement être victée et la procédure démarra le 3 février 1998. Encore une fois, il fit référence aux fenmes de Malicounda Bambara et à la manière positive avec laquelle elles avaient réussi à apporter le changement social par le biais de l'éducation et du dialogue.

\section{LA DECLARATION DE DIABOUGOU : AUGMENTATION DES SERMENTS PUBLICS}

Demba Diawara, Imam de Keur Simbara n'avait pas attendu l'appel du Président de la République. Accompagné de son neveu Cheikh Traoré, il avait déjà rendu visite à d'autres villages bambara près de Joal pour discuter de leurs points de vue sur l'abandon de la pratique de l'excision. Ils visitèrent plusieurs villages sur une période de trois mois de novembre 1997 à janvier 1998, convaincus que leur propre village ne pouvait mettre un terme à l'excision s'ils ne réussissaient pas à le faire en même temps que d'autres membres de leur famille. Demba tenait souvent à préciser : «Kër Simbara, dafa tuuti waaye dafa mag.» (Tout en étant un petit village Keur Simbara est grand par ses ramifications.) Le moment était donc venu de mettre un terme à la pratique de l'excision, mais ils avaient besoin de l'assentiment et de l'engagement de toute la famille, dispersée dans dix autres villages puisque des mariages avaient été contractés entre fils et filles des différentes familles.

Les deux hommes rendirent aussi visite au siège de Tostan en décembre et débattirent du problème pendant presque 3 heures. «Je n'avais pas la moindre idée de tous ces problèmes,» dit Demba en secouant la tête. «J'ai entendu des histoires extraordinaires dans les dix villages que nous avons visité - de souffrances endurées par les jeunes filles pendant l'excision et par les femmes au moment des rapports sexuels et de l'accouchement. Auparavant, les femmes ne se sont jamais plaintes, n'ont jamais fait état de leur douleur, n'avaient jamais évoqué ces problèmes à Keur Simbara - je crois que la plupart n'avaient jamais réalisé que ces douleurs étaient des conséquences de leur excision. Elles pensaient que toutes les femmes souffraient comme elles. Si nous avions appris plus tôt ce que nous venons de découvrir pendant les réunions publiques qui se sont tenues sur notre passage, il y a longtemps que nous aurions insisté pour que soit mis un terme à.l'excision.»

Demba expliqua aussi la stratégie qu'ils avaient utilisé en prenant l'exemple du village de Samba Dia. «Lorsque nous sommes arrivés à Samba Dia, je suis allé dans la concession de mon cousin et j'ai d'abord discuté de la question avec lui. II $\mathrm{m}$ 'a aussitôt amené chez le Chef de village qui m'a fait comprendre qu'il adhérait à nos efforts d'abandon de la pratique de l'excision, mais préférait que nous rencontrions l'agent de santé et la sage-femme de leur localité. Nous allâmes ensembles les voir, discutâmes avec eux du problème et ils nous dirent le constat qu'ils avaient fait sur les conséquences néfastes de l'excision sur la santé dans le village. Le Chef de village était convaincu que tout le village devait assister à la réunion qui alier suivre et que tous devaient discuter du problème. Pendant cette réunion, plusieurs personnes firent état de problèmes liés à l'excision qu'elles avaient vécus personnellement. Même le Chef de village jorit ia parole car dans sa propre famille certaines personnes avaient aussi payé un lourd tribu cette pratique.» 
Vers la fin du mois de janvier, Demba et Cheikh invitèrent l'équipe de Tostan à venir visiter certains de ces villages. Ils pensaient qu'il était important que nous ayons une idée des progrès qu'ils avaient faits, car comme ils le disaient : «ll y a un an, vous auriez pu être assassiné pour avoir ne serait-ce qu'évoqué le problème avec ces personnes.: Dans chaque village visité, les hommes et les femmes parlèrent de l'excision, bien qu'avec une certaine réserve, mais en toute franchise. Ils exprimèrent leur désir de participer au programme d'éducation, car Demba Diawara er Cheikh Traoré leur avait appris des choses dont ils n'avaient jamais soupconné l'existence.

Dans le village de Faajal, nous avions rencontré Fatou Kiné Diawara, âgée de 66 ans et sneur de Demba Diawara : «C'est moi qui m'occupais des jeunes filles après qu'elles aient subi l'opération,» explique-t-elle devant tout le monde, «un jour ce fut le tour de ma propre nièce et il y eut des complications. Elle fit une hémorragie. Je fis tout ce qui était en mon pouvoir pour l'arrêter mais en vain. J'étais terrifiée et n'osais l'amener nulle part de peur qu'on ne m'arrête et me mette en prison. Je me disais que l'excision étaient illégale et par conséquent je ne pouvais pas l'amener à l'hôpital. En ûn de compte, vers 4 heures de l'après-midi, l'Imam est venu, a fait des prières et lui a donné sa bénédiction. L'hémorragie s'est finalement arrêtée, mais regardez ce qu'est devenue ma nièce. Elle souffre de troubles psychologiques et est restée toute maigre.» Dans le même village de Faajal, un jeune homme prend hardiment la parole : «Nous les hommes, nous souhaitons vivement qu'un terme soit mis à cette 'tradition' parce qu'à dire vrai - nous sommes fatigués ! Nous voulons que nos femmes puissent connaître le plaisir sexuel mais cela demande tellement d'efforts que quelques fois nous finissons par baisser les bras. Plusieurs hommes de notre groupe ethnique sont allés prendre une deuxième femme d'un autre groupe ethnique qui he pratique pas lexcision pour cette raison .» Un rire nerveux parcoumut l'assistance.

La plupart des femmes de ces villages exprimèrent leur souci de voir leurs filles tomber enceintes si elles n'étaient pas excisées. D'autres répondirent qu'elles avaient vu beaucoup de cas de filles excisées qui étaient tombées enceintes et que l'excision n'était plus la solution aux problèmes de grossesses précoces. Plusieurs dirent qu'elles avaient besoin de cours d'éducation pour être en mesure d'informer leurs filles sur les questions de santé et de sexualité. Leurs filles aussi devaient recueillir ces informations des écoles qu'elles fréquentaient.

Bileau Diawara, une jeune femme de 30 ans fit un récit de son expérience de l'excision : «Il y a une vingtaine d'années, ma mère vint me dire de me préparer pour aller à Thiés pour une visite. Ma grande sœur devait nous accompagner. Aussitôt arrivées, on nous emmena dans une concession que nous ne connaissions pas. On ne nous avait rien dit. Tout d'un coup des femmes $m$ 'ont attrapé et m'ont tenu allongée sur une natte à l'arrière de la case qui faisais office de cuisine. J'étais terrifiée en particulier parce que je n'avais aucune idée de ce qui se passait. Une femme est ensuite venue avec une lame de rasoir et me dit de ne pas verser de larmes. Elle me dit que ce serait une honte, un déshonneur pour ma famille si je pleurais. J'étais pétrifiée mais dans l'incapacité de bouger. Ensuite elle me coupa et je ressentis une douleur très atroce mais n'osais ni pleurer encore moins crier. Pendant deux jours, je n'osais pas uriner jusqu'à ce qu'on me force à la faire malgré la douleur causée par la brûlure des urines. Ma sœur et moi avions été placées dans une case spéciale et plusieurs femmes vinrent nous rendre visite. Elles chantèrent, battirent des mains et dirent que nous avions été 
braves, que nous étions maintenant de vraies femmes. Ceci nous aida à oublier la douleur.

Arrivée au secondaire, notre professeur nous fit un cours sur l'excision. Pendant qu'elle parlait, je me suis rendu compte que c'était ce qu'on m'avait fait subir. Jusqu'à ce moment-là, il ne m'était jamais venu à l'esprit que je pouvais être différente des autres filles. Je me souviens de la rage qui m"animait. Arrivée à la maison ce jour-là je criais à ma mère : «Comment as-tu pu me faire ça ? Tu as détruit ma vie.» Elle me regarda calmement et me dit : «Tu me remercieras le moment venu de te trouver un époux.» L'ironie du sort c'est que j'ai épousé un wolof. Aujourd'hui je veux aider Demba Diawara à convaincre les autres habitants du village. Il peut y arriver, alors que moi personne ne $m$ 'aurait jamais écoutée.»

Les populations de ces 10 villages exprimèrent le souhait de se réunir tous ensemble en tant que communauté de villages unie avec des représentants désignés : le Chef de village et deux femmes. Ils choisirent le week-end du 14 au 15 février 1998 pour tenir cette rencontre. L'équipe de Tostan leur fit clairement comprendre qu'elle n'attendait d'eux aucune décision définitive. En fait, nous leur expliquâmes que si plus tard ils se décidaient à mettre un terme à la pratique de l'excision, nous pouvions choisir un autre jour où plus de personnes pourraient participer à la réunion et prendre part à la déclaration publique.

Le jour choisi, les fermmes de Malicounda Bambara et de Nguerigne Bambara étaient en retard. Lorsqu'en fin de compte elles finirent par arriver, leurs visages étaient illuminés et le soulagement se lisait dans leurs attitudes, une réaction normale après les longs mois d'incertitude et de tension qu'elles avaient du endurer. Elles étaient convaincues que leurs problèmes avaient pris fin puisque aujourd"hui, elles étaient reçues comme des invitées honorées et courageuses de cette rencontre qui réunissait d'autres membres de leur propre groupe ethnique.

La rencontre de Diabougou débuta par les témoignages des femmes, ensuite deux chefs religieux exprimèrent leur opinion sur la question. L'un venait de Nguerigne Bambara, l'autre était un membre de la confrérie Qadriya, de la famille» «Kounta», la chefferie religieuse la plus respectée par le groupe ethnique Bambara du Sénégal. Un agent de santé expliqua très précisément les dangers de l'excision, tout le monde fut intéressé et les participants posèrent ensuite des questions. Le Président de l'Organisation Nationale des Droits de l'Homme, Mâ̂tre Sidiki Kaba, lui-même un Bambara, parla de l'excision et expliqua pourquoi elle était considérée comme une violation des droits de la personne et en particulier des Droits de l'Enfant. Le Directeur de Cabinet du Ministre de la Famille, de l'Action Sociale et de la Solidarité Nationale, M. Cheikh Tidiane Diop, parla au nom du Gouvernement. Les villageois apprécièrent grandement la présence à cette rencontre d'un officiel respecté et de haut rang du gouvernement. Ils posèrent plus de questions ef partagèrent plus d'informations et d'expériences vécues.

Les invités étrangers quittèrent Diabougou à 15 heures pour donner le temps aux représentants des 13 villages (50 personnes à peu près), de discuter entre eux en langue bambara.

Lorsque l'équipe de Tostan revint à 2 heures du matin pour rencontrer les représentants des villages, ils avaient déjà discutée en Bambara et élaboré la Déclaration de Diabougou. Nous passâmes 2 heures à traduire la déclaration en français et wolof, en collaboration avec plusieurs villageois. Molly remarqua alors 
qu'elle ąvançait dans la traduction qu'il n'y était nullement fait mention de rites d'initiation alternatifs, un point qui avait été soulevé comme une possibilité aviant la rencontre. «Pourquoi n'en parlez-vous pas ?» demande Molly aux femmes.

«Nous avons décidé à l'unanimité de ne pas exiger de rites d'initiation alternatifs. Nous avons plutôt besoin de nous séparer de tous ces rites. II nous faut un moyen de contrôler ce qui se fait, et les battements du tam-tam accompagnés de chants sont associés à l'opération. Certains utiliseront ce prétexte pour continuer de pratiquer l'excision en secret. Ceci doit prendre fin.»

Une autre femme ajoute : «Soyons honnêtes, ces dernières années, nous excisions nos filles à 2 semaines et jusqu'à trois mois après la naissance, ce qui ne faisait même plus partie du rituel. Ceci est une notion romantique que vous avez, vous gens du monde occidental et que vous voulez nous imposer maintenant.» Les femmes demandèrent plutôt qu'on leur donne des informations sur le leadership, le processus de résolution de problèmes, les notions de santé et de sexualité à travers des classes d'éducation. Elles ont dit qu'elles parleront aux femmes âgées et leur expliquant toute l'importance de transmettre les traditions et la culture de leur groupe ethnique. Elles étaient inflexibles et n'avaient aucune envie de revenir sur leur décision.

Les anciennes exciseuses annoncèrent toutes qu'elles étaient prêtes à mettre un terme à cette pratique même si pour elles cela signifiait une perte de revenus. Elles avaient aussi adhéré à la déclaration vigoureuse de Fatou Kiné Diawara qui avait si souvent annoncé : «Une tradition qui nuit, une tradition qui tue ne devrait pas être une tradition.» Les autres furent invités à revenir au village le jour suivant à $11 \mathrm{~h}$ du matin et les villageois lurent leur déclaration. 


\section{LA DECLARATION DE DIABOUGOU}

Nous, les 50 représentants de plus de 8.000 personnes des 13 villages suivants :

$\begin{array}{llll}\text { Keur Simbara } & \text { Diabougou } & \text { Soudiane } & \text { Sorabougou } \\ \text { Bagana } & \text { Boubacar } & \text { Kobongoy } \\ \text { Médina Fajal } & \text { Samba Dia } & \text { Samb Diallo } \\ \text { Ngeriñ Bambara } & \text { Fajal } & \text { Malicounda Bambara }\end{array}$

Réunis dans le cadre des Rencontres de Diabougou (Région de Thiés) les 14 et 15 février 1998 autour de la pratique de l'excision dans la communauté bambara :

- Considérant les nombreux témoignages des femmes et des filles de nos communautés, des autres localités bambara du Sénégal et de plusieurs autres pays africains qui attestent que l'excision peut être source de souffrance, de maladie, de traumatismes graves et même de perte en vies humaines ;

- Considérant que les travailleurs de la santé certifient que l'excision est souvent à l'origine de difficultés d'ordre médical pour les filles et les femmes qui l'ont subie et peut entraîner : des hémorragies pouvant aller jusqu'à la mort, diverses infections, la stérilité, des complications pendant et après l'accouchement, les MST, des problèmes psychologiques, etc.

- Considérant que nos valeurs religieuses assurent l'importance de la santé physique et psychologique de la femme et garantissent le droit à la santé ;

- Considérant que les différentes déclarations, conventions et chartes relatives aux Droits de la Personne stipulent que l'excision constitue une violation des droits de l'enfant pour la fille et des droits de la personne pour la femme ;

- Considérant que le Gouvernement du Sénégal, par la voix du Président de la République a clairement pris position contre la pratique de l'excision en vue de protéger la santé des femmes et des jeunes filles et de tenir les engagements du Gouvernement à respecter les déclarations, les conventions et les chartes internationales qu'il a ratifiées ;

- Affirmant que les traditions doivent être positives et bénéfiques pour l'individu et pour la société et ne pas être une source de souffrances, de divers traumatismes, de maladie voire pertes en vies humaines;

- Affirmant que les femmes jouent un rôle prépondérant dans notre société et doivent, par conséquent jouir de leurs droits de bénéficier pleinement des meilleures conditions de santé tout au long de leur vie ; 


\section{DECLARONS}

Avoir pris l'engagement solemnel de mettre un terme à la pratique de l'excision au sein de notre communauté.

Avoir pris l'engagement solemell de divulger nos cominaissances ef de propager l'esprit de notre décision auprès dles populations de mos villages respectifs et auprès dles autres communautés où l'excision est encore pratiquée.

Notre souhait est de continuer le processus de prise de conscience et de transformation sociale enclenché durant cette expérience en bénéficiant du Programme d'Education de Base qui nous permettra d'acquérir des comaissances en lecture, en écriture et en calcul, ainsi qu'en matière de santé, d'hygiène, de résolution de problemes, de gestion, de leadership, de droits de la personne et de démocratie.

Nous saisissons l'opportunité offerte pour exprimer nos sentiments de profonde reconnaissance aux femmes de Malicounda Bambara, Nguerigne Bambara et Keur Simbara, qui malgré les conditions difficiles, ont ouvert la voie et indiqué la marche à suivre aux autorités et aux autres communautés concemées afin que plus jamais nos filles et nos femmes ne subissent les conséquences néfastes de l'excision. La détermination de ces femmes courageuses est la raison d'être des présentes Rencontres de Diabougou.

Nous disons aussi merci au Président de la République, Monsieur Abdou Diouf, qui, par son engagement personnel pour l'éradication de l'excision, un sujet aussi sensible dans notre pays, a fait montre d'un courage exemplaire en engageant la communauté nationale à perpétuer le processus qui a conduit au Serment de Mialicounda Bambara.

Nous exprimons notre gratitude à Tostan, à l'UNICEF, au Ministère de la Famille, de l'Action Sociale et de la Solidarité Nationale, au Ministère de la Santé, à l'Organisation Nationale des Droits de l'Homme (ONDH), à l'UNIFEM, au FNUAP et à l'OMS pour leurs diverses actions dans ce domaine et les exhortons à continuer de soutenir et d'accompagner nos efforts pour l'éradication de cette pratique.

Nous demandons au Gouvernement de nous soutenir pour la mise en ouvre d'un programme d'éducation de base en langues nationales dans les dix villages qui n'avaient pas bénéficié auparavant d'un tel programme, étant donné que l'éducation est au cour de cette rencontre historique de Diabougou et du fait que l'éducation de base est un élément primordial pour la promotion de l'individu en particulier et de la société en général.

Nous lamnçons un appel solemmel à la communauté nationalle et innternationalle affin qu'elles se molbilisent pour qu'aucune fille, aucume femme me souffire plus jamais des effets néfiastes de l'excision.

Nos remerciements vont à l'endroit des leaders religieux et traditionnels et des autorités publiques et à tous : femmes, hommes et jeunes qui ont bien voulu s'associer à notre initiative.

Les 50 représentants des 8.000 habitants de 13 Villages de la Région de Thiés et de Fatick DIABOUGOU, SENEGAL Le 15 février 1998 
Le Directeur de Cabinet du Ministre de la Famille exprima ses remerciements. Les danses et les chants Bambaras continuèrent à résonner bien après que les invités officiels eurent quitté le village. Lorsque l'équipe de Tostan s'apprêtait à faire ses adieux aux représentants des villages, elle les trouva occupés à un débat animé dans l'une des classes de l'école. Ils étaient en train d'élaborer un plan pour le suivi de leur déclaration et de décider quelles sanctions devraient être appliquées à tous ceux qui violeraient le nouveau serment. Certains pensaient qu'il était importent de poursuivre ces contrevenants en justice. Demba Diawara insista sur le fait que l'éducation et la persuasion sont les meilleures méthodes pour apporter un changement durable. Ils s'accordèrent sur le fait que toute forme de «retour en arrière» serait honteuse et jetterait le déshonneur sur leur groupe. Une fois qu'un Bambara se décide, c'est pour de bon. Il met du temps à se décider, mais dès l'instant qu'il le fait, il s'y conforme.» déclarèrent-ils sans cesse.

Leur décision fut télévisée et rapportée dans les journaux et à la radio, attirant de nouveau l'attention de l'opinion nationale sur ce problème.

Le 23 décembre, Molly rendit visite à trois des villages qui avaient participé à la Déclaration de Diabougou. Avec le soutien de l'UNICEF, Tostan a actuellement ouvert des classes dans les dix villages et a rencontré les Chefs de village, les autorités locales et les 70 femmes participant aux classes. Dans tous les villages, les informations recueillies font état d'un abandon total de la pratique de l'excision depuis leur déclaration du 15 février 1998.

\section{MmE CLINTON APPORTE SON SOUTIEN AU MOUVEMENT}

La Première Dame des Etats Unis, Mme Hillary Rodham Clinton, visita le Sénégal pour la première fois du 17 au 18 mars 1997. Lors de ce séjour, elle visita le village de Saam Njaay, où Molly Melching avait vécu dans le cadre d'un projet expérimental d'éducation financé par l'USAID. Suite à cette visite, Molly śchangea une correspondance suivie avec Mme Clinton, lui faisant part des évinements extraordinaires qu'elle était en train de vivre concernant le problème de l'excision et reçut le soutien et l'encouragement de la Maison-Blanche. Lors de la seconde visite de Mme Clinton au Sénégal avec son époux, le Président William Jefferson Clinton, en avril 1998, elle demanda à voir pour les féliciter, les courageuses personnes qui avaient enclenché ce mouvement contre la pratique de l'excision. Le 2 avril, les femres de la classe de Malicounda Bambara, Demba Diawara, Cheikh Traoré (Keur Simlara), et Ourèye Sall (Nguerigne Bambara) se rendirent tous à l'Hotel Méridien Président où le couple présidentiel était descendu, pour rencontrer la Première Dame.

La préparation de cet événement fut quelque peu difficile. Les hommes de Malicounda Bambara étaient encore une fois sceptiques. «Vous irez là-bas et vous vous ferez exploiter. Vous ne rencontrerez jamais la Première.» dirent-ils aux femmes. Les hommes essayèrent de les convaincre de ne pas aller au rendez-vous. À la dernière minute, un des hommes donna l'ordre à sa femme de rester à la maison malgré sa participation active à la classe et au mouvement pour l'abandon de l'excision. Les femmes décidèrent qu'il était trop tard pour protestater contre cette décision et quittz̀rent le village déçues et soucieuses. 
L'arrivée de la Première Dane dans la salle de réunion de l'hôtel dissipa rapidement toutes les appréhensions. Mme Clinton serra les mains de chaque participant, les saluant chaudement et les remerciant de s'être déplacés de leurs villages pour venir la rencontrer. La Maison Blanche avait soigneusement préparé l'événement et tous les villageois avaient des écouteurs pour la traduction simultanée en wolof et en anglais.

Le Ministre de la Famille, de l'Action Sociale et de la Solidarité Nationale, Aminata Mbengue Nidiaye, ainsi que trois autres femmes qui avaient participé à la lutte pour 1'abandon de la pratique de l'excision au Sénégal, Marianne Ndiaye Sidibé (COSEPRAT), Marie Hélène Mottin Sylla (ENDA) et Awa Thiam (Femmes et Société) étaient aussi présentes pour une table ronde. Mme Khadidia Sidibé, Présidente de l'Association Malienne pour le Suivi et l'Orientation des Pratiques Traditionnelles (AMSOPT) était aussi présente ainsi que Molly Melching (Tostan) et Maimouna Mills de la Voie de l'Amérique qui était le modérateur de la table ronde.

Maimouna Traoré, Présidente du Groupement de Promotion Féminine de Malicounda Bambara, ouvrit les débats en donnant une brève description de la façon dont les femmes, inspirées par leurs classes d'éducation de base, prirent l'initiative d'informer les autres hommes, femmes et enfants de leur village sur les dangers pour la santé que représentent la pratique de l'excision et la nécessité de mettre un terme à cette tradition. Elle expliqua que bien que leur déclaration publique pour mettre un terme à la pratique le 3 ! juillet 1997 se heurta à une forte résistance de la part des autres membres de leur groupe ethnique, les femmes ne se sont jamais rétractées, tilisant comme arguments leurs connaissances des droits de la personne et des conséquences néfastes de l'excision.

Les femmes de la classe de Malicounda Bambara jouèrent une pièce de théâtre dans ia laquelle une jeune villageoise meurt des suites de l'excision et qui prouve la complexité du changement de mentalités et des iraditions, malgré les cangers réels indiqués dans la pièce.

Ourèye Sall de INguerigne Bambara expliqua qu'elle avait personnellement vécu la pièce que Mme Clinton venait de voir jouer. Elle déclara que l'éducation non formelle est le meilleur moyen pour changer les mentalités et encourager l'application du processus de résolution de problèmes et l'amélioration des conditions socioéconomiques par les villageois eux-mêmes.

Demba Diawara, l'Imam expliqua le point de vue de l'islam qui, en aucun cas, ne fait de l'excision une obligation. Il exprima ses sincères remerciements à Mme Clinton pour son soutien et ses efforts pour la protection de la santé et les droits des femmes et des enfants africains.

Le Ministre de la Famille, de l'Action Sociale et de la Solidarité Nationale, Mme Aminata Mbengue Ndiaye remercia l'UNICEF pour son soutien au programme d'éducation de base de Tostan qui est à l'origine de ces résultats, ainsi que toutes les femmes présentes à la table ronde et représentant les organisations actives dans la lutte contre l'excision - ENDA, COSEPRAT, Femmes et Société et ASBEF. Elle donna lecture d'une partie de la déclaration du Président de la République du Sénégal, encourageant l'abandon de la pratique de l'excision et incitant les villageois à suivre l'exemple de Malicounda Bambara, et expliqua ensuite l'importance de la Déclaration de Diabougou et la loi votée pour mettre un terme à cette pratique initiée par le gouvernement du Sénégal le 3 février 1998. 
Madame Khadidia Sidibé du Mali parla du taux élevé de l'excision au Mali (95\%) et des résultats positifs que son organisation et plusieurs autres ont accompli dans la lutte pour mettre un terme à cette pratique traditionnelle néfaste. Elle précisa que l'intérêt de Mme Clinton pour ce problème sera très utile pour encourager les femmes du Mali et d'autres pays d'Afrique de l'Ouest à mettre un terme à cette pratique.

Molly Melching remercia Mme Clinton pour le soutien qu'elle a apporté pendant toute cette année aux femmes de Malicounda Bambara ce qui les a beaucoup motivées durant les moments difficiles. Elle mit l'accent sur l'importance de l'éducation de base et la connaissance des droits de la personne pour permettre aux femmes d'assumer leurs responsabilités et de prendre des décisions primordiales qui affectent leur vie et celle de leurs enfants.

Mme Clinton félicita les villageois pour le «grand mouvement» qu'ils avaient initié et les informa qu'elle avait rédigé un article sur leur expérience. «Ce ne devait pas être facile pour que des femmes et des hommes ensemble s'érigent contre une tradition séculaire et importante pour votre société. Le courage et l'engagement des femmes, des hommes et des chefs religieux de Malicounda Bambara a servi d'exemple et a rapproché des milliers d'autres sénégalais.» leur dit-elle. Selon Mme Clinton, l'éducation de base est primordiale pour la responsabilisation des femmes dans tous les domaines.

A la fin de la table ronde, Mme Clinton prit dans ses bras les bébés qui avaient effectué le déplacement avec leurs mamans et une photo de famille fut prise. Ensuite Mme Clinton invita tout le monde à prendre part à la réunion sur les Droits de la Personne en Afrique, à laquelle devaient participer des représentants de plusieurs pays africains et que devait présider son époux le Président Clinton. C'est alors que Mme Clinton parla de la contribution de ces villageois au respect et à la promotion des droits humains et leur demanda de se mettre debout. Ils furent acclamées chaleureusement par les nombreux participants venus de tout le continent.

Après la réunion, les villageois rencontrèrent le Président Clinton qui les félicita pour leur décision et leur courage. Il rendit aussi hommage au travail effectué par l'ONG Tostan. Plus tard, la Maison Blanche fit parvenir les photos prises avec le Président et Mme Clinton. Elles furent remises aux femmes et exposées par Demba Diawara dans tous les autres villages lors de réunions publiques.

Cet événement inhabituel fut couvert par la télévision et encore une fois aida à influencer l'opinion publique au Sénégal. Tostan reçu plusieurs appels téléphoniques émanant de tout le territoire, au cours desquels les personnes commentaient le grand respect accordé aux villageois. Plusieurs personnes remarquèrent que $\mathrm{Mme}$ Clinton n'avait proféré aucune attaque contre la tradition de l'excision, mais qu'elle avait plutôt félicité les villageois pour leur courage, indiquant ainsi son intérêt pour la promotion de la santé de la femme et de l'enfant en Afrique.

La chaleureuse réception qu'avait réservée Mme Clinton aux femmes de Malicounda Bambara eut aussi un grand impact sur les mentalités, en particulier celles des hommes du village qui réalisèrent soudain que les femmes étaient en effet à l'origine d'un mouvement historique. 


\section{ABANDON DE LA PRATIQUE DE L'EXCISION A KOLDA - LE MOUVEMENT PREND UNE NOUVELLE AMPLEUR}

Tostan fit une traduction en pulaar de la Déclaration de Diabougou en février 1998 et l'achemina dans la région de Kolda où 14 villages participaient au Module 8 sur le Développement du Jeune Enfant. Dans le Département de Kolda, $88 \%$ de la population pratique l'excision. Tostan est présente dans cette zone depuis 1989 et plus particulièrement dans le village de Médina Chérif qui est connu pour son respect des traditions et pour la piété de ses habitants.

La Déclaration de Diabougou fut commentée en classe pendant les séances sur l'excision et il y eut beaucoup de discussions sur le sujet. Lorsque le responsable de la formation de Tostan évalua le module en collaboration avec les deux formateurs, les habitants de Médina Chérif lui firent savoir qu'après avoir étudié le module et appris les conséquences néfastes de l'excision sur la santé, ils avaient pris la décision de mettre un terme à cette pratique. Tostan fut surprise par cette décision puisque lors d'une expérience précédente avec deux villages pulaar qui participaient aux Modlulles 7 et 8 , les femmes avaient décidé de mettre un terme à la pratique, mais ne voulaient pas s'exprimer publiquement sur la question. Tostan respecta bien sûr leur souhait et n'en parla plus jamais, pensant que les pulaars étaient plus réservés que les Bambaras. Par conséquent le souhait des Al pulaar de Médina Chérif de rendre leur engagement public était surprenant, surtout venant d'un village particulièrement religieux et conservateur. Encore une fois, la décision fut prise en collaboration avec la classe, le Chef de village, les hommes et l'Imam. Lorsque les trois villages les plus proches de. Médina Chérif eurent vent de cette décision, eux aussi décidèrent rapidement de mettre un terme à la pratique, étant donné leurs liens de parenté et leur collaboration dans toutes les activités de la vie quotidienne. Tostan décida d'organiser une réunion pour ces quatre villages et constata que les 10 autres villages qui avaient participé au programme se réunirent aussitôt pour discuter du sujet et demandèrent à prendre part à la réunion. Bien qu'ils n'eussent pas suivi les classes d'éducation, quatre autres villages des environs souhaitaient aussi participer. Les membres de la classe s'étaient rendus dans leurs villages et les avaient informés de la décision, ils leur avaient expliqué comment ils en étaient arrivés là, ce qui avait motivé leur volonté de prendre part au mouvement.

La grande réunion se tint du $1^{\text {er }}$ au 2 juin à Médina Chérif et trois représentants de chaque village y participèrent, y compris le Chef de village ainsi que 2 représentantes des femmes. Les chefs religieux locaux furent aussi invités et parlèrent avec une grande conviction. La femme du Chef de village, Talata Baldé était décédée la semaine précédente et ce dernier nous dit combien elle soutenait la décision des femmes de mettre un terme à cette pratique. «Le nom de ma femme est Talata (qui signifie mardi)», dit le chef, «Elle naquit un mardi, décéda un mardi et cette importante réunion se tient aujourd'hui mardi ! Elle aurait été tellement fière de notre village si elle avait été là ?» Pour cette raison, la réunion fut dédiée à sa mémoire et fut appelée la «Rencontre Talata Baldé de Médina Chérif».

Fatou Lala Baldé, la jeune Présidente du Groupement de Promotion Féminine de Médina Chérif, une femme très intelligente, forte et influente, raconta lors de la réunion l'expérience pathétique de sa propre fille. Cette dernière avait fait une hémorragie lors de la cérémonie d'excision avec 10 autres fillettes à l'âge de quatre ans : 
«Regardez-la maintenant,», dit-elle alors qu'elle 1'appelait, «Elle a neuf ans mais semble en avoir quatre. Elle n'a plus été la même depuis. Imaginez une si jeune enfant avec de tels problèmes de santé. Je me sens tellement fautive. A l'époque, je pensais que c'était les mauvais esprits qui avaient causé l'hémorragie, maintenant je sais pourquoi.» Lala expliqua que les participants à la classe s'étaient rendu chez le Chef de village et l'Imam pour leur parler aussitôt après la fin de la séance sur l'excision. «Ce jour là, nous nous sommes tous mis à pleurer.» dit-elle.

Dada Boiro, une femme du groupe ethnique mandingue, qui avait excisé dans plusieurs villages des environs dit : «J'ai entendu certaines exciseuses demander qu'on initie des projets pour elles ou qu'on leur donne de l'argent pour qu'elles arrêtent cette pratique. Je ne veux pas de cet argent, je demande le pardon des populations pour avoir causé tant de mal aux filles et aux femmes. Dorénavant, nous serons comme toutes les autres femmes du village qui doivent conjuguer leurs efforts pour créer des projets générateurs de revenus.»

«Nous devons être honnêtes à ce sujet,» dit une autre exciseuse, «Nous avons vu des filles mourir à cause de cette pratique. A l'époque, nous pensions que les mauvais esprits étaient la cause de ces décès. Aujourd'hui nous en avons appris la cause réelle, arrêtons donc.»

Sékou Baldé, éducateur pour la santé, représentant le Ministère de la Santé dans le Département de Kolda, parla des problèmes qu'il rencontrait tous les jours et qui étaient liés à la pratique de l'excision. Dans une interview accordée plus tard, M. Baldé cita une étude effectuée dans le Département de Kolda et qui révèle que $88 \%$ des femmes du département pratiquent 1'excision et que $79 \%$ d'entre elles ont eu des problèmes.

Thiekoto Baldé, le Chef de village et Thierno Ibrahima Bah, le très respecté chef religieux de Médina Chérif, parlèrent longuement de la nécessité de mettre un terme à la pratique de l'excision étant donné les risques de santé qu'elle induit.

Les représentants des villageois se réunirent dans l'après-midi pour discuter de la déclaration qu'ils allaient rédiger pour confirmer publiquement leur engagement de mettre un terme à la pratique des Mutilations Génitales Féminines dans 18 villages. Cette déclaration fut lue le 2 juin 1998 lors d'une cérémonie où les populations chantèrent et dansèrent. 


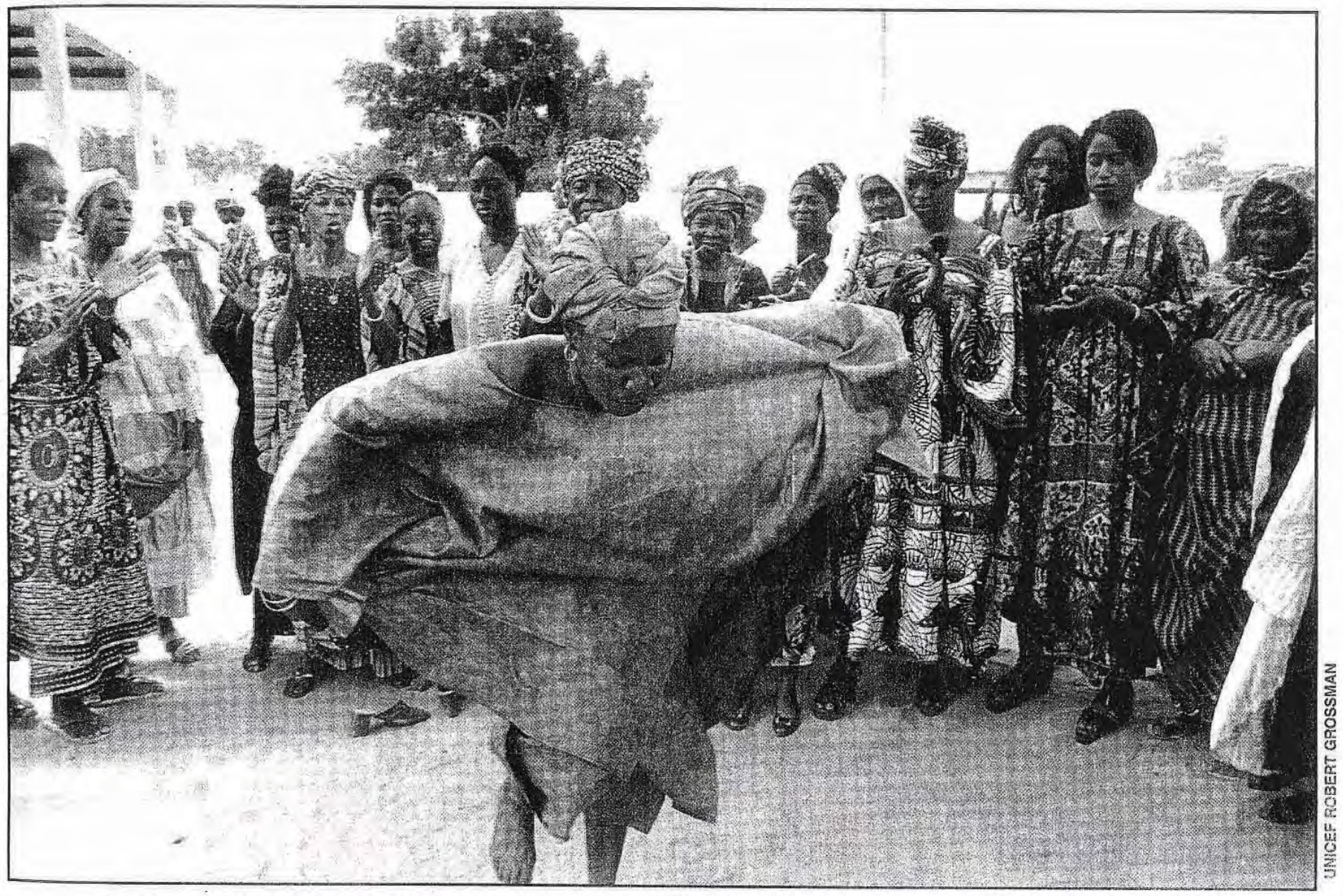

Les Femmes de Malicounda célèbrent leur bonne nouvelle : Pour l'avenir, une meilleure santé de lenvs filles 
Nous renonçons à la pratique de l'excision, cependant, nous tenons à réaffirimer solennellement et fortement notre attachement à la perpétuation de toutes nos valeurs positives, notre attachement à l'éducation de nos filles qui devra passer par la mise en valeur d'un programme d'éducation à leur intention afin qu'elles puissent à leur tour, respecter et faire valoir les droits de leurs futurs enfants.

Nous savons que notre appel sera entendu par le Gouvernement de notre pays et plus particulièrement par le Ministère de la Femme, de l'Enfant et de la Famille, dont l'engagement pour la promotion de la Femme n'est plus à démontrer et nos partenaires au développement à l'endroit desquels nous exprimons notre profonde gratitude.

Nous remercions tout particulièrement TOSTAN, l'UNICEF et AJWS, mais également tous les participants et tous ceux qui ont bien voulu partager avec nous ces moments si importants de notre vie de citoyennes engagées dans ce combat qui a pour ambition d'assurer un mieux-être à nos enfants.

\section{LES SERMENTS PUBLICS FONT UNE DIFFERENCE}

Plusieurs autres articles furent rédigés dans la presse écrite sénégalaise et la Déclaration de Médina Chérif fut diffusée à la radio et à la télévision. Le public Sénégalais devenait maintenant de plus en plus conscient qu'un formidable mouvement à la base pour l'abandon de l'excision était né dans leur pays. Un traditionaliste mandingue de renommée, M. Doudou Camara, qui initialement en voulait beaucoup à Molly Melching pour son implication dans la lutte pour «l'éradication de traditions mandingues séculaires», commença à changer d'attitude et fit savoir à Molly que la déclaration des femmes de Kolda l'avait touché. Il commençait à comprendre que le mouvement allait au-delà de l'éradication des traditions.

Un al pulaar, chef de service dans un bureau à Dakar, remercia Molly pour le travail que Tostan avait accompli en éduquant les membres de son groupe ethnique. II expliqua qu'il était horrifié par toutes les souffrances que son épouse endurait à cause de cette pratique. «Pour notre nuit de noces, j'étais dans l'incapacité de consommer le mariage tellement l'orifice était minuscule. Une semaine plus tard, la mère de mon épouse est venue avec une exciseuse qui avec une lame de rasoir, a élargi l'orifice pour que nous puissions avoir des relations sexuelles. Ma femme souffrait atrocement et me dit que si elle avait su que c'était cela le mariage, elle n'aurait jamais accepté. Cette tradition est si injuste que je m'étais juré de ne jamais faire subir ce supplice à mes filles. Cependant, un jour pendant que j'étais au travail, ma grand-tante paternelle vint chez moi avec une exciseuse. A mon retour du travail ce jour-là, je sentis que quelque chose de terrible était arrivé. Mes filles ne vinrent pas m'accueillir comme elles le faisaient d'habitude. Dans la maison, le silence n'était entrecoupé que de sanglots : mes deux filles avaient été excisées à mon insu. J'étais tellement furieux que je menaçais ma grand-tante de l'amener à la police. «Vas-y.» cria-t-elle «Je préfère aller à la police plutôt que de voir tes filles non excisées! Tu me remercieras au moment de leur mariage.»

«Vous voyez donc !» dit-il à Molly, «Vous êtes en train de m'aider en montrant à ma grand-tante que ce ne sont pas seulement les intellectuels (à qui l'on 
impute le rejet des traditions) qui s'érigent contre ces souffrances inutiles - mais aussi des milliers de villageois parmi les plus grands défenseurs de nos traditions. Elle les écoutera! »

Demba Diawara continua de rendre visite aux villages Bambara d'août à novembre 1998. «Il me rendit dans un village et trouva tout le monde à la réunion, ils lui dirent «Nous vous attendions ! Nous n'aurions jamais pu initier ces réunions seuls. Nous avons eu connaissance de vos serments publics pour l'abolition de l'excision et nous souhaitons nous joindre aux autres villages bambaras qui ne faisaient pas partie de la déclaration et mettre, nous aussi, un terme à cette pratique.»

Neuf villages visités par Demba Diawara dans la région de Thiés ont demandé qu'on organise une rencontre dans un proche avenir pour rendre publique leur déclaration d'abandon de l'excision : Ndiassane, Daaf, Njajaan, Tawa, Cawon Mbambara, Baaliga, Puut Mbambara et Toucouleur, Mbambara Karamoko, Mbambara Chérif, Xeramakono et Keur Issa Mbambara. Serigne E1 Hadj Bouna Kounta, grand chef religieux et vénéré par le groupe ethnique bambara et qui réside à Ndiassane a assuré Demba Diawara de son soutien personnel dans cette lutte.

A la réunion qu'a tenue Molly avec les villageois de Samba Diallo le 23 décembre, des représentants de Fimela, la ville voisine étaient présents. «Nous avons entendu dire que Demba Diawara et Tostan seraient ici aujourd'hui,» dit un jeune homme bambara, « et nous avons voulu savoir pourquoi nous n'avons pas fait partie de la Déclaration de Diabougou. Les Bambaras qui résident à Fimela souhaitent aussi mettre un terme à l'excision, et nous avons été frustrés de n'avoir pas été invité pour prendre part à la Déclaration de Diabougou.» Demba Diawara lui donna l'assurance . qu'ils seraient cette fois-ci invités à la prochaine rencontre qui devrait se tenir à Baaliga durant le mois de juin 1999.

Ces villages ont tous demandé à bénéficier du programme d'éducation de base de Tostan pour que leurs communautés puissent bénéficier des informations et des connaissances en matière de santé, d'hygiène, de droits de l'homme, de processus de résolution de problèmes, ainsi que des compétences en gestion.

\section{LA REGION DE ST LOUIS, UNE ZONE CONSERVATRICE REMET EN CAUSE LA PRATIQUE DE L'EXCISION}

Depuis 1992, Tostan avait mis en oeuvre le programme d'éducation de base dans 70 villages des départements de Podor et de Matam. Les programmes pour adultes et pour adolescents avaient eu beaucoup de succès dans la zone et avaient été très appréciés par les villageois.

Le 27 juillet 1998, Tostan se rendit dans la région de St Louis pour effectuer une visite dans les classes pour adolescents et pour adultes, mais aussi pour discuter de la question de l'excision avec les formateurs et les facilitateurs afin de recueillir leurs impressions sur la possibilité, comme cela s'est fait dans les autres régions du pays, de mener des activités sur l'excision avec le groupe ethnique pulaar. Dans ses recherches sur l'excision, Molly avait appris à sa grande surprise, que beaucoup de Pulaars pratiquaient l'infibulation de la même façon que les Bambaras, en ne recousant pas mais en recollant les lèvres après l'opération et en laissant le sang sécher. 
Sur ce voyage, Molly écrit ce qui suit :

Tous les formateurs pulaar et plusieurs facilitateurs m'attendaient la nuit de mon arrivée à Bokidjawe, le 27 juillet. Lors de nos discussions, ils me firent comprendre que je devais faire très attention à la manière dont $\mathrm{j}$ 'aborderais le problème de l'excision au Fouta. Ils avaient l'impression que les populations de cette zone étaient plus conservatrices que celles des régions de Thiés et de Kolda. «Ne vous en faites pas,» leur répondis-je, «Je ne suis pas venue les persuader de rejoindre le mouvement. Je suis venue me rendre compte de l'avancée de notre programme, parler aux villageois et recueillir leurs impressions sur les Ecoles Communautaires de Base que nous sommes en train d'implanter. Je souhaiterais aussi avoir leurs impressions sur les Modules d'Education Continue sur la Santé et la Démocratie.»

Les formateurs et facilitateurs étaient visiblement soulagés et expliquèrent que l'abandon de l'excision dans la région de St Louis serait un processus très long. Ils étaient eux-mêmes très peu sûrs d'avoir une opinion sur la question et je me rendis compte qu'ils avaient peur ne serait-ce que d'en parler. Je pouvais lire l'inquiétude et l'anxiété dans leur regard.

Le lendemain, nous rendîmes visite aux villages de Mow et Keddele, mais malheureusement la route avait été rendue inaccessible par une crue saisonnière et notre véhicule ne put passer. Nous fûmes donc obligés de prendre une pirogue pour traverser le fleuve et dûmes louer une charrette car il n'y avait pas de transport public sur l'autre rive. Le trajet jusqu'à Keddele dura une heure et demie sous un soleil de plomb. Au loin, le ciel était menaçant.

Lorsque les habitants du village me virent drapée dans mon grand boubou accompagnée des six formateurs et faciliateurs, sur une charrette, ils n'en revinrent pas. L'accueil fut chaleureux, à la mesure des efforts que nous avions fournis pour venir les voir.

Après nous être restaurés et reposés sur les nattes qu'on avait étendues à notre intention sous les vérandas en banco, les membres du Comité de Gestion demandèrent à toute la population de se réunir. Les jeunes femmes étaient assises sur la gauche, les hommes sur la droite et les femmes âgées sous l'arbre plus loin devant moi. On m'avait octroyé un siège d'honneur sur une jolie couverture étalée sur un matelas sous la véranda. Nous parlâmes de choses et d'autres : du programme pour adolescents, des changements qui s'étaient opérés dans le village, des espoirs des femmes. Soudain, une jeune femme prit hardiment la parole : «Oui» dit-elle, «Nous avons même discuté du problème de la tradition, ce qui était impensable auparavant. Nous en connaissons maintenant tous les dangers et savons qu'elle est à l'origine de certains problèmes de santé auxquels nous sommes confrontés. En fait, nous les femmes, nous souhaitons mettre un terme à l'excision, mais malheureusement nos époux, les hommes et les chefs religieux s'y opposent.» Le silence était total. Il était évident que les villageois étaient surpris par le fait que cette femme ait osé parler de la tradition lors d'une réunion publique. J'étais moi-même assez surprise, mais je préférais ne pas le montrer. «Enfin,» leur répondis-je, «Tostan n'a jamais essayé de dire aux gens de mettre un terme à leur tradition. Les femmes de Malicounda Bambara ont pris leur décision de leur propre chef et nous les avons soutenues dans la mesure de nos possibilités. Mais je crois que la décision doit venir de vous avec le soutien de la communauté,» Je me tournais ensuite vers les hommes et leur demandais : «Et vous, qu'en pensez-vous ? Pensez-vous que les 
femmes doivent continuer à pratiquer cette tradition si elle est néfaste pour la santé de vos filles et de vos femmes?»

Le Chef de village me répondit : «Les femmes ne nous avaient jamais demandé notre opinion auparavant. Il est évident que nous ne nous opposerons pas à l'abolition d'une pratique néfaste sur leur santé.» Les femmes n'en revenaient pas. D'autres hommes prirent la parole et affirment soutenir l'abandon de l'excision. Les formateurs et facilitateurs de Tostan s'exprimèrent pour la première fois et firent connaître leur opinion sur la question. Parce que les femmes elles-mêmes avaient fait connaître leur opposition, parce que les hommes du village semblaient ouverts au changement et prêts à soutenir les femmes, les formateurs et les facilitateurs pouvaient enfin donner leurs opinions avec conviction!

Le retour en charrette fut long, et nous avions juste eu le temps d'atteindre le fleuve, de traverser en pirogue et de regagner la grande route avant que le ciel qui menaçait tout l'après-midi ne déversât sur nous une forte pluie alors que nous nous dirigions sains et saufs vers Ourossogui. Si la pluie était tombée plus tôt, nous nous serions embourbés dans le champ qui mène à la grande route, ou alors aurions pu être emportés par le courant du fleuve ou laissés en rade sur l'autre rive. «Ceci est un signe,» dit un des facilitateurs de Tostan. «Le fait que 1'on ai été épargnés du déluge doit être un signe du Bon Dieu pour que nous continuions la lutte pour l'abandon de l'excision dans le Fouta!» Tous les autres montrèrent leur assentiment et j'y adhérais moi aussi.

«Nous les femmes nous souhaitons voir abolir cette tradition mais les hommes et les chefs religieux s'y opposeront. » fut le même message qui nous fut répété dans les autres villages que nous visitâmes par la suite. Il devint évident que cette idée était solidement ancrée dans leurs esprits mais n'était pas systématiquement prouvée. En général, les hommes ne discutent pas du tout de ce sujet avec les femmes Par conséquent pour celles-ci, les hommes et les chefs religieux attendaient d'elles qu'elles soient excisées.

Nous étions maintenant convaincus que l'opinion des chefs religieux serait primordiale pour l'abandon de l'excision dans le Fouta. C'est pourquoi je décidais de rendre visite, le 30 juillet 1998, à Sergine Amadou Bah, l'un des chefs religieux les plus respectés de la région. La veille, je n'ai pu fermer l'oeil de la nuit car si le marabout refusait de soutenir le désir des femmes d'abandonner l'excision, le mouvement allait au devant de moments difficiles.

Nous arrivâmes chez le marabout à 8 h30 et traversâmes un dédale de pièces jusqu'à sa chambre. J'étais accompagnée de plusieurs formateurs et facilitateurs de Tostan et nous parlâmes de plusieurs sujets liés au programme, et aussi de l'épouse du marabout que je connaissais bien. J'étais assez nerveuse quand je me jetais finalement à l'eau et dis au marabout la raison de notre visite. Je lui expliquais que notre travail consistait à contribuer à améliorer la santé des filles et des femmes et lui racontais les histoires que j'avais entendu chez les travailleurs de la santé de la région de St Louis qui avaient été témoins de tant d'hémorragies et de perte de vies humaines dues à l'excision. Je lui fis quand même comprendre que je respectais profondément son opinion et que j'avais besoin de connaître ses idées sur la question avant de continuer le travail que nous avions initié pour l'abandon de la tradition. Tout le monde se tait. Le fils du marabout nous dit que son père était dans 1 'incapacité de nous répondre séance tenante 
et qu'il aurait besoin de réfléchir. Personne ne l'avait jamais interpellé là-dessus et c'était un sujet délicat et sensible. Il y eut un nouveau silence. Puis la voix profonde du marabout résonna dans la pièce : «Non. Je peux répondre à la question. Je peux même y répondre aujourd'hui. Je connais votre organisation et l'UNICEF depuis des années, et j'ai vu ce que vous avez accompli. Lutter pour la santé des enfants et des femmes est une noble cause. Vous devez continuer de mener cette bataille et ne pas vous décourager... car vous gagnerez. Dieu est de votre côté. J'enverrai mon propre fils travailler à vos côtés sur la question et je me mettrai à votre disposition en cas de besoin.» Le marabout avait non seulement choisi de soutenir les femmes voulant abondonner l'excision, mais en plus il l'avait fait avec tellement de conviction et dans le seul but de les aider que je ne pouvais plus retenir mes larmes.

Le même jour nous nous rendîmes au village de Golléré. Les femmes me firent part de leurs efforts pour influencer les autres à mettre un terme à l'excision en jouant une pièce de théâtre devant les villageois. «Les gens avaient beaucoup apprécié notre pièce sur les droits de l'homme,». se rappela une femme, «mais pour la pièce sur l'excision, nous avons été huées. Néanmoins, nous continuerons d'essayer de changer les mentalités sur ce sujet.» Je demandais si vingt femmes pouvaient peser sur la balance dans une population de 3000 habitants. Une femme du nom de Bani Bousso me répondit : «Lorsque deux femmes seulement sont déterminées, c'est déjà important, lorsque vingt femmes sont déterminées, il y a beaucoup d'espoir.» Lorsque je fis part du soutien que nous venions de recevoir du marabout de Tchikkité, les femmes étaient très enjouées, car elles avaient maintenant des arguments nouveaux et plus pertinents à utiliser dans la lutte pour l'amélioration de leur santé. Elles travaillaient aussi sur la question des mariages précoces dans le village, un problème qui, pour elles, était tout aussi important.

En octobre 1998, après le voyage de Molly, Tostan et l'UNICEF appuyèrent un groupe pour la mobilisation sociale qui se rendit dans 15 villages pour animer des discussions publiques parmi les communautés Toucouleurs au sein desquelles Tostan avait exécuté les Modules 7 et 8. Lala Baldé, Présidente du Groupement de Promotion Féminine de Médina Chérif, se porta volontaire pour accompagner des formateurs et des facilitateurs de Tostan, les travailleurs locaux de la santé et le fils du marabout de Tchikkité. Le soutien du marabout fut une fois encore décisif et fut ressenti dans la manière dont le groupe fut reçu au sein de ces communautés

Les travailleurs de la santé firent état des nombreux problèmes qu'ils rencontrent dus à l'excision. Un infirmier dit avoir enregistré le décès de cinq filles entre 1997 et 1998 qui ont fait des hémorragies ou des infections après avoir subi l'opération. Plusieurs villageois exprimèrent leur intérêt pour l'organisation d'une rencontre à l'intention des villages où l'on connaissait les conséquences néfastes de l'excision et qui avaient l'intention de mettre un terme à la pratique à travers une action commune. Tous les villages qui avaient bénéficié du programme de Tostan seraient invités ensemble à participer et à discuter du programme. Une fois encore, il n'y aurait pas de pression pour faire une déclaration publique si les villageois ne sont pas prêts. Cependant, plusieurs villages ont exprimé leur désir de mettre un terme à cette pratique lorsque cette assemblée aura lieu. 


\section{LES SERMENTS, SERONTILS RESPECTÉS?}

Lors du serment de Malicounda Bambara, une journaliste de la presse écrite avait demandé si les femmes se conformaient à leur décision de mettre un terme à l'excision. Tout le monde fut étonné par la question. «Pourquoi faire une déclaration si nous n'avons pas l'intention de nous y conformer ?» répondirent-elles.

«C'est une question d'honneur !» dit une femme âgée à Mampatim dạns la région de Kolda. «Et pourquoi reviendrions-nous sur notre décision maintenant? Nos ancêtres passaient leur temps à boire du vin de palme et il est aujourd'hui impensable de consommer de l'alcool dans ce village ! Le changement n'est pas aussi difficile surtout s'il y va de notre intérêt !».

Dans les villages qui avaient participé à la Déclaration de Diabougou, un comité avait été élu pour assurer le suivi de l'application des décisions de la rencontre, en s'assurant qu'aucun village participant n'organiserait de cérémonies d'excision. Demba Diawara expliqua que si une personne arrivait impunément à pratiquer l'excision sur son enfant, elle créerait un précédent dans le mouvement pour l'abandon de cette pratique. «Nous serions dans l'obligation d'aller en justice pour l'exemple,» dit-il. «Si nous n'agissons pas, les gens penseraient que la décision n'était pas sérieuse et en profiteraient pour recommencer la pratique par peur de ne pas trouver d'époux pour leurs filles.»

A Médina Chérif, les hommes dirent qu'ils surveillaient les exciseuses de leurs localités pour s'assurer qu'elles ne pratiquaient plus leurs activités traditionnelles.» Nous pouvons vous assurer qu'elles ont arrêté depuis la déclaration! «dit l'un dès hommes à l'équipe de Tostan. Les femmes aussi nous parlèrent d'un village qui avait d'abord refusé de prendre part à la Déclaration de Médina Chérif et qui par la suite avait changé d'avis.» Lorsqu'ils organisèrent leur cérémonie d'excision cette année, l'une des fillettes décéda des suites d'une hémorragie,» relata tristement Lala Baldé «exactement comme cela se passe dans la pièce de théâtre que nous avions jouée devant eux pour les inciter à mettre un terme à l'excision. Ills se sont rendu compte que la petite était morte des suites de l'opération et non à cause d'un quelconque mauvais esprit. Tout le village se décida alors à mettre un terme à cette pratique. Personne ne recule, nous avons plutôt de nouveaux adhérents au mouvement.»

Lorsque nous leur demandâmes si elles avaient la nostalgie des chants et des danses des cérémonies d'initiation, une femme âgée nous répondit : «Les chants et les danses font plaisir, mais que signifient-ils lorsque vous tenez dans vos bras le corps sans vie d'un enfant?»

Sur l'ensemble du territoire sénégalais, 31 villages ont officiellement et publiquement décidé de mettre un terme à la pratique de l'excision et ont continué à respecter et à défendre leur décision. En mars 1999, douze autres villages Bambara ont demandé la tenue d'une rencontre afin de déclarer publiquement leur volonté d'abandonner la pratique de l'excision. Plusieurs autres villages à Kolda plannifient leur déclarations. Les serments se poursuivent donc et perdurent. 


\section{LA LOI QUI A ETE VOTEE CONTRE L'EXCISION}

Le 6 janvier 1999, Abdou Fall, député et Président d'un groupe parlementaire à l'Assemblée Nationale Sénégalaise, vint demander conseil à Tostan sur la loi qui était sur le point d'être débattu par l'Assemblée Nationale et portant sur l'excision. Etant donné l'expérience positive que Tostan avait vécue dans les villages qui ont abandonné l'excision, il était très intéressé par l'opinion de l'équipe de Tostan.

La proposition officielle pour la modification de certaines dispositions du code pénal reposent sur le raisonnement suivant pour pénaliser la pratique de l'exicision : «Les Mutilations Génitales Féminines, bien que relevant de pratiques traditionnelles ou coutoumières constituent des atteintes intolérables à l'intégrité physique et psychique et à la santé de nombreuses femmes et petites filles. Ces pratiques n'ont plus leur place dans le nouveau dynamisme socioculturel du Sénégal. Leur répression pénale telle que prévue par le nouvel article 299 du code pénal s'inscrit résolument dans cette logique et dans le respect des conventions internationales ratifiées par le Sénégal, notamment la Convention de 1979 sur l'Elimination de Toutes les Formes de Discriminations à l'Egard des Femmes et la Convention de 1990 relative aux Droits de 1'Enfant.»

La loi en instance stipule :

«Sera puni d'un emprisonnement de six mois à cinq ans quiconque aura porté ou tenté de porter atteinte à l'intégrité de l'organe génital d'une personne de sexe féminin par ablation totale ou partielle d'un ou plusieurs de ses éléments, par infibulation, par insensibilisation ou par tout autre moyen.

La peine maximum sera appliquée lorsque ces mutilations sexuelles auront été réalisées ou favorisées par une personne relevant du corps médical ou paramédical. Lorsqu'elles auront entraîné la mort, la peine des travaux forcés à perpétuité sera toujours prononcée.

Sera punie des mêmes peines toute personne qui aura, par des dons, promesses, influences, menaces, intimidations, abus d'autorité ou de pouvoir, provoqué ces mutilations sexuelles ou donné les instructions pour les commettre.»

Article 299 bis

La loi devait être votée le 13 janvier 1999. Tostan suggéra à M. Fall de rendre visite pendant le week-end aux communautés qui avaient décidé de mettre un terme à l'excision pour discuter directement de la question avec les personnes concernées. Il semblait aussi approprié d'inviter une délégation de ces villageois pour discuter avec un nombre assez important de députés avant le vote de la loi le mercredi 13 janvier. L'UNICEF reçut une lettre du Président de la Commission de la Santé et des Affaires Sociales de 1'Assemblée Nationale, demandant de les appuyer en acheminant les dits représentants à Dakar, le 12 janvier 1999, pour une telle rencontre.

Lors de sa visite des villages de Malicounda Bambara, Nguerigne Bambara et Diabougou, M. Fall fut surpris de comprendre que les problèmes liés à l'excision étaient beaucoup plus sérieux qu'il ne l'avait imaginé. Durant les discussions avec les femmes, les hommes et les enfants, il découvrit que la plupart des souffrances des femmes avaient été tues aux hommes. Aujourd'hui que la vérité faisait surface, le tableau n'était pas beau à voir. Elles exprimèrent leurs souffrances, leurs problèmes à 
l'accouchement, les hémorragies et les pertes en vies humaines. Les villageois néanmoins précisèrent que seul le programme d'éducation et les débats publics sur la question les avaient poussés à mettre un terme à cette pratique.

Mí. Fall se rendit compte qu'une stratégie d'éducation et de mobilisation sociale était nécessaire avant l'application de la loi pour éviter un conflit sérieux sur la question, dans le pays. Un Bambara de Diabougou lui expliqua : «Nous, Bambara nous sommes têtus. Lorsque nous apprenons une chose et décidons que c'est une bonne chose, nous nous y tenons et nous nous y conformons toute notre vie. Mais lorsque quelque chose de l'extérieur veut nous être imposé, nous prenons nos armes et nous battons jusqu'au bout sans hésiter.» Après son voyage, M. Fall décida de voter pour la loi, puisque l'Etat doit protéger la santé des filles et des femmes, mais se dit qu'il serait important de mettre l'accent, durant le débat, sur l'importance de l'éducation et de la mobilisation sociale. Ne serait-il d'ailleurs pas préférable de retarder l'application de la loi pour permettre la mise en place de stratégies de mobilisation sociale et d'éducation à l'intention des villageois?

Le 12 janvier 1999, une délégation de 13 villageois comprenant des femmes, des hommes et une fillette de Malicounda Bambara, Keur Simbara, Nguerigne Bambara et Médina Chérif rencontrèrent des membres de l'Assemblée Nationale, de différents partis politiques. Mata Sy Diallo, Vice-Présidente du Collectif des Femmes Parlementaires et Présidente de la Commission de la Santé et des Affaires Sociales présidait la réunion. D'autres organisations féminines qui pendant des années ont milité pour le vote d'une loi pour l'abandon de la pratique de l'excision étaient présentes.

Le message que les villageois firent passer aux députés fut clair :

- L'excision est une pratique dangereuse pour la santé qui a causé assez de souffrances parmi les femmes et les enfants

- Les femmes ont toujours caché aux hommes, parmi lesquels beaucoup ne sont toujours pas conscients des dangers de la pratique de l'excision sur la santé, les souffrances qu'elles ont endurées.

- L'Islam ne fait pas de l'excision une obligation

- Une tradition qui porte atteinte à la santé et qui peut entraîner la mort n'est pas une bonne tradition

- Toutes les populations doivent bannir la pratique de l'excision

- Nous avons été capables de renoncer à la tradition grâce aux connaissances acquises à travers le programme d'éducation de base de Tostan

Les villageois exprimèrent des inquiétudes pour les autres membres de leur groupe ethnique qui n'avaient pas encore bénéficié de classes d'éducation de base et qui n'avaient donc aucune idée des risques que comportait la pratique de l'excision. A leur avis, il était important que le gouvernement adopte une position ferme à l'égard de cette pratique en votant cette loi, tout en demandant à l'unanimité un délai pour l'application de la loi.

Durant la réunion technique qui suivit la rencontre, les membres de la Commission de la Santé et des Affaires Sociales firent référence aux opinions des villageois et décidèrent de demander un amendement à la loi pour prévoir un délai dans son application.

Le 13 juillet à 16 h30, débuta le débat sur l'amendement à l'Assemblée Nationale. Mata Sy Diallo du Collectif des Femmes Parlementaires introduisit le débat 
et parla des dangers liés à la pratique de l'excision. Elle remercia les villageois qui avaient témoigné la veille devant son collectif et parla de leur désir de voir entrer en vigueur des mesures d'accompagnement pour assurer une éducation efficace avant l'application de la loi. Beaucoup d'autres députés parlèrent des dangers de l'excision et de la nécessité de mettre un terme à cette tradition. Ils se faisaient tout de même du souci sur la réaction des villageois qui n'avaient pas bénéficié du programme d'éducation. Plusieurs citèrent Malicounda Bambara comme un exemple de réussite qui pouvait être généralisé afin d'éclairer les populations sur la nécessité de mettre un terme à la tradition. Quelques députés dirent ne pouvoir voter pour la loi parce qu'ils ne voulaient pas faire de leurs parents des criminels pour avoir respecté leur tradition et leur religion. Le même jour, un chef religieux influent avait fait distribuer un tract sur la pratique de l'excision disant que cette dernière était recommandée par l'Islam. Plusieurs députés furent perturbés par ce document et posèrent des questions sur la relation entre l'excision et la religion. Malheureusement, les déclarations d'autres chefs religieux influents expliquant que l'excision n'est pas une obligation de l'Islam, n'avaient pas été distribuées auparavant ni aux députés ni à la presse.

Il était assez évident pendant la séance à l'Assemblée que toutes les femmes, la plupart appartenant à des groupes ethniques où l'on pratique l'excision, étaient les plus grands défenseurs de la loi et critiquaient sévèrement la pratique, alors que les hommes étaient plus réticents.

Le Ministre de la Justice refusa d'accorder un délai pour l'application de la loi, déclarant qu'il était inutile de voter une loi qui ne serait pas applicable immédiatement. Le 13 janvier 1999 à 23:20, l'Assemblée Nationale vota la loi pour l'élimination totale de la pratique de l'excision au Sénégal, telle qu'elle avait été soumise.

\section{NOTE DE TOSTAN}

Depuis la parution de la version anglaise de ce livre en janvier 1999, cent quarante trois autres villages ont rejoint les trente et un villages pionners ayant organisé les premières déclarations de Malicounda Bambara, Diabougou et Médina Cherif. Il s'agit des communautés bambaras de Baliga dans la région de Thiès, peuhls dé Bagadadji dans la région de Kolda, et sérrères niominka de Niodior dans les îles du Sine Saloum. D'autres déclarations sont aussi prévues dans le courant de l'année 2000.

Cet élan national qui constitue un mouvement historique en Afrique pour l'abandon de l'excision, traduit une nette prise de conscience des communautés de leur capacité d'apporter elles-mêmes des changements profonds et porteurs d'espoir pour l'avenir. 


\section{RESUME DES EVENEMENTS}

\begin{tabular}{|c|c|}
\hline Janvier 1995 & $\begin{array}{l}\text { Début du programme d'éducation non formelle de } \\
\text { Tostan à Malicounda Bambara en collaboration avec } \\
\text { l'UNICEF et le Gouvernement du Sénégal }\end{array}$ \\
\hline Juillet-août 1996 & $\begin{array}{l}\text { Tostan Module } 7 \text { - Module sur la Santé de la Femme } \\
\text { exécuté à Malicounda Bambara et financé par AJWS }\end{array}$ \\
\hline Septembre 1996 & $\begin{array}{l}\text { Les femmes de la classe de Malicounda Bambara décident } \\
\text { de mettre un terme à la pratique de l'excision }\end{array}$ \\
\hline Octobre 96 - mai 97 & $\begin{array}{l}\text { Les femmes de Malicounda mènent une campagne } \\
\text { dans le village avec leurs époux, les chefs religieux, les } \\
\text { autres femmes et le Chef de village pour mettre un } \\
\text { terme à la pratique de l'excision }\end{array}$ \\
\hline Juin 1997 & $\begin{array}{l}\text { Le coordonnateur de Tostan évalue le programme et } \\
\text { atteste qu'aucune cérémonie d'excision n'a eu lieu à } \\
\text { Malicounda Bambara cette année }\end{array}$ \\
\hline Juillet 1997 & $\begin{array}{l}\text { Tostan rende visite au village et interview les femmes, } \\
\text { l'Imam et le Chef de village }\end{array}$ \\
\hline 31 Juillet 1997 & $\begin{array}{l}20 \text { journalistes sénégalais rendent visite à Malicounda } \\
\text { Bambara où les femmes déclarent avoir mis un terme à } \\
\text { la pratique de l'excision }\end{array}$ \\
\hline Août 1997 & $\begin{array}{l}\text { Un débat national sur l'excision s'installent dans les } \\
\text { journaux, à la radio et à la télévision }\end{array}$ \\
\hline Août 1997 & $\begin{array}{l}\text { Les femmes de Malicounda Bambara rendent visite au } \\
\text { village de Keur Simbara pour discuter de l'abandon de } \\
\text { la pratique de l'excision }\end{array}$ \\
\hline Septembre 1997 & $\begin{array}{l}\text { Les hommes de Malicounda Bambara ne sont pas à } \\
\text { l'aise avec la publicité faite autour des femmes concernant } \\
\text { leur décision }\end{array}$ \\
\hline Septembre 1997 & $\begin{array}{l}\text { Le journaliste Roland-Pierre Paringaux du journal Le } \\
\text { Monde passe une semaine dans les villages avec Tostan } \\
\text { pour effectuer des recherches sur l'événement }\end{array}$ \\
\hline 14. Octobre 1997 & $\begin{array}{l}\text { Un article d'une page apparaît dans le journal Le } \\
\text { Monde sur le serment des Femmes de Malicounda } \\
\text { Bambara }\end{array}$ \\
\hline 6 Novembre 1997 & $\begin{array}{l}\text { Les femmes de Nguerigne Bambara font une déclaration } \\
\text { publique attestant de leur ferme volonté de mettre un } \\
\text { terme à l'excision }\end{array}$ \\
\hline 22 Novembre 1997 & $\begin{array}{l}\text { Abdou Diouf, Président de la République du Sénégal, } \\
\text { fait état de sa position contre la pratique de l'excision } \\
\text { lors de la réunion de la Ligue Internationale des Droits } \\
\text { de l'Homme en soutien aux femmes de Malicounda } \\
\text { Bambara }\end{array}$ \\
\hline
\end{tabular}




\begin{tabular}{|c|c|}
\hline $\begin{array}{l}\text { Novembre } \\
\text { Décembre } 1997 \\
\text { Janvier } 1998\end{array}$ & $\begin{array}{l}\text { Cheikh Traoré (facilitateur de Tostan) et Demba } \\
\text { Diawara (participant au programme de Tostan et Imam } \\
\text { de Keur Simbara) rendent visite à } 10 \text { villages près de } \\
\text { Joal pour discuter de leur décision d'abandonner la } \\
\text { pratique de l'excision avec leurs parents }\end{array}$ \\
\hline 3 Février 1998 & $\begin{array}{l}\text { Le Président Abdou Diouf, lors de son Conseil des } \\
\text { Ministres, demande qu'une loi soit votée pour } \\
\text { abandonner la pratique de l'excision au Sénégal }\end{array}$ \\
\hline 14-15 Février 1998 & $\begin{array}{l}11 \text { villages du groupe ethnique Bambara décident de } \\
\text { soutenir Malicounda Bambara et Nguerigne Bambara } \\
\text { dans leur décision de mettre un terme à la pratique de } \\
\text { l'excision. } 50 \text { représentants de } 8.000 \text { villageois rédigent } \\
\text { et annoncent la Déclaration de Diabougou }\end{array}$ \\
\hline Février - Avril 1998 & $\begin{array}{l}14 \text { villages de la région de Kolda étudient le Module } 8 \\
\text { de Tostan sur le Développement du Jeune Enfant com } \\
\text { prenant des séances sur la pratique de l'excision }\end{array}$ \\
\hline Mai 1998 & $\begin{array}{l}\text { Médina Chérif prend la décision commune de mettre } \\
\text { un terme à la pratique de l'excision suivi de } 13 \text { autres } \\
\text { villages avoisinants qui participent au programme de Tostan }\end{array}$ \\
\hline 1-2 Juin 1998 & $\begin{array}{l}4 \text { villages supplémentaires rejoignent le mouvement et } \\
18 \text { villages du Département de Kolda (ou } 88 \% \text { de la } \\
\text { population pratiquent l'excision) déclarent publiquement } \\
\text { avoir décidé de mettre un terme à cette tradition }\end{array}$ \\
\hline Juillet 1998 & $\begin{array}{l}\text { Molly Melching visite la région de St Louis du Sénégal } \\
\text { où Tostan a mis en ouvre le programme dans } 70 \text { villages. } \\
\text { Certains villages expriment le désir de mettre un terme } \\
\text { à la pratique de l'excision. Tostan reçoit le soutien et } \\
\text { les bénédictions du marabout de Tchikkité }\end{array}$ \\
\hline Octobre 1998 & $\begin{array}{l}\text { Une équipe de al pulaars, Lala Baldé de Kolda, le fils } \\
\text { du marabout de Tchikkité et les travailleurs locaux de } \\
\text { la santé visitent } 15 \text { villages dans la Région de St Louis } \\
\text { pour discuter de l'excision }\end{array}$ \\
\hline $\begin{array}{l}\text { Septembre - } \\
\text { Novembre } 1998\end{array}$ & $\begin{array}{l}\text { Demba Diawara rend visite à d'autres villages bambaras } \\
\text { pour discuter de l'abandon de la pratique de l'excision. } \\
\text { Il obtient le soutien d'un chef religieux influant au sein } \\
\text { du groupe ethnique bambara. Douze autres villages } \\
\text { expriment le désir de mettre un terme à la pratique de } \\
\text { l'excision en solidarité avec d'autres villages bambara } \\
\text { dans une déclaration publique. }\end{array}$ \\
\hline Décembre 1998 & $\begin{array}{l}\text { Le Conseil des Ministres approuve une loi pour l'aban } \\
\text { don de la pratique de l'excision. }\end{array}$ \\
\hline 12 Janvier 1999 & $\begin{array}{l}13 \text { membres des communautés bambara, mandingues et } \\
\text { pulaar rencontrent des membres de l'Assemblée } \\
\text { Nationale }\end{array}$ \\
\hline 13 janvier 1999 & $\begin{array}{l}\text { La loi sur l'abandon de la pratique de l'excision est } \\
\text { votée par l'Assemblée Nationale }\end{array}$ \\
\hline
\end{tabular}




\begin{tabular}{|ll|}
\hline 20 juin 1999 & $\begin{array}{l}\text { Déclaration publique de 12 villages pour l'abandon de } \\
\text { l'excision à Baliga, dans la région de Thiès }\end{array}$ \\
\hline $\begin{array}{l}\text { Décembre - } \\
\text { Octobre 1999 }\end{array}$ & $\begin{array}{l}\text { Programme d'Education de Tostan réalisé en } \\
\text { collaboration avec l'OFAD à Bagadadji dans la région } \\
\text { de Kolda (financement CEDPA) }\end{array}$ \\
\hline Août - Septembre 1999 & $\begin{array}{l}\text { Sensibilisation dans les îles du Sine Saloum par les } \\
\text { membres de la classe Tostan - Unicef de Samba Dia, } \\
\end{array}$ \\
\hline Ami Bana Diouf, Yaka Diameye et Cheikh Traoré \\
\hline 28 Novembre 1999 & $\begin{array}{l}\text { Déclaration publique de 105 villages à Bagadadji dans } \\
\text { la région de Kolda }\end{array}$ \\
\hline Déclaration publique de 26 îles dans le Sine Saloum \\
\hline
\end{tabular}




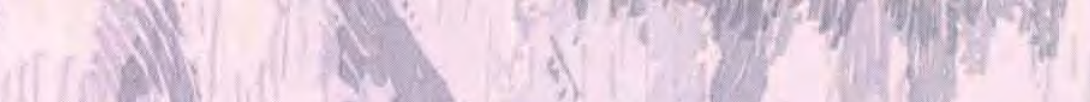 \\ 3ème PARTIE \\ Réflexion sur \\ l'expérience}

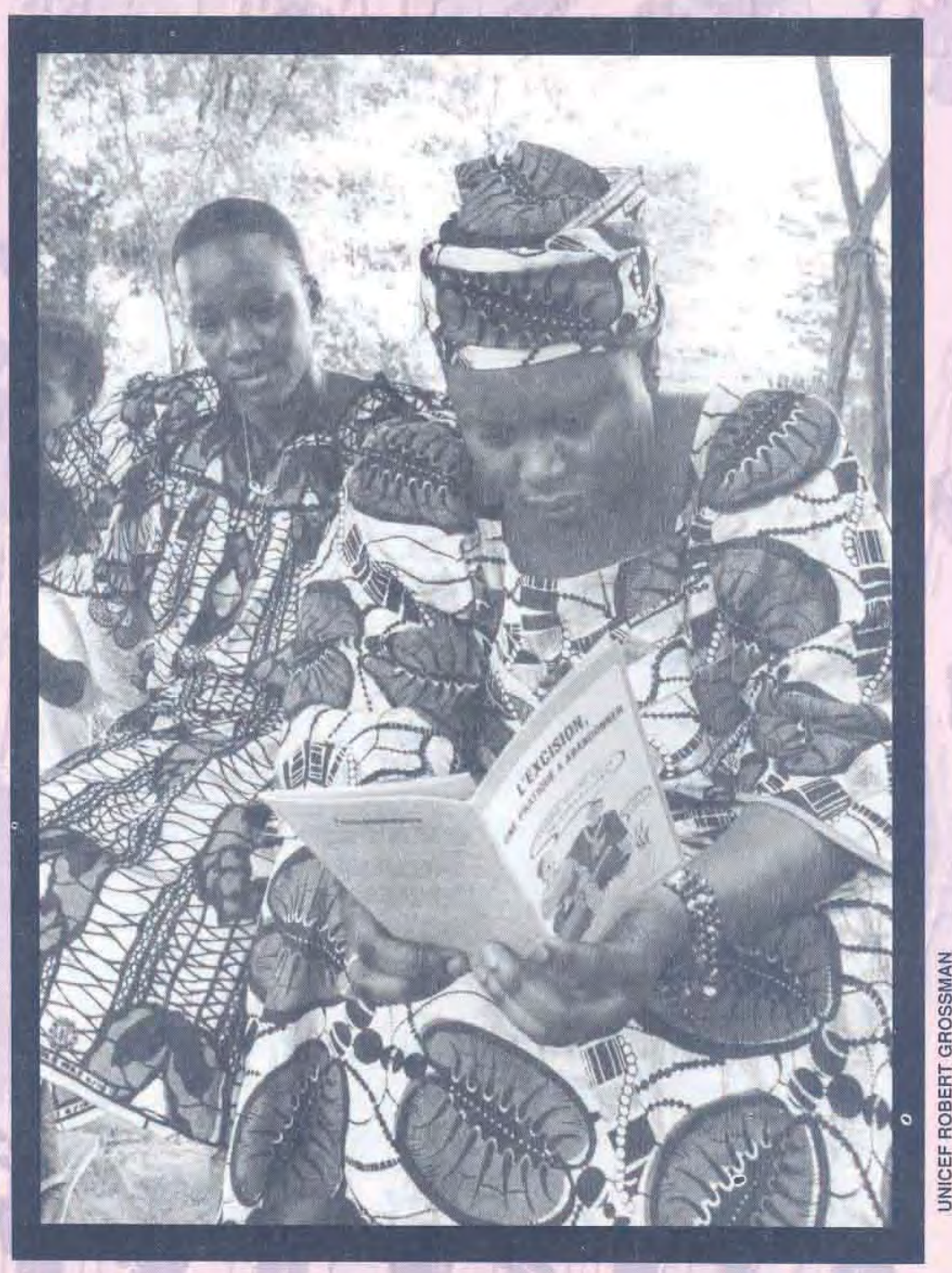

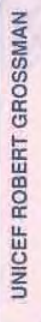


Hygiène: Transmission des Microbes : une notion essentielle

Dans une des activités du Module 2, un bol d'eau auquel le facilitateur ajoute de l'eau de toilette circule dans la classe et chaque femme doit y rincer les mains. Bien que les participantes admettent ne rien voir, elles savent cependant qu'il y a autre chose dans le bol puisqu'elles sentent l'odeur du parfum sur leurs mains. Cette «autre chose» a donc la même propriété que les microbes - elle est invisible. Les femmes font souvent l'analogie apprise lors de cette leçon pour discuter de la façon dont une lame de rasoir utilisée sur plusieurs filles peut transmettre des microbes.

Dans un village Bambara, le chef religieux s'opposait à ce que les femmes mettent un terme à l'excision et déclarait que cette pratique ne pouvaient en aucun cas être la cause des infections, tel que l'insinuaient les travailleurs de la santé. Une femme qui avait participé au programme de Tostan assise près de Molly Melching murmura : «S'il avait étudié le Module 2 il aurait appris que la tradition ne mène pas à l'infection, mais plutôt que c'est la transmission des microbes d'une jeune fille à une autre par l'utilisation d'une même lame non stérilisée qui, elle, peut mener à l'infection !»

La transmission des microbes et le besoin d'hygiène furent développés au Module 3 - diarrhées et vaccinations.

\section{Les compétences en leadership aident à prendre et à défendre d'importantes décisions}

Les séances sur le leadership au Module 5 ont aidé au renforcement des compétences dans ce domaine chez les femmes, et ont donné l'occasion de débattre du processus de prise de décision et des caractéristiques des bons leaders. Lorsque les femmes se sont levées pour défendre leur décision de mettre un terme à la pratique de l'excision, leur confiance en elles, leur détermination et les compétences qu'elles avaient acquises en leadership furent remarquées par tous ceux qui étaient présents.

\section{MODULES 7 ET 8 : LE FACTEUR DECISIF}

Les Modules 7 et 8 furent les deux modules qui contenaient le plus d'informations et qui ont servi de base aux femmes dans leur prise de décision de mettre un terme à l'excision.

\section{Les informations sur la santé créent la différence}

Le fait de connaitre leur corps, en particulier les organes reproductifs, l'importance et l'interdépendance de tous les systèmes, et les fonctions du corps, fut primordial et a beaucoup aidé les femmes à comprendre les dangers liés à l'excision. Beaucoup de femmes ne savaient d'ailleurs pas que leurs consours n'étaient pas excisées et lorsqu'elles l'apprirent, n'avaient aucune idée de ce que cela voulait dire. Beaucoup d'entre elles n'avaient aucune idée de la morphologie des organes féminins et pour la première fois voyaient des dessins et des représentations de ces organes.

\section{Débat sur la sexualité}

Tostan croit que les séances sur la sexualité ont aussi joué un rôle important sur la décision des femmes de mettre un terme à l'excision. Cette séance s'est révélé être une des plus débattues du module dans tous les villages, qu'ils pratiquent ou non l'excision. Le contenu a aidé les femmes à comprendre, à travers des discussions, 
qu'elles avaient droit à une vie sexuelle saine. Encore une fois, les jeux de rôle furent utilisés pour aider les femmes à apprendre à discuter avec leurs époux sur ce sujet délicat. D'évaluation en évaluation, les femmes se sont rendues compte que grâce à la Séance 7 du Modulle, elles ont réussi à trouver des voies par lesquelles elles ont pu discuter pour la première fois avec leurs époux de leurs besoins sexuels. La séance ne fait jamais spécifiquement état des femmes excisées. Cependant, les femmes excisées réalisent très tôt que leur plaisir sexuel est plus difficile à atteindre que pour les autres femmes. «Lorsque les femmes se rendent compte qu'elles sont incapables d'avoir le même genre de plaisir sexuel que les autres femmes, elles se demandent si ce n'est pas la raison pour laquelle leurs époux prennent une seconde ou troisième épouse, souvent chez un groupe qui ne pratique pas cette tradition.» commentait un journaliste mandingue de la radio.

\section{sociale \\ Apprentissage et expérimentation des stratégies de transformation}

Les stratégies de transformation sociale par l'organisation de groupes de solidarité entre femmes et le travail avec les chefs traditionnels et religieux ainsi qu'avec les responsables locaux de l'administration, sont aussi mis en relief dans plusieurs séances des Modules 7 et 8 . La paix étant un concept clé de la société sénégalaise, il était par conséquent très important d'encourager l'adoptioni de méthodes pacifiques de changement au sein du village. Les femmes se sentaient à l'aise dans l'utilisation de ces stratégies, parce qu'elles leur permettaient d'impliquer dans leurs activités les très respectés leaders d'opinion de leur communauté. Beaucoup de femmes s'aperçurent que les hommes et les chefs religieux les soutenaient et étaient plus progressistes qu'elles ne l'imaginaient. En fait, les hommes étaient particulièrement contents d'être impliqués dans ces discussions et de voir les femmes prendre leurs points de vue en considération. Par conséquent, les hommes devinrent plus ouverts au changement. Ce processus conduit à l'avènement d'un nouveau type de dialogue et d'un nouveau consensus autour d'autres problèmes importants de leur communauté et pas seulement par rapport à la question de l'excision.

\section{Adoption d'une amie, partage des connaissances}

Pour les séances des Modules 7 et 8, Tostan demanda aux femmes d'adopter une sour ou une amie (ndey-dikke en wolof) avec qui elles partageraient les connaissances acquises lors du module. La stratégie s'est avérée être un succès total pour plusieurs raisons :

- les femmes étaient motivées et rédigeaient des résumés de ce qu'elles avaient appris en classe, renforçant ainsi leurs compétences en lecture et en écriture ainsi que leur compréhension des sujets ;

- l'expérience rendait les femmes plus responsables. Lors des évaluations, elles déclaraient que leurs 'ndey dikke' faisaient montre de beaucoup de respect envers elles du fait des nouvelles connaissances qu'elles avaient acquises ;

- plusieurs femmes choisirent de partager leurs connaissances avec d'autres femmes en organisant de petits groupes dans leur voisinage. Dans la région de St Louis, les femmes dirent aussi avoir adopté leurs époux et les chefs religieux, en plus d'une amie ;

- la pratique que les femmes avaient acquise en partageant les nouvelles 
informations avec leurs scurs d'adoption leur donna la confiance requise pour le faire à une plus grande échelle. Plusieurs participantes développèrent des thèmes du Module 7 lors des réunions élargies du groupe des femmes ou organisèrent des séances publiques au bénéfice du village entier.

\section{Lier la connaissance à l'action}

Un autre élément des Modules 7 et 8 fut l'effort de l'équipe de conception de Tostan d'inclure une objectif-action pour chaque thème, et quelques fois pour chaque séance. Ainsi, l'engagement devint plus orienté vers 1'action et les résultats furent immédiatement observables dans les différents villages participants.

\section{Éducation sur les Droits Humains}

L'éducation sur les Droits de l'Homme qui débuta au Module 7 fut aussi un facteur déterminant ayant contribué à la décision de mettre un terme à l'excision dans ces villages. Tostan débuta les cours sur les Droits de l'Homme après une recherche participative effectuée en 1994 avec l'aide de centaines de femmes, pour l'élaboration du Module 7. Les résultats de cette recherche indiquaient que les problèmes des femmes liés à la famille, la santé, l'éducation, l'environnement, le droit et l'économie étaient souvent dus à leur méconnaissance de leurs droits et de leurs responsabilités, ainsi que de ceux de la communauté. Cette lacune compromettait aussi leur participation à la vie publique. Tostan décida alors, non seulement d'informer les villageoises de leurs droits et de leurs responsabilités, mais aussi de les aider à se les approprier. Ceci fut fait en utilisant leurs propres histoires et expériences, ensuite en leur foumissant un espace chaleureux et accueillant où trouver dés solutions et atteindre les changements désirés, en tenant compte de l'environnement social, culturel et économique dans lequel elles évoluent.

Tostan croit que l'expérience de cette éducation dynamique sur les droits de la personne a conduit à une transformation rapide et positive, pas seulement pour l'abandon de l'excision mais aussi dans d'autres domaines. Par exemple, après l'étude du Module 8 sur le Développement du Jeune Enfant se référant à la Convention Relative aux Droits de l'Enfant, les femmes de Touba Toul reconnurent qu'elles violaient les droits de leurs enfants en envoyant leurs filles âgées de 10 à 12 ans travailler comme domestiques dans les centres urbains : droit de vivre avec leurs parents, droit à l'éducation, droit à l'amour et à l'affection, droit d'être protégé contre les travaux pénibles ou de ne pas être exploités par d'autres, et enfin droit aux loisirs. La classe décida d'utiliser les stratégies débattues lors du module pour changer la situation. La Présidente du Groupement de Promotion Féminine organisa des réunions dans les différents quartiers du village durant lesquelles les femmes jouèrent des pièces de théâtre et lurent des poèmes sur les droits de l'enfant et sur les conséquences néfastes du travail des enfants comme domestiques à un âge précoce. Ces méthodes furent utilisées pour susciter les commentaires et encourager les discussions avec les autres villageois. Elles discutèrent ensuite de la violation des droits de l'homme que constitue cette pratique. Pour plus d'impact, elles firent référence aux articles spécifiques qui avaient ainsi été violés. En mars 1998, elles organisèrent une journée spéciale de mobilisation sociale, sur l'envoi des enfants dans les villes pour travailler comme domestiques, invitant les chefs de villages et les autorités gouvernementales de la localité à participer et à s'exprimer sur le problème. La décision commune de cesser d'envoyer 
les petites filles chercher du travail de domestique à la ville fut prise ce jour-là et un comité fut élu pour poursuivre cet engagement.

II est important de mentionner cette autre expérience afin de montrer que le Serment de Malicounda Bambara ainsi que les Déclarations de Diabougou et de Médina Chérif faisaient partie intégrante d'un mouvement pour une justice sociale. Cet exemple prouve l'impact qu'un village entier peut avoir lorsque les membres de la communauté participent de concert aux prises de décisions qui affectent leurs vies et celles de leurs enfants, et lorsque ceux-ci détiennent les connaissances, la confiance et le courage nécessaires pour prévoir et élaborer des stratégies de transformation sociale positive et pacifique, dans le respect des normes des droits humains, et en tenant compte de leur propre environnement socio-culturel.

\section{ROLE DU DIALOGUE DANS LA CLASSE : DEMYSTIFICATION DU NGIR-NGIRO}

\section{L'excision et la loi du silence}

En 1995 une équipe de Tostan dont Molly Melching présenta aux femmes bambara de Keur Simbara la séance sur l'excision du Module 7. Molly leur expliqua qu'elle était venue recueillir leurs impressions, sachant qu'elles étaient issues d'un groupe ethnique qui pratiquait l'excision. Les femmes qui d'habitude étaient ouvertes, enthousiastes et plutôt bavardes étaient soudain devenues assez silencieuses. Il y avait dans l'air une tension qu'auparavant elle n'avait jamais ressentie dans le village. Lorsqu'elle leur demanda pourquoi elles ne voulaient pas discuter du problème, elles̀ répondirent que c'était une tradition ancienne. Aucun problème n'avait jamais été associé à « la tradition » dans leur village, alors pourquoi en débattre ?

Molly était perplexe. Il était évident qu'il fallait aller plus au fond des choses pour comprendre leur attitude. Pourquoi ces femmes étaient-elles aussi réticentes à parler de l'excision? Elle les connaissait bien et avait toujours pu discuter librement avec elles, pourtant, tout d'un coup, elles étaient devenues irritées et évasives. Il y avait autre chose au-delà de cette réticence... On pouvait lire une certaine peur dans leurs yeux, que Molly ne comprenait pas. Elle leur demanda alors s'il n'était pas préférable d'éliminer la séance, puisque à l'évidence elle les gênait. «Non !» direntelles avec beaucoup d'empressement «N'éliminez pas la séance.» Mais elles n'expliquèrent pas non plus pourquoi elles souhaitaient que la séance soit maintenue. Molly était confuse, mais décida de la maintenir. Bien après, une des personnes âgées du village rapporta à Molly qu'elle avait eu de la chance de n'avoir pas été banni à vie du village pour avoir ne serait-ce qu'évoqué la question de l'excision.

La pratique de l'excision était vraiment un sujet tabou au Sénégal. Tout effort pour évoquer le sujet, en discuter, et encore plus suggérer d'y mettre un terme était inimaginable dans plusieurs régions du pays. Les éducateurs de santé et les travailleurs du développement avaient essayé différentes approches pour amener ces populations à mettre un terme à cette pratique néfaste mais sans beaucoup de résultats. Dans les pays d'Afrique où existe cette pratique, le pourcentage de personnes pratiquant l'excision n'a presque pas diminué. L'une des raisons est que les populations qui pratiquent l'excision refusent d'en parler.

Molly pensait que ce silence était similaire au silence des femmes dans tous les 
the peuvent pas s'en plaindre. C'est un sacrifice pour l'humanité. Elles doivent aussi toujours obéir à leurs pères et à leurs époux qui sont leurs maîtres. Ne pas se conformer pourrait attirer le malheur sur leurs familles. (Légende racontée par Daouda Ndiaye).

L'initiation prépare la femme à son rôle de femme et de mère : elle apprend à être patiente, polie, obéissante, calme, respectueuse, prête à servir et à aider ceux qui sont dans le besoin. Elle doit savoir être réservée et ne jamais parler de ce qui concerne sa famille, elle doit faire preuve d'honneur à l'égard de ses parents et de sa parenté, aimer son époux et adorer ses enfants. On apprend aux filles les signes de respect envers les personnes âgées et les hommes : ne jamais regarder droit dans les yeux lorsque l'on parle, effectuer une génuflexion lorsque l'on salue ou que l'on sert de l'eau, parler peu et doucement, ne pas rire aux éclats. Beaucoup de gestes discrets leur sont enseignés pour une communication silencieuse entre homme et femme et entre femmes initiées.

On dit à la femme initiée qu'elle est féconde, que le mauvais sort et les esprits du mal ne pourront jamais traverser son rideau de politesse et de respect, qu'elle sera tolérante et saura gérer les situations difficiles. L'initiation qu'elle reçoit la suit toute sa vie et forge sa place au sein de la société.

\section{2) L'aspect souffrance physique de l'initiation}

Lors des épreuves physiques de l'initiation, les filles doivent prouver qu'elles sont prêtes à faire face aux difficultés de la vie adulte. On les opère sans anesthésie, mais elles ne doivent ni pleurer, ni montrer de signes de peur ou de souffrance et elles sont punies si elles ne réagissent pas comme on le leur a appris. Il est dit que si la fille endure les souffrances de l'initiation, elle sera à même de faire face à toute forme de souffrance à laquelle elle pourra être confrontée au cours de sa vie. Ainsi les rites de passage deviennent une préparation aux difficultés de la vraie vie et sont considérés comme des outils essentiels pour forger chez la femme un caractère bien solide.

Beaucoup de femmes parlent de la façon dont l'exciseuse les a menacées et leur a murmuré de ne pas pleurer pendant $1^{2}$ opération, sous peine de déshonnorer leur famille.

3) Le serment solennel - jurer de ne jamais parler de l'expérience de l'initiation

Un autre aspect important du rite d'initiation est le serment solennel de ne jamais divulguer les secrets de l'initiation. Il est particulièrement interdit de parler de la douleur ou des souffrances endurées pendant la période d'initiation. Toute personne qui transgresse ces tabous encourt de grands risques :

«Pour le groupe ethnique mandingue, Ngir-Ngiro est un «rab», un esprit qui attaque les femmes qui osent briser le silence et parler des souffrances ou des conséquences néfastes de leur expérience de l'excision. En fait, il est interdit aux femmes de discuter de tout ce qui a trait à ce qu'elles ont appris ou enduré durant.cette opération, les conséquences d'une telle désobéissance pouvant être assez sérieuses : maladie mentale, paralysie ou mort. C'est pourquoi les femmes n'ont jamais osé parler de l'excision, encore moins à un non initié.» explique Daouda Ndiaye.

Ngir-Ngiro et ce qu'il représente existe sous un autre nom dans d'autres groupes ethniques. Apprendre l'existence de cet esprit mandingue et l'importance de garder le silence sur la tradition nous a aidé à comprendre beaucoup de situations 
auxquelles nous avions été confrontées ces deux dernières années, telles que:

- Ie refus des femmes de parler de l'excision en classe et en public ;

- la peur dans leurs yeux lorsqu'on les interpelle sur le sujel, en particulier en présence d'une personne d'un autre groupe ethnique ou d'un étranger

- la rêpugnance des hommes de Malicounda Bambara à débattre publiquement de la question

- la forte réaction lorsque des étrangers à leur groupe se mettent à critiquer la pratique de l'excision

- Les nombreuses mises en garde de Demba Diawara qui faisat constamment référence à ces 'secrets' pour parter avec les autres Bambaras.

Aprês avoir pris connaissance de ce qu'était le Ngir-Ngiro. Molly Melching tint une réunion avec Demba Diawara et lui demandit : As-tu connaissance de Ngir-Ngiro. l"esprit qui attaque les personnes qui osent parler des secrets de l'initiation "?

Demba sourit : "Tu viens de comprendre ce dont je parlais, Voilà pourquoi il m était difficile de rendre visite à d'autres villages ! Les gens sont inquiets à lidée d'attirer le malheur sur eux el sur leurs familles en parlant de l'initiation. C'est interdit. Cette croyance est tellement ancrée dans les esprits des personnes de mon groupe ethnique, qu'il est difficile de faire tomber les barrières.s.

L'excision et la loi du silence ; Tostan et l'utilisation du dialogue dans le programme d'éducation de base

Peut-être que la plus importante contribution du programme d'éducation de base de Tustan, dans l'abandon de l'excision dans les villages sénégalais. fut les méthodes élaborées par le programme qui permit aux femmes de discuter de ce problème tabou, dans un espace accueillant et chaleureux.

Au Sénégal, on peut penser que le dialogue soit une méthode naturelle d'éducation, puisque le Sénégal est réputé être une terre de dialogue et d'échange. Sefon un proverbe wolof très connu $₹$ XXloo amul, ñakk waxtaan moo am.m (Il n'existe pas de disputes. il n'existe qu'un manque de dialogue.) Malheureusement. dans lat société sénégallaise. le dialogue et les échanges qui se font naturellement au marché, dans les maisons oú sous l'arbre à palabre, ne sont pas assez pris en comptc dians la vic d'une classe d'éducation.

Le système éducatif français ainsi que l'éducation religieuse ont tellement influencê la société sénégalaise, que l'idée de l'enscignement et de l'apprentissage est muintenant associéc au smaître qui enseigne et inculque des comnaissances aux apprenants, qui n'ont qu’un rôle passif de mémoriser, souvent sans possibilité de remettre en question les informations donnees par le maitre. Au cours des nombreuses annes pendant lesquelles le programme d'éducation de Tostan fut claboré, la notion pédagogique la plus difficile a assmiler et à utiliser par les formateurs lut le droit de lapprenant, que nous appelons eparticipanto de réllement participer, de s'exprimer, d'avoir une opinion differente de celle du maître. plus connu sous le nom de facilitateurs, La plupart des facilitateurs qui avaient reçu une éducation formelle pensaient qu'ils n tetaient pas de bons enseignants stils ne donnaient pas de longs cours. Ils se faisaient du souci non seulement sur lopinion que les participants pourraient avoir d'eux s'ils ne faisaient pas comme tous les autres maitres dans le pays, 
mais aussi sur la possibilité d'être mal jugés par des étrangers venus rendre visite à la classe.

Tostan travaillait avec des formateurs, des facilitateurs et des participants pour les aider à découvrir que la forme participative de l'éducation est en fait tirée de la culture africaine. L'art de s'asseoir en cercle (comme on le fait traditionnellement sur la place du village en Afrique), de permettre à chacun d'exprimer ses idées (comme cela se fait lors d'une réunion villageoise), d'écouter attentivement et patiemment les idées exprimées par les autres (comme on l'enseigne dans une éducation africaine traditionnelle), d'atteindre un consensus par la négociation et la médiation (aptitudes africaines reconnues), de faire usage de la tradition orale; d'apprendre en observant et en reproduisant soi-même (méthode utilisée pour l'apprentissage traditionnel de travaux comme la forgerie, la cordonnerie ou l'art de tresser) sont des méthodes qui furent renforcées et utilisées par le programme d'éducation de Tostan.

L'équipe de conception de Tostan s'efforça aussi de rédiger les séances de manière à provoquer le débat parmi les participants et de former des facilitateurs capables de permettre aux participants de résoudre des problèmes par eux-mêmes, en petits groupes ou en groupes plus élargis.

La pratique acquise dans la classe, appliquée à des situations de la vie de tous les jours, fit que les femmes commencèrent à participer de plus en plus aux réunions villageoises, exprimant leurs opinions en public et pour la première fois. L'échange d'expériences conduisit aussi les participants à communiquer les uns avec les autres, et à faire de plus en plus confiance aux autres femmes de la classe. Ceci fut fondamental dans le processus d'abandon de l'excision dans les villages participants.

À plusieurs occasions, il fut demandé aux femmes des villages comment elles allaient faire pour remplacer les rites d'initiation. Leur réponse était assez édifiante : «La classe de Tostan remplacera nos rites d'initiation.» répondirent-elles souvent. «Les membres de la classe sont devenues pour nous comme des consceurs avec qui nous avions partagé les rites d'initiation. Nous avons partagé avec elles des idées, des expériences et des secrets pendant que nous apprenions en classe et nous partageons aujourd'hui un lien commun, nous sommes fortement liées sur la base d'une confiance mutuelle. Nous nous sommes aussi rendu compte que nos conditions de vie se sont améliorées parce que nous travaillons en équipe pour le même objectif.»

Lorsque Demba Diawara se rendit de village en village, il fit remarquer que certaines croyances traditionnelles étaient en rupture avec les enseignements du Coran et devaient être abandonnées. Il suggéra aussi que les classes d'éducation puissent donner aux femmes une nouvelle force et une nouvelle confiance pour faire face aux défis de l'avenir. De tels arguments eurent pour effet de convaincre les populations de 21 autres villages de déclarer leur décision d'abandonner l'excision. 


\section{AUTRES FACTEURS AYANT CONTRIBUÉ \\ A L'ABANDON DE L'EXCISION \\ DANS LES VILLAGES SENEGALAIS}

\section{LE MOMENT ÉTAIT OPPORTUN}

Pendant plusieurs années, les groupements et les associations féminines travaillant pour l'amélioration de la santé de la femme au Sénégal avaient préconisé l'abandon de l'excision. Au cours de séminaires, de conférences publiques, d'ateliers et de séances de formation sur la santé, initiées par le gouvernement, de plus en plus de médecins et d'influents responsables sénégalais s'exprimaient sur les effets néfastes de la pratique des MGF. Des Organisations Non Gouvemementales telles que ENDA, Femmes et Société, ASBEF, le Population Council, PATH et le COSEPRAT (Comite Sénégalais contre les Pratiques Traditionnelles), ainsi que des Organisations Internationales comme 1'UNIFEM, I'UNICEF, le FNUAP et I'OMS étaient tous en train d'élaborer des stratégies pour éradiquer cette pratique. Des conférences où des chefs traditionnels et religieux étaient invités étaient souvent retransmises à la radio.

Comme on s'y attendait au début d'une telle campagne, il y eu beaucoup de résistance de la part des populations rurales qui pratiquaient l'excision.

La matrone traditionnelle de Malicounda Bambara se rappelle : «Il y a cinq ans, je rentrais d'un programme de formation sur la santé initié par le gouvernement et durant lequel on nous incitait à dissuader les populations de pratiquer l'excision. Lorsque je m'aventurais à en parler aux femmes de mon village, elles se sont toutes moquées de moi et m'ont demandé de garder le silence sur notre 'tradition'. Je n'en avais plus jamais parlé.» Maimouna Traoré relate aussi une réunion en 1994 où il fut demandé aux Présidentes des Groupements de Promotion Féminine d'encourager les femmes de leur localité à mettre un terme à l'excision. «À cette époque.» dit-elle «je n'étais pas d'accord pour l'abolition de l'excision et m'en exprimais ouvertement lors de la réunion.» Cependant, les femmes de Malicounda Bambara étaient conscientes que de plus en plus de gens s'opposaient à cette pratique dans le pays.

Demba Diawara déclare : «Cinq ans auparavant ceux qui auraient osé soulever un tel problème se seraient heurtés à des difficultés insurmontables $\gg$ La différence est que les temps ont changé et que les villageois ont entendu à la radio des récits dans les langues nationales et qui font état des dangers de l'excision. «Nous avons même entendu dire que la question est maintenant à l'étude au Mali !» s'exclama un villageois.

\section{PAPTICHPATION POSITIVE DES CHEFS RELIGIEUX}

Dans un pays où $95 \%$ de la population est musulmane et où la religion joue un rôle important dans la vie de tous les jours, il est évident que l'opinion des chefs religieux joue un rôle décisif dans le mouvement grandissant au sein des communautés sénégalaises pour l'abandon de la pratique de l'excision. 
Bien que ces dernières années, plusieurs chefs religieux exprimaient des positions contre la pratique lors de conférences publiques ou de séminaires (souvent dans les centres urbains), les villageoises continuaient de penser à tort que leurs chefs religieux locaux et nationaux soutenaient la pratique de l'excision. En fait, la majorité des villageoises croyaient que l'excision était une pratique islamique recommandée par le prophète (PSL) et que par conséquent on ne pouvait pas la remettre en question. Certains pensaient que c'était une «suuna» (une préférence, une recommandation) d'autres croyaient que c'était une «farata» (obligation du Coran) et que par conséquent, elle devait être perpétuée. Puisque tout débat public sur la question était tabou, les femmes $n^{\prime}$ avaient pas $l^{\prime}$ occasion d'interpeller les chefs religieux sur leurs opinions, présumant de fait qu'ils étaient pour la tradition.

Tostan s'est rendu compte que beaucoup de chefs religieux n'avaient aucune idée des conséquences néfastes sur la santé liées à l'excision, et par conséquent ne donnaient que très peu d'importance à la question. Parce que le problème n'avait tout simplement jamais été porté à leur attention en ces termes par les plus concernées c'est à dire les femmes, ils ne s'intéressaient pas du tout à la pratique et n'en discutaient jamais.

Le programme d'éducation de Tostan favorisa la compréhension et le partage d'informations entre les femmes et les chefs religieux dans les villages participants, en encourageant le débat sur ces sujets si rarement soulevés. Tostan s'est rendu compte très tôt, dans la mise en ouvvre de son programme, qu'il était primordial de travailler en collaboration avec les chefs religieux locaux et nationaux. Ces demiers s'étaient toujours montrés ouverts et avaient toujours aidé et soutenu nos efforts d'éducation dans les villages. Qu'un marabout respecté de Tivaouane, Serigne Mansour Sy (aujourd'hui Calife général des Tidianes) parraina le Programme d'Education des Filles et qu'un Imam fut formateur dans l'équipe de Tostan avait permis aux villageois de se rendre compte du respect et de la considération que Tostan porte aux chefs religieux. Tous les documents sont d'abord discutés avec les chefs religieux avant d'être publiés et leurs idées sont non seulement prises en considération, mais souvent citées comme partie intégrante des séances d'éducation.

Lorsque les femmes de Malicounda Bambara décidèrent de faire une déclaration publique, Tostan invita les chefs religieux locaux à participer à l'évènement et à parler aux journalistes. Les femmes firent constamment référence à l'opinion de l'Imam qui les avait conseillées dans leur décision. Au journal télévisé on montra le marabout expliquant sa position sur la question, ce qui eut une grande influence sur les autres populations du pays.

Lorsque Demba Diawara, Imam du village de Keur Simabara débuta sa campagne au sein de sa propre famille dans 10 villages près de Joal, le fait d'être un chef religieux et d'être très respecté dans la famille et la communauté fit une énorme différence pour les personnes à qui il rendit visite. Il expliqua la position de llstam par rapport à la pratique de l'excision et montra comment l'inquiétude perpétuelle d'étre «attaqué» par les esprits pour s'être exprimé sur les conséquences néfastes de la pratique, était contraire aux enseignements de l'Islam. Ceci semble avoir été un des facteurs principaux dans la décision de ces villages le 14 fevrier 1998 , de mettre un terme à l'excision. 
Lors de la Déclaration de Diabougou par les 13 villages Bambaras, Sidi Kounta, chef religieux très respecté au sein du groupe Bambara du Sénégal, s'adressa aux participants à la réunion et expliqua que l'Islam ne demandait pas aux femmes de pratiquer l'excision. Après avoir écouté l'exposé d'un travailleur local de la santé sur les dangers liés à la pratique, il déclara que l'Islam était plus préoccupé par la protection de la santé des populations et par la promotion de pratiques bénéfiques, que par celles qui pourraient porter atteinte à la santé des filles et des femmes. Sa position fut renforcée par les autres leaders religieux et Imams présents à la réunion. Leurs opinions eurent un énorme impact sur la décision des participants.

Serigne Ibrahima $\mathrm{Ba}$, très respecté chef religieux, était présent lors de la Déclaration de Médina Chérif les 2 et 3 juin 1998. Il fit une déclaration importante rejetant l'idée que l'excision était obligatoire pour les femmes musulmanes. Ce chef religieux est influent dans sa région et son soutien aux femmes fut un facteur important pour la défense de leur décision.

\section{IMPORTANCE DES DECLARATIONS PUBLIQUES}

La déclaration publique des femmes de Malicounda Bambara déclencha un débat national sur la question de l'excision au Sénégal. Des villageoises qui elles-mêmes pratiquaient la tradition décidèrent, devant 20 journalistes, de mettre un terme à la pratique de l'excision dans leur communauté. Le débat sur la question ne devait plus jamais être le même. Dans le mois qui suivit la parution des articles, le public Sénégalais commença à étudier le problème en profondeur, à discuter et à remettre en question cette pratique ancestrale. De nouveaux articles furent rédigés sur l'excision et pour la première fois, plusieurs émissions radiophoniques interactives invitèrent les auditeurs à téléphoner pour donner leurs points de vue sur la question. Certaines personnes étaient contentes de voir la fin d'une tradition controversée et qui faisait souvent trop souffrir; d'autres étaient mécontentes et soupçonnaient les femmes d'avoir été «soudoyées» avec de l'argent ou des projets.

Après la Déclaration de Diabougou en février 1998 et l'importante couverture médiatique positive qui s'en suivit, attestant que plus de 8.000 villageois avaient rejoint un mouvement pour l'abandon de la pratique de l'excision dans leur communauté, l'impact fut encore plus grand. Pas 1, mais 12 autres villages avaient publiquement déclaré avoir mis un terme à l'excision ! Durant ce même mois, le Président de la République du Sénégal, dans un conseil des Ministres, annonça une proposition de loi pour l'abandon de la pratique de l'excision. Encore une fois la question de l'excision fut largement couverte par les médias. Puis en mai 1998, lorsque les villageois de Kolda exprimèrent à Tostan leur volonté de mettre un terme à l'excision et demandèrent qu'une rencontre soit convoquée avec tous les villages concernés pour prendre un engagement commun, Tostan accepta d'emblée. L'équipe se réunit cependant pour discuter de 1'importance de ces déclarations publiques. Est-ce vraiment la meilleure stratégie pour mettre un terme à l'excision ? Devraient-ils continuer d'apporter leur soutien à ce genre de réunion ou dépenser leurs ressources financières limitées dans des activités éducatives avec de nouveaux villages ? Ils hésitaient.

Tostan et UNICEF, en décidant d'appuyer les cérémonies de déclarations 
publiques, ne cherchaient ni publicité ni folklore. Les deux organisations se sont plutôt persuadées que ces cérémonies traduisaient la volonté sincère des communautés de renoncer à une pratique préjudiciable et d'être lié par un engagement commun, mais également d'exhorter les autres communautés à en faire autant.

Heureusement, pendant le mois de juillet, Molly Melching reçu une lettre de Gerry Mackie, chercheur à I'Université d'Oxford en Angleterre, qui avait lu les Déclarations de Malicounda Bambara et de Diabougou dans le «Intemational Herald Tribune.» M. Mackie avait rédigé un article pour «La Revue de la Sociologie Américaine» en décembre 1996, arguant que parce que l'excision est une pratique nécessaire pour les mariages internes au sein d'un groupe ethnique donné, elle ne pourrait être abolie que si toute la communauté dans son ensemble décide d'un commun accord d'y mettre un terme. Sa thèse se basait sur une pratique similaire en Chine, le bandage des pieds des femmes, qui perdura pendant plus d'un millénaire, mais connut une fin rapide au début du XXe siècle. Dans cet article, M. Mackie démontre brillamment que les serments publics pour l'abolition de cette pratique furent déterminants dans l'abandon du bandage des pieds en Chine et pourrait constituer le catalyseur pour mettre un terme à l'excision dans les pays qui la pratiquent.

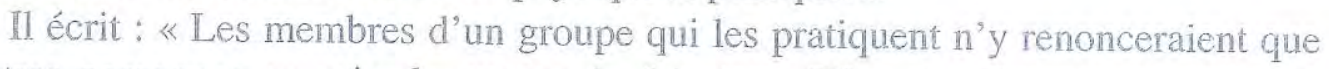
si d'autres personnes au sein du groupe le faisaient. Elles constituent une sorte de «convention Schelling» : les choix des famillles sont liés. Pour le comprendre, imaginez un groupe lié par une convention qui stipule que les spectacteurs (cinéma, théâtre, récital) doivent se tenir debout plutôt que de s'asseoir. L'idée de s'asseoir a été oubliée. La station debout est devenue a la fois universelle et ancrée. Un étranger arrive en disant qu'ailleurs les spectacteurs s'assoient. Après ce choc initial, certaines personnes commencent à penser qu'il vaudrait peut être mieux s'asseoir, mais ce qui serait mieux si assez de personnes s'asseyaient en même temps. Si une seule personne s'assied, elle st condamnée à ne rien voir sur la scène. Si une seulefamille abandonne la pratique des MGF, sa fille ne se mariera pas parce que seules les fermmes infidèles y font exception. Cependant, si un nombre important de personnes peuvent s'organiser pour s'asseoir, ne serait-ce qu' une rangée qui ne constitue pas la majorité, elles se rendront compte qu' elles peuvent bénéficier du confort de la station assise aussi bien que d'une bonne vue du spectacle. Ce groupe sera alors motivé pour convaincre le reste des spectacteurs de s'asseoir tout comme le reste de ces spectacteurs aura raison d'accepter.

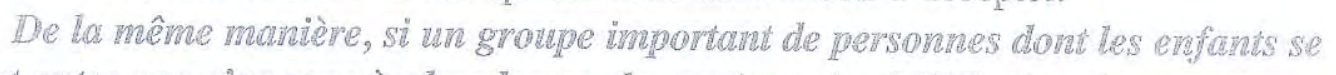
marient entre eux s'engage à abondoner la pratique des MGF, alors la conscience d'être un groupe important les confonte inmédiatenent dans leutri position ể les pousse à persuader les autres de les rejoindre, ensuite tont le monde funtit par frowachin le pas

Seule une bonne compréhension des mécanismes qui sous-tendent la pratique des MGF, la fin soudaine d'une pratique si enracinée au moyen d'une simple déclaration publique revèlerait presque du miracle.

Ce qui caractérise une telle convention c'est que même si chacun dans un groupe particulier vient à penser qu'il serait mieux d'abandonner l'excision, personne me peut $\mathrm{y}$ parvenin tout seul. Tout le monde peut penser qu'il vau mieux s'asseoir que de se tenir debout, mais tout individu s'asseyant seul ne ferait que compliquer la situation. Un nombre assez important de personnes doit s'asseoir en même temps. 
Une manière d'y parvenir est de déclarer un engagement public marquant le changement d'une convention. Toutes les familles pourraient être amenées à penser que les MGF sont une erreur, mais cela ne suffira pas à les arrêter car toute famille qui les abandonnerait seule hypothèquerait l'avenir de ses filles. Elles doivent être rejetées par un grand nombre de familles à la fois pour sécuriser l'avenir de leurs filles.»

Tostan et l'UNICEF se réjouirent de recevoir un tel article qui expliquait de façon plausible ce qui se passait au Sénégal, qui donna une crédibilité scientifique au processus et mit l'accent sur la nécessité de continuer les déclarations publiques lorsque les villageois le souhaiteraient. D'autres évènements et interviews confirmèrent encore aujourd'hui la pertinence de l'hypathèse de Mackie. 


\section{ENSEIGNEMENTS TIRES}

L'abandon de I'excision dans 31 villages du Sénégal a conduit Tostan à promouvoir une stratégie pour sa mise à fin dans d'autres zones du Sénégal ainsi que dans d'autres pays africains. Cette stratégie comprend quatre étapes importantes:

L'éducation de base

Les débats publiques

Les déclarations publiques

Les campagnes médiatiques

Pour chaque étape, Tostan a tiré des enseignements qui peuvent être pris en compte pour les prochains programmes.

\section{ÉDUCATION DE BASE}

L'éducation a été le fondement qui non seulement a permis aux villageois de prendre la décision de mettre un terme à l'excision sur la base d'informations pertinentes sur la santé, mais encore a permis de défendre et d'encourager cette décision. Les villageois de Mampatim dans la région de Kolda qui signèrent la Déclaration de Médina Chérif mais n'avaient pas bénéficié du programme d'éducation dirent : «Ill est nécessaire pour nous de bénéficier du programme de Tostan au plus tôt parce que nos parents et nos amis nous demandent pourquoi nous nous sommes joints à la Déclaration de Médina Chérif. Bien que nous ayons compris de nos parents de Médina Chérif les explications sur les conséquences néfastes de la pratique de l'excision, nous ne sommes pas capables de fournir ces explications aux autres et le programme de Tostan nous permettra de le faire.»

Certains éléments clés du programme d'éducation de base de Tostan sont fondamentaux dans le processus d'abandon de la pratique de l'excision:

- Tostan choisit une approche intégrée et holistique dans le programme. L'abandon de l'excision ne constitue pas l'objectif spécifique du programme;

- Tostan ne dit jamais aux villageois ce qu'ils doivent faire, mais leur présente des informations et des procédés crédibles pour une délibération souveraine où les participants prennent leurs propres décisions ;

- Les facilitateurs ne condamnent pas les participants ni ne les accusent d'être des violents, des non civilisés, des brutes et des barbares, ills sont plutôt compréhensifs et bienveillants à l'égard de l'importance de la tradition et des raisons des femmes de la pratiquer. Ils font très attention à ne jamais demander aux femmes de mettre un terme à la pratique, en mettant l'accent sur le fait qu'elles doivent prendre leur décision elles-mêmes ;

- Des arguments expliquant l'amélioration du plaisir sexuel des femmes ne furent d'aucune utilité dans le processus d'abandon de l'excision, en particulier lors des réunions publiques. Au contraire, les femmes se mettaient sur la défensive et réagissaient. Tostan se rendi compte qu'il stait préférable de souligner les effets néfaste ar a sante et les crots humains dt théficier des niveaux les plus élevés de 
santé et de les utiliser comme arguments pour discuter avec les hommes, les femmes et les enfants ;

- Les villageoịs acquièrent d'autres informations pertinentes et des connaissances dans le programme qui les aident à effectuer des changements importants et profonds dans leurs communautés : éducation aux droits humains, leadership, prise de décision, négociation et confiance en soi ;

- Le programme de Tostan met l'accent sur les voies et moyens de trouver des solutions pacifiques, non agressives aux problèmes de la communauté. Les femmes se sentent à l'aise avec cette approche et les hommes sont plus ouverts et tolérants lorsqu'ils sont impliqués au processus ;

- Le programme fournit aux facilitateurs une formation leur apprenant à diriger les séances d'une manière participative et qui permette un dialogue et un débat authentiques dans la classe ;

- Le programme renforce les valeurs culturelles et les traditions positives ;

- Le programme offre la possibilité aux participants de préparer et de répéter les jeux de rôle, pièces de théâtre, chansons et poèmes qui leur permettent de présenter et d'argumenter les informations recueillies en classe.

- Un autre aspect important du programme est la réputation que Tostan a acquise dans les villages : ce sont des personnes sur lesquelles on peut compter, des personnes crédibles qui placent le village participant au coeur du programme.

\section{DEBATS PUBLICS}

Des sujets importants qui affectent le bien-être de la communauté ne peuvent pas se limiter à la classe et ont besoin d'être présenté par les participants eux-mêmes pour un débat public et une délibération. Les participants ont donc besoin de compétences pour débattre de sujets importants avec les membres de la communauté y compris les chefs traditionnels et religieux, leurs époux et les autres hommes, femmes et enfants. La présence d'étrangers à ces premières réunions n'est pas préférable selon les villageois qui ont été interviewés. Cependant, Tostan a renforcé et facilité les débats publics en envoyant des membres du même groupe ethnique, des chefs religieux, des travailleurs de la santé et des villageois qui ont déjà pris la décision de mettre un terme à l'excision dans d'autres villages. L'Imam du village de Mampatim à Kolda raconte qu'il avait déjà écouté des émissions radiophoniques diffusées de la Guinée avec comme invités des Imams influents qui récusaient la tradition : «Je me faisais du souci à propos des conséquences néfastes sur la santé.» dit-il «mais je ne savais pas comment faire pour mettre un terme à la pratique dans mon village. Par chance les populations de Médina Chérif organisèrent une réunion publique pour nous informer de leur décision et nous l'avons perçu comme une opportunité de nous joindre à eux et d'abandonner l'excision nous-mêmes.»

Tostan s'est rendu compte que lors des discussions publiques il était important de mettre l'accent sur ce qui suit :

Les conséquences néfastes des MGF sur la santé

L'un des slogans les plus populaires entendus lors des réunions publiques fut : «Nous ne sommes pas en train de combattre une tradition, nous sommes en train de 
nous battre pour la santé de nos filles et de nos femmes.» Lors de ces réunions, les témoignages personnels des femmes, des hommes et des exciseuses furent déterminants. Très souvent les autres villageois ne se rendaient pas compte que certains problèmes de santé étaient liés à la pratique de l'excision et d'entendre que leurs filles et leurs amies qui avaient eu de sérieux problèmes de santé après la cérémonie ou à l'accouchement a permis aux gens de se rendre compte pour la première fois des dangers encourus. Demba Diawara déclare que lors de la première réunion dans un village, toutes les femmes disent inévitablement ne jamais avoir eu de problèmes avec l'excision. Il donne ensuite l'exemple d'autres femmes de sa connaissance qui ont eu des problèmes et c'est alors que 1'une d'elles dira : «Oh ! Ceci m'est arrivé aussi ! »

«Une fois que la porte est ouverte, de plus en plus de témoignages sont recueillis ! » nous dit-il.

\section{L'opinion des chefs religieux sur la question}

L'invitation de chefs religieux pour intervenir lors de ces réunions est l'un des aspects les plus importants des réunions publiques. À l'évidence, il est important de débattre des problèmes avec ces chefs religieux avant la réunion et de les impliquer dans la planification des séances.

Demba Diawara a aussi mentionné les croyances religieuses traditionnelles (tabous, esprits, etc.) liées à l'excision et mène des discussions à ce propos avec les villageois. Ceci a permis de démystifier certaines croyances et superstitions qui empêchaient les femmes de parler du sujet.

\section{La présentation des déclarations précédentes}

Les villageois de Médina Chérif utilisèrent pour leurs réunions la Déclaration de Diabougou que Tostan avait traduite en pulaar. Ceci les a aidés à montrer qu'ils n'étaient pas le seul groupe à débattre des conséquences de cette pratique et à prendre la décision importante d'y mettre un terme au niveau communautaire.

\section{DECLARATIONS PUBLIQUES}

Lorsqu'un groupe de villages de même ethnie pense mettre un terme à la pratique de l'excision, il est important pour eux de se rencontrer et de discuter du problème en tant que communauté élargie. La réunion de deux jours peut être organisée par les villageois eux-mêmes, avec l'assistance d'organisations extérieures pour couvrir les frais de transport, de nourriture et d'hébergement. Lors des réunions de Diabougou et de Médina Chérif, les villageois choisirent ceux qui devaient faire les présentations et choisirent aussi les travailleurs de la santé et les chefs religieux qui, selon eux, étaient les plus convaincants. Pour ce qui est de la Déclaration de Diabougou, les villageois invitèrent le juriste Sidiki Kaba pour discuter des droits humains en relation avec l'excision.

Le gouvernement envoya aussi des représentants à ces réunions parmi lesquels Cheikh Tidiane Diop, Directeur de Cabinet du Ministre de la Famille, de l'Action Sociale et de la Solidarité Nationale qui présenta la position déterminée du gouvernement concernant l'excision et la nouvelle loi pour son abolition au Sénégal. Sa présence fut 
très appréciée des villageois.

Il est important qu'un travailleur de la santé que les villageois connaissent et en qui ils ont confiance fasse un bref et simple exposé puis réponde à toutes les questions. Tostan appris aussi qu'il était préférable que le travailleur de la santé n'explique pas en public les dessins des organes sexuels. De tels dessins sont plus acceptables en classe où les participants sont habitués à ce genre d'illustrations.

Madame Henriette Alavoe, chef du bureau information de l'UNICEF, choisit soigneusement les membres de la presse qui devaient participer aux déclarations, prépara la documentation et organisa des séances de briefing avant le voyage. Il était important que certains journalistes soient du même groupe ethnique que les villageois et qu'ils interviewent les participants en langues nationales. Ces émissions de radio peuvent avoir un impact décisif sur les autres communautés du pays. Mme Alavo élabora des kits pour la presse et une brochure sur l'excision qui fut largement distribuée. Ce matériel était culturellement sensible et encore une fois ne montraient pas d'organes sexuels, de sang ou de fillettes en pleurs qu'on avait opérées, mais plutôt une image positive de familles radieuses ainsi que de leurs enfants et qui proclamaient avoir choisi la santé et les droits humains.

L'UNICEF invita aussi une délégation du Mali à la cérémonie de Déclaration de Médina Chérif. Les Maliens étaient très enthousiastes au sujet de l'expérience êt demandèrent qu'à l'avenir des échanges se fassent entre les deux pays.

Lors des déclarations publiques, les femmes qui avaient déjà subi l'excision furent aussi assurées qu'elles ne seraient ensuite ni raillées ni ridiculisées. Comme le déclare Demba Diawara : «Si cela arrive, ce sont les langues qui devront être excisées !» L'autre femme âgée que nous avons interviewée nous dit que ceci était particulièrement important pour elles.

Un fait important est que les participants sentaient qu'il ne s'agissait pas d'une tentative de destruction de la tradition, mais plutôt d'un désir de promouvoir et de protéger la santé des filles et des femmes ainsi que les droits humains.

\section{LES CAMPAGNES MEDIATIQUES}

Les médias ont joué un rôle décisif dans le processus qui a mené à l'abandon de l'excision. La couverture médiatique des déclarations publiques, des interviews des chefs religieux, des travailleurs de la santé ainsi que des hommes et des femmes qui ont déjà mis un terme à la pratique, les entretiens radiodiffusés où le public peut exprimer ses idées et les articles dans la presse écrite locale sont d'excellents moyens de susciter le dialogue sur la question. Il est particulièrement important d'identifier les gens qui comprennent que certains de leurs propres problèmes de santé ou ceux de leurs filles sont dus à l'excision. Partager ses expériences avec un auditoire important à la radio, dans les journaux et à la télévision, peut avoir un effet salutaire sur des gens qui autrement pourraient défendre l'excision au nom de la tradition. De courageuses personnes telles que Ourèye Sall qui parle ouvertement de sa fille qui a failli perdre la vie à la suite de l'opération, Fatou Kine Diawara qui déplore l'état psychologique de sa petite-nièce, D.B. qui admet qu'il arrive que des filles perdent la vie durant les cérémonies d'excision, D.D. qui se dit que sa stérilité peut avoir été dû à une infection suite à son excision, et I.N. qui déplore les terribles souffrances de son épouse pendant les premières semaines 
de leur mariage, ont aidé à en convaincre des milliers d'autres qu'il y a en réalité de vrais dangers de santé liés à l'excision.

Il serait néanmoins bénéfique de fournir des programmes de formation de courte durée aux journalistes de la presse écrite, radiophonique et télévisé pour les aider à mieux comprendre la complexité du problème et à participer plus efficacement au processus d'écucation.

Tostan croit qu'une loi nationale interdisant la pratique de l'excision peut aussi être dissuasive lorsque ces trois conditions auront été réunies. De cette façon, la transformation sociale se fait pacifiquement, et permet de lutter pour le bien-être et non contre ceux qui pratiquent l'excision. Comme Gerry Mackie le dit si bien : «Les personnes qui pratiquent l'excision sont des personnes honorables, honnêtes, qui aiment leurs enfants et leur souhaitent tout le bien du monde. C'est la raison pour laquelle ils pratiquent l'excision, et c'est la raison pour laquelle ils décideront d'y mettre un terme, une fois qu'un moyen sûr sera trouvé.» 


\section{L'EQUIPE TOSTAN}

Molly Melching

Abdoulaye Thiam

Marie Augustine Sall

Dieymaba Dieng Abdourahmane Diallo

Mohamed Basse

Abou Amel Camara

Maimuna Kane

Abou Diack

Malick Gueye

Boussan Diaw

Meissa Dieng

Ramata Dia

Khalidou Sy

Seydou Baldé

Guele! Djigo

Awa Fall

Mareem Dieng

Binta Thiam

Mallick Pouye

Abdou Aziz Sy

Madiakher Mbousp

Cheikh Omar Naliaye

Abdoullaye Baldé

Samba Sy

Chiekh Diouf

Abdoulayye Cissé

Magieye Ndiaye

Saliou Badiane

Ramatoulaye Diop

Mamadou Diallo

Modon Gueye

Bara Kébé

Touty Dieng

Momadou Diouf

Abdoulaye Kandé

Mannsour SOW

Djibi Sow

Ousmane Noliaye

Cheikh Traopé

Moustapha Sall

Djibrill Dramé

Oumpar Nam

Ousseymon Trouré

Ilorohima Tounkaro

Fotimata Bapry 


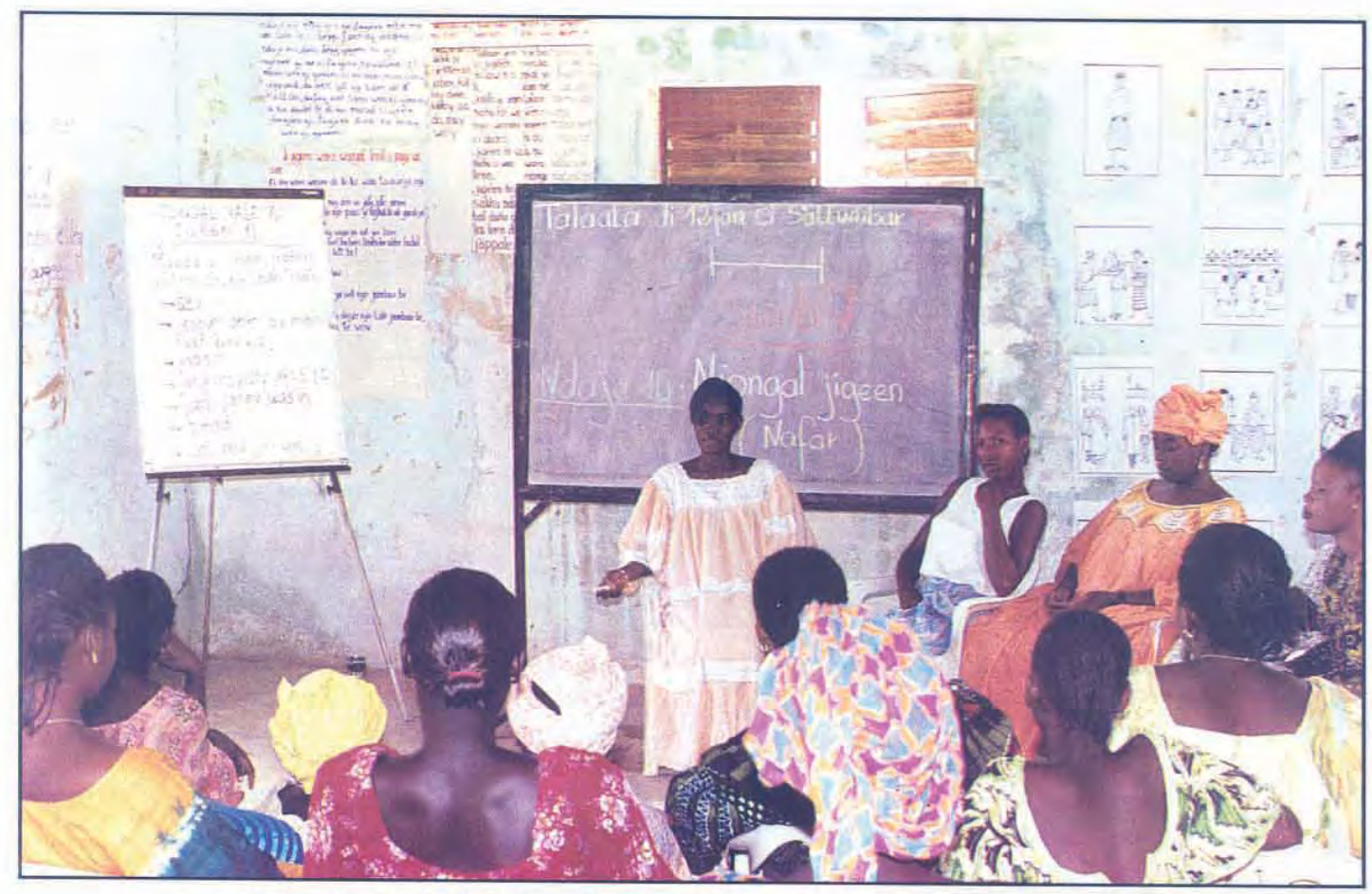

Au cours du Module 7 sur la santé de la femme, les villageoises de Malicounda Bambara discutent de l'excision.

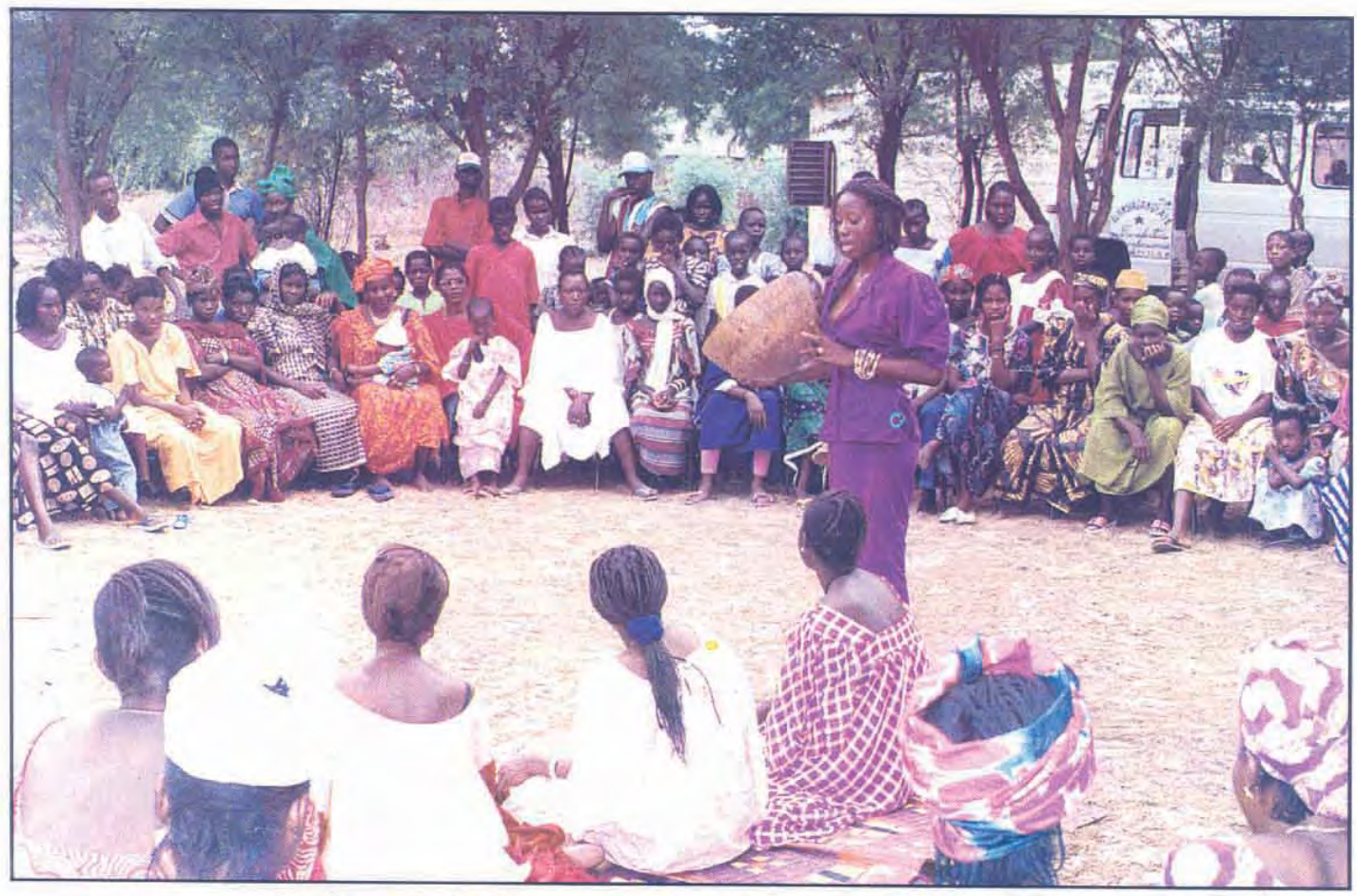

La classe de Malicounda Bambara joue une pièce de théâtre pour le village de Kër Simbara (Août 1997). 


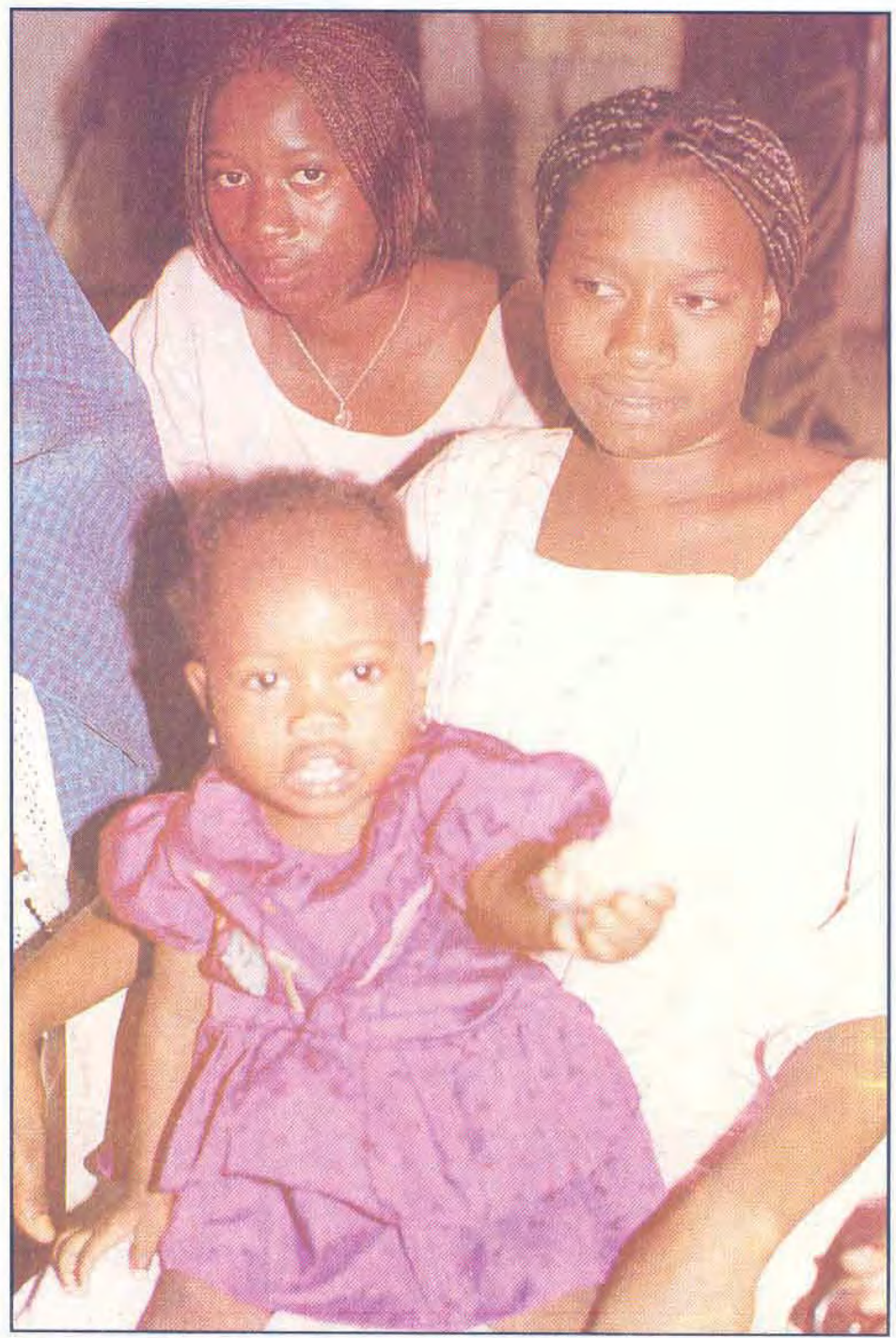

Alima Sañ-Sañ, (Alima Droits Humains), la première petite fille qui bénéficie de la décision d'abandonner l'excision à Malicounda Bambara. 


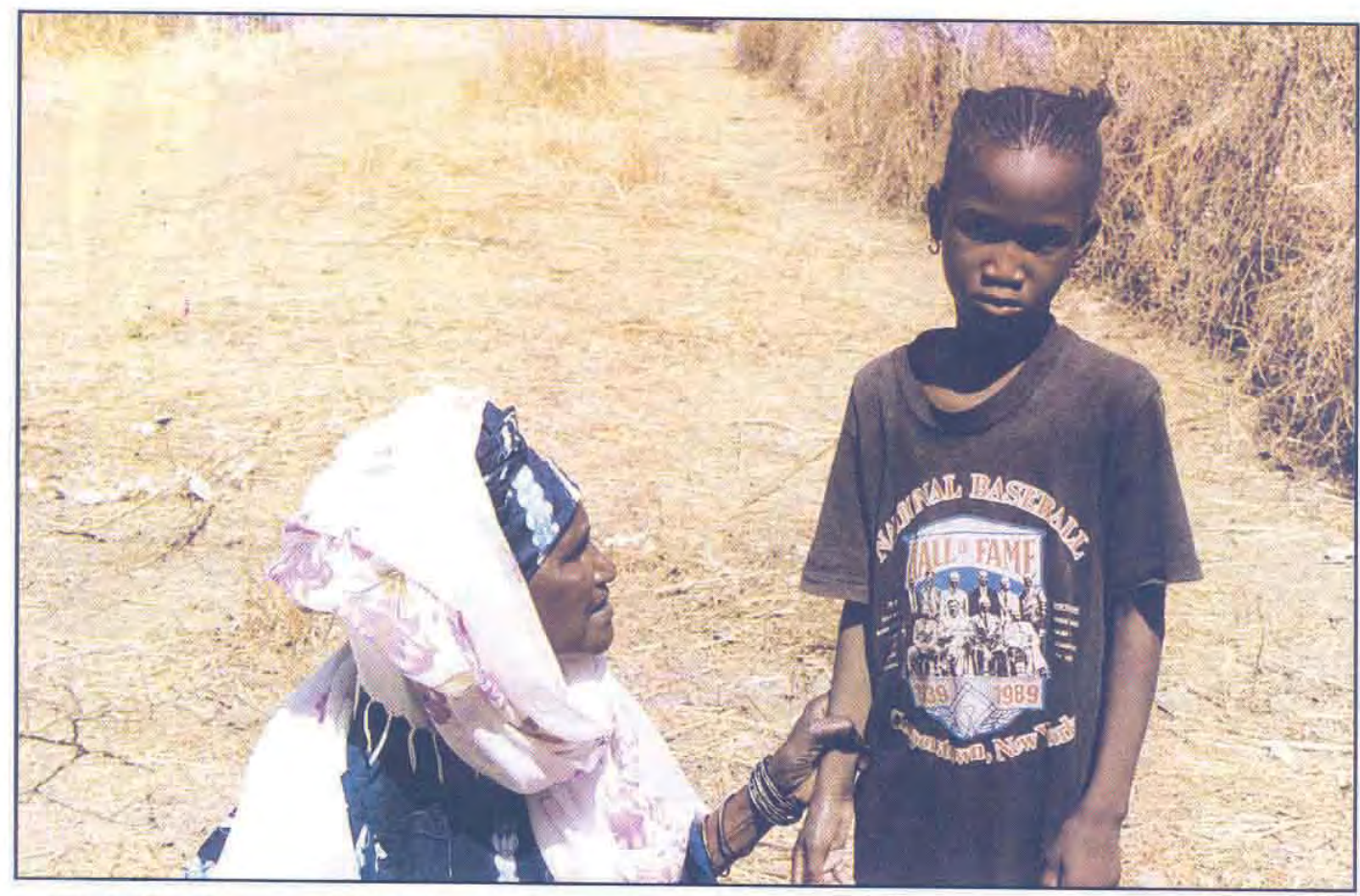

Fatou Kine Diawara déplore le cas de sa petite nièce qui a failli mourrir au cours de l'excision.

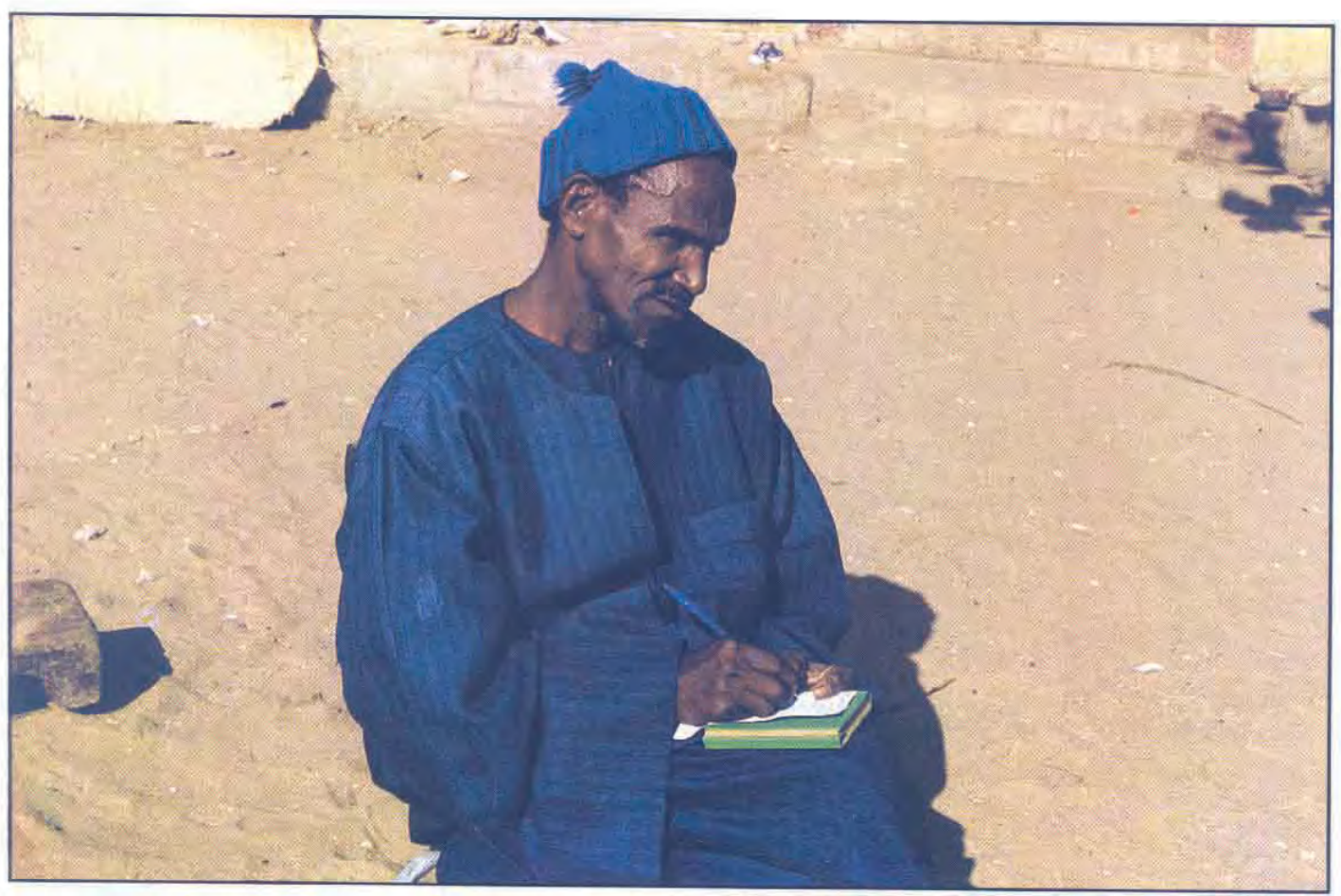

Demba Diawara, Imam de Kër Simbara, a marché de village en village et discuté avec ses proches des effets néfastes de l'excision sur la santé de la femme. 


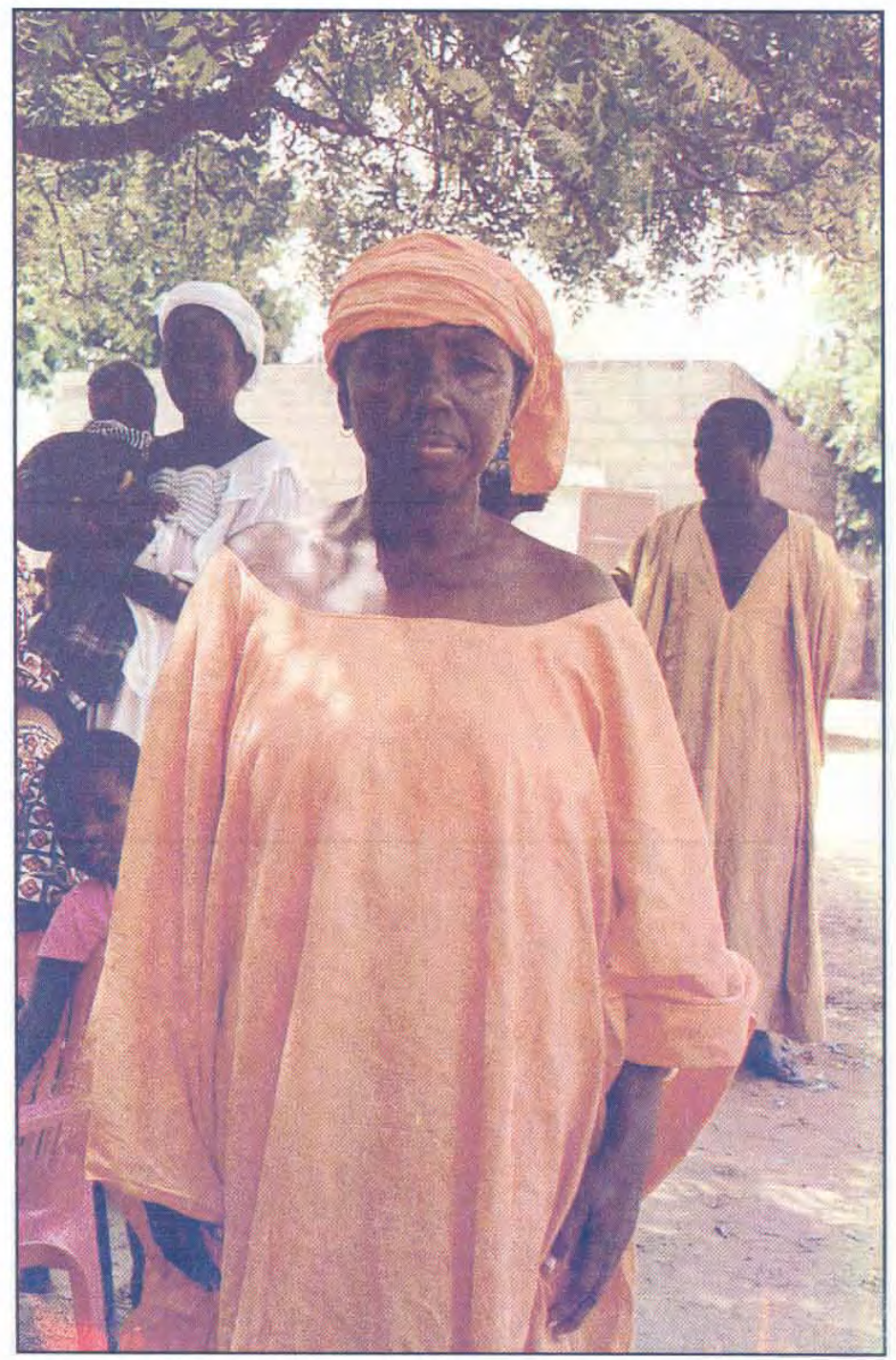

Ourèye Sall, exciseuse traditionnelle du village de Nguerigne Bambara, ne pratique plus l'excision. D'autres exciseuses qui participent aux classes Tostan ont suivi son exemple. 


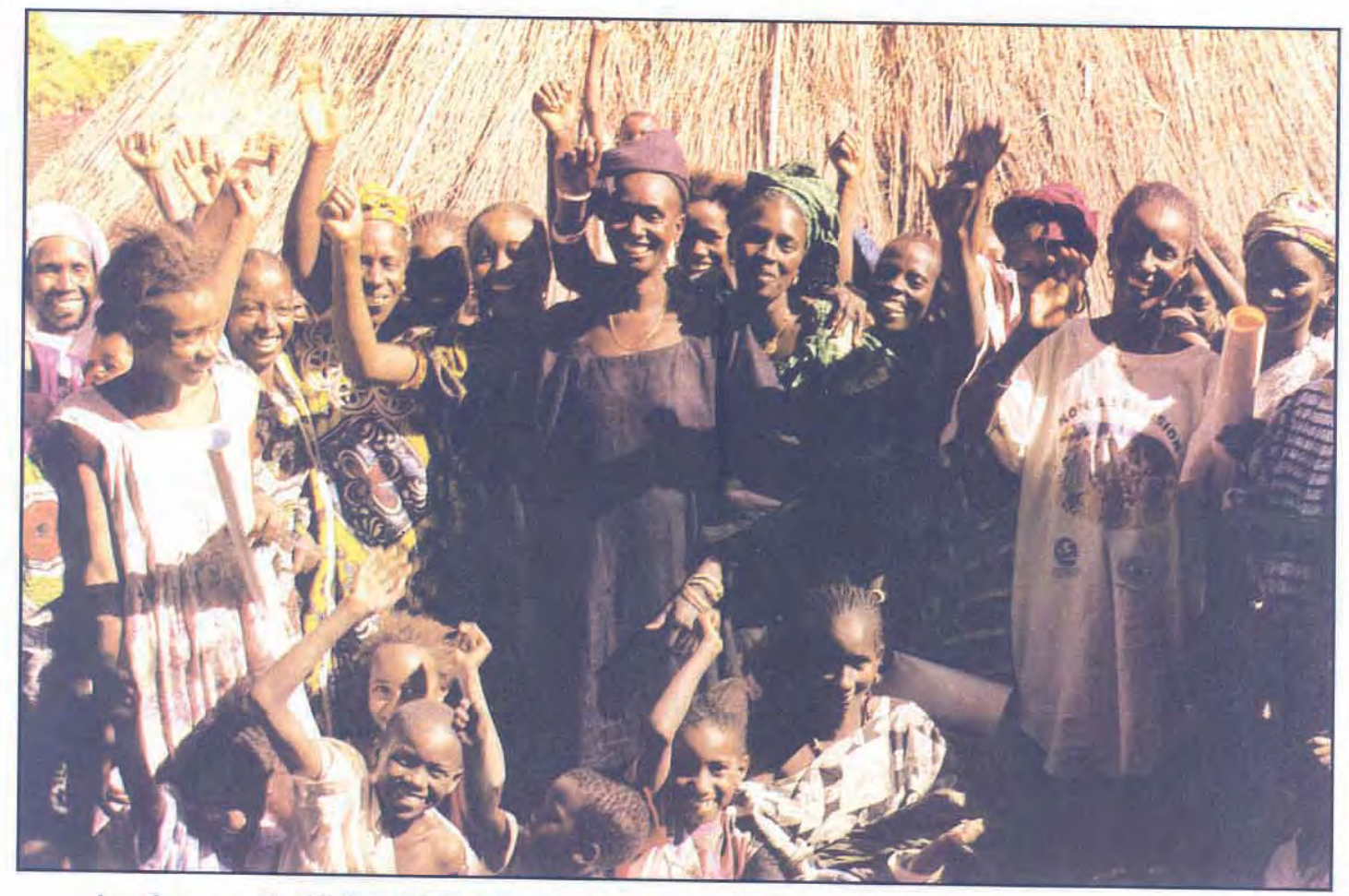

Les femmes de Médina Chérif ne regrettent pas l'importante décision qu'elles ont prises.

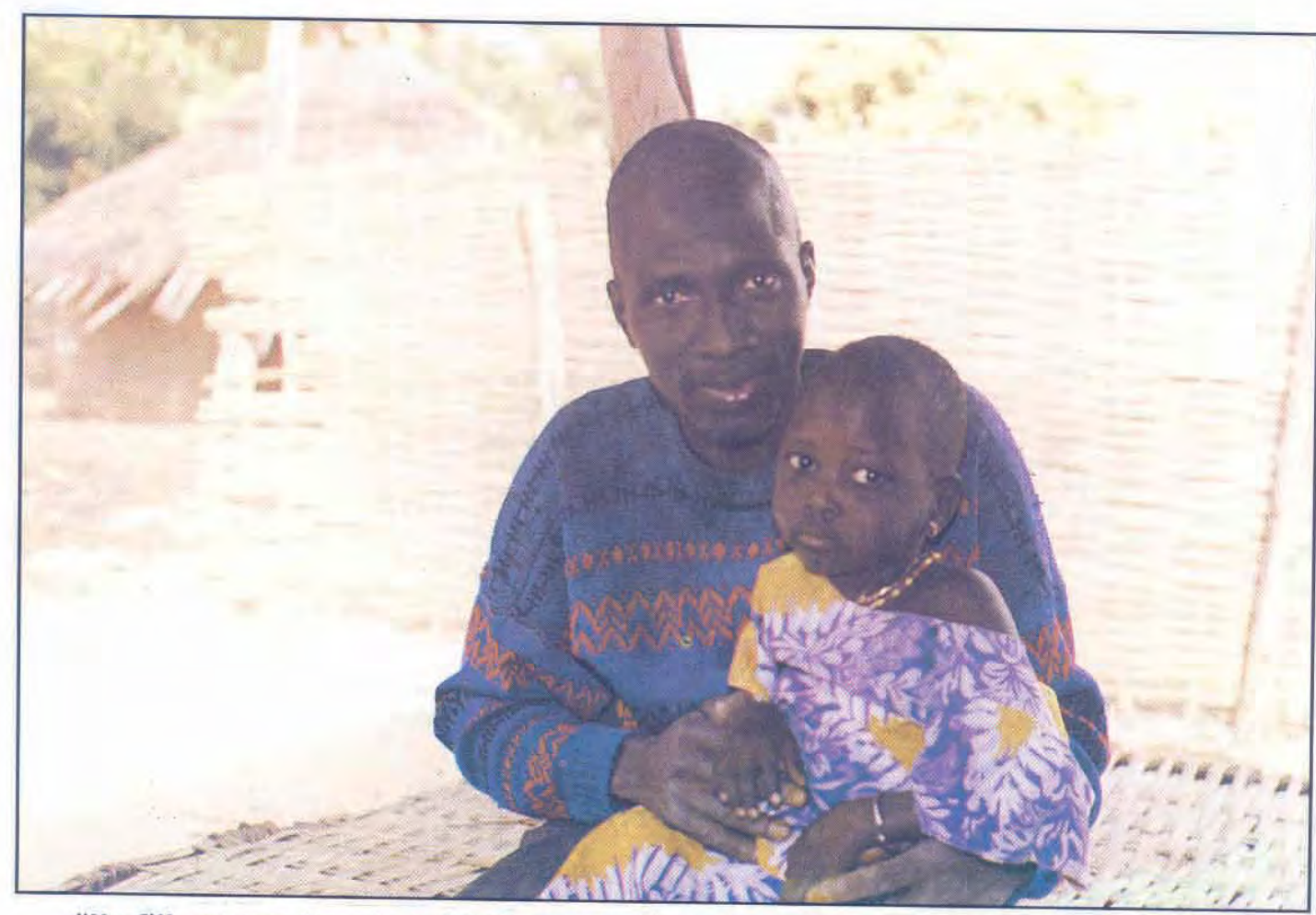

"Ma fille ne sera jamais excisée!" nous confie un homme de Mampatim et qui a participé à la Déclaration de Médina Cherif les 1 et 2 juillet 1998. 


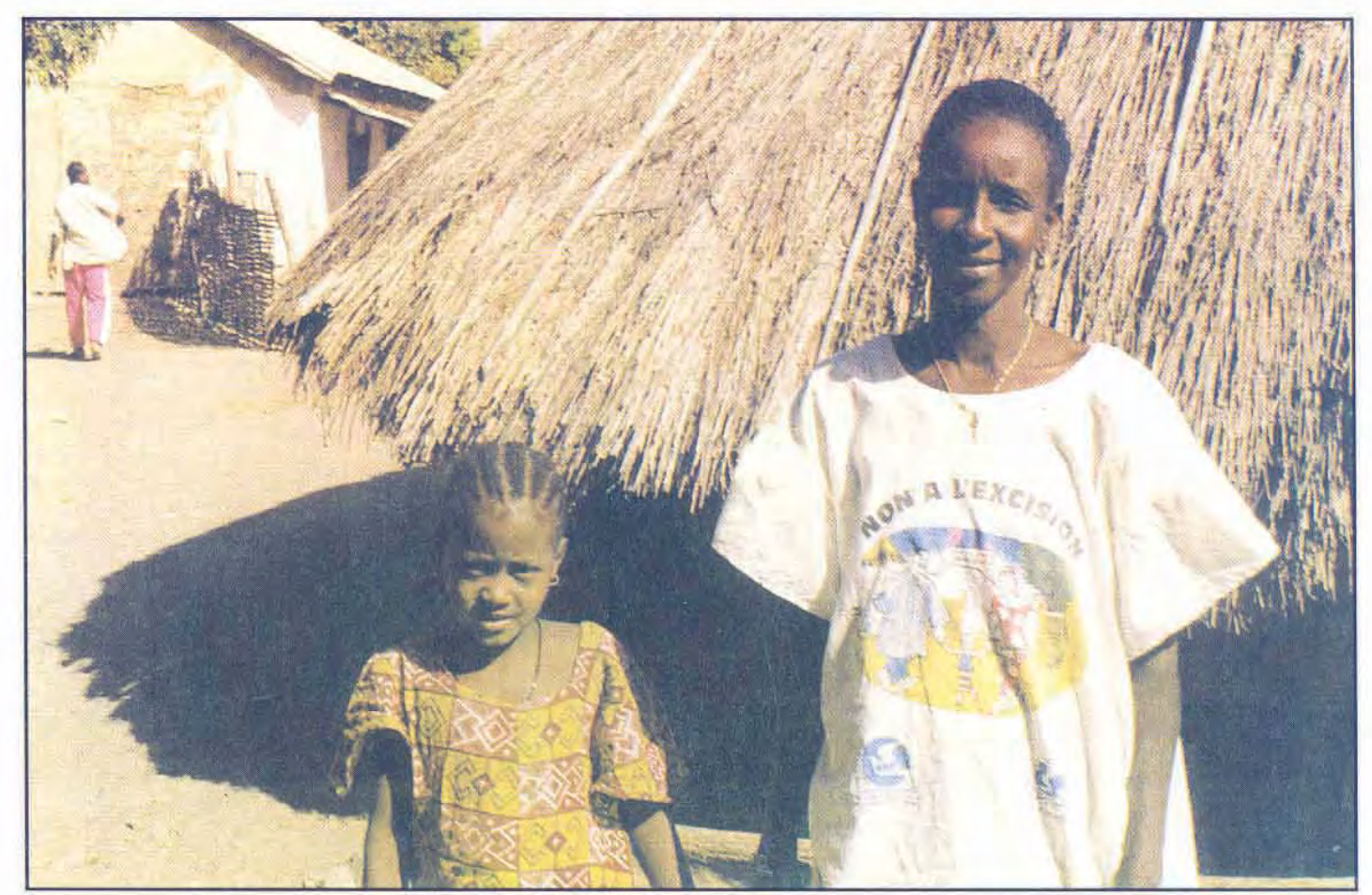

Lala Baldé a voyagé dans le Nord du Sénégal et expliqué pourquoi 18 villages de la Région de Kolda ont décidé d'abandonner l'excision

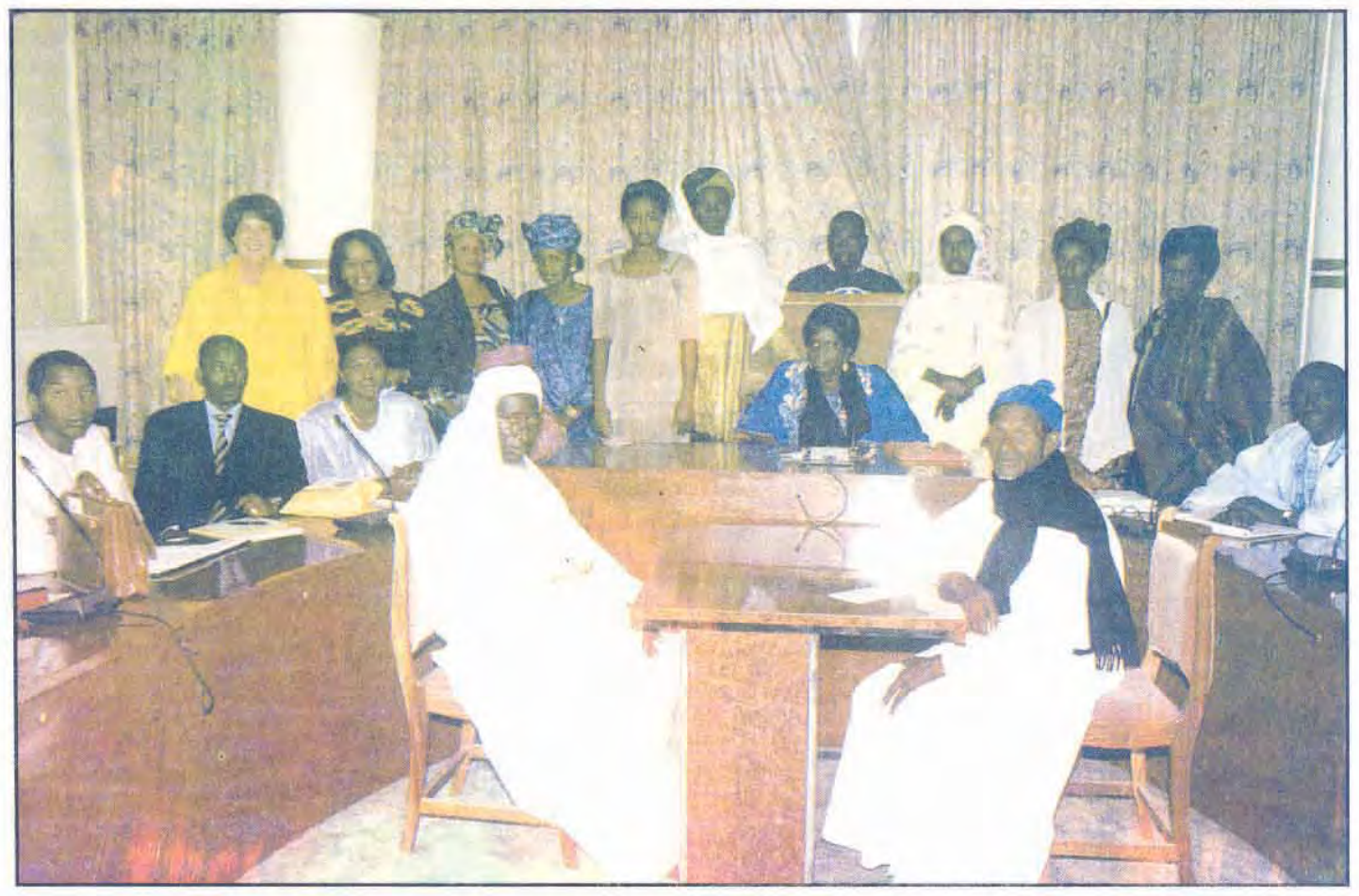

Le 12 Janvier 1999, 13 représentants des villages ont témoigné en présence des membres du parlement. 


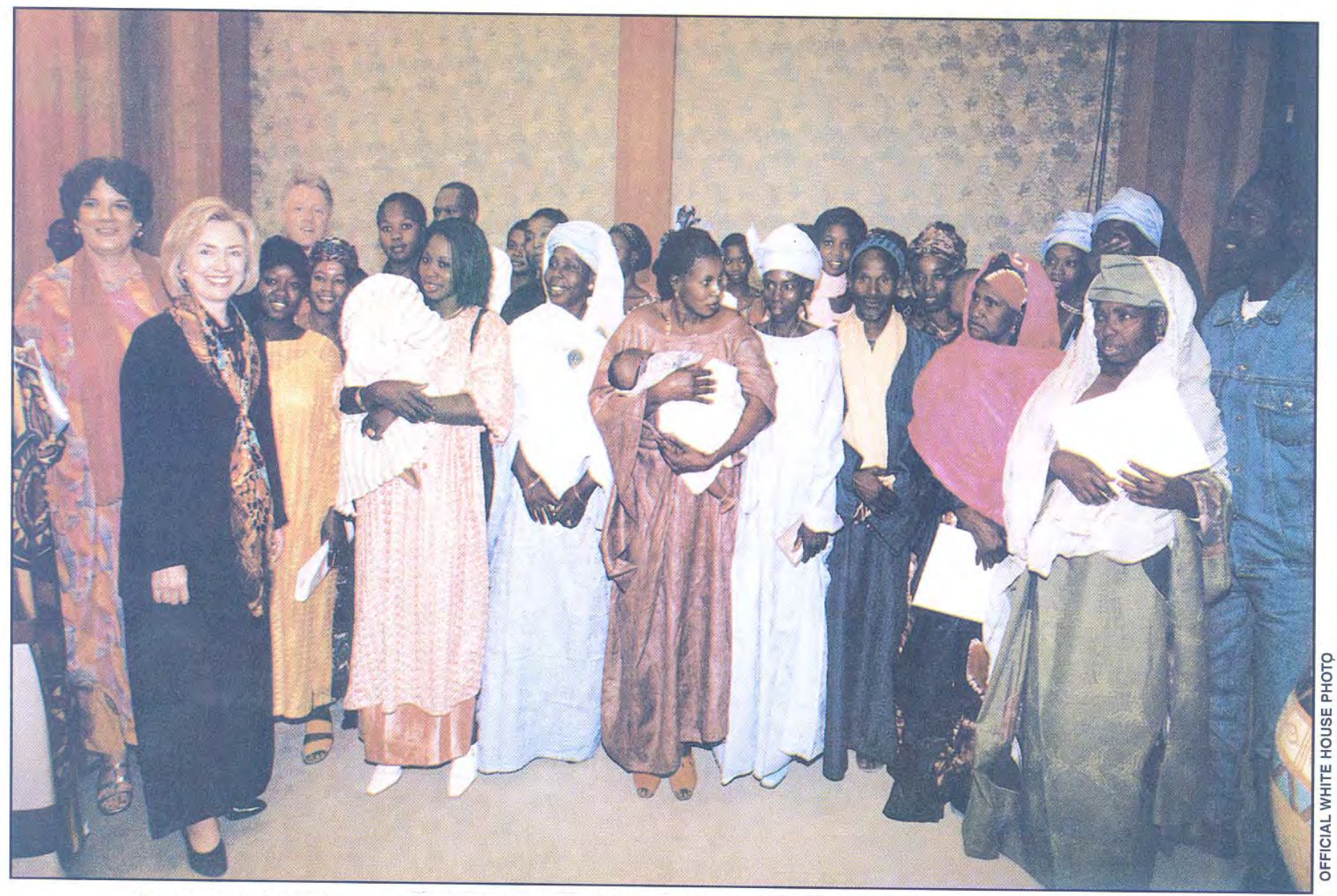

Au cours de leur visite au Sénégal en Avril 1998, le Président et Madame Clinton félicitent les femmes et les hommes qui ont beaucoup travaillé pour mettre fin à la pratique de l'excision. 
